University of San Diego

Digital USD

2005-05-01

\title{
How Leaders Use the Construct of Culture to Influence Change Resistance: A Study of a Planned Change Initiative in a Combined Government and Military Organization
}

Derek R. Noether EdD

University of San Diego

Follow this and additional works at: https://digital.sandiego.edu/dissertations

Part of the Leadership Studies Commons

\section{Digital USD Citation}

Noether, Derek R. EdD, "How Leaders Use the Construct of Culture to Influence Change Resistance: A Study of a Planned Change Initiative in a Combined Government and Military Organization" (2005).

Dissertations. 749.

https://digital.sandiego.edu/dissertations/749

This Dissertation: Open Access is brought to you for free and open access by the Theses and Dissertations at Digital USD. It has been accepted for inclusion in Dissertations by an authorized administrator of Digital USD. For more information, please contact digital@sandiego.edu. 


\title{
HOW LEADERS USE THE CONSTRUCT OF CULTURE TO INFLUENCE CHANGE RESISTANCE: A STUDY OF A PLANNED CHANGE INITIATIVE IN A COMBINED GOVERNMENT AND MILITARY ORGANIZATION
}

\author{
by \\ DEREK R. NOETHER \\ A dissertation submitted in partial fulfillment \\ of the requirements for the degree of \\ Doctor of Education \\ University of San Diego
}

May 2005

Dissertation Committee

Robert Donmoyer, Ph.D., Chair

Terri Monroe, Ed.D., Member

Johanna S. Hunsaker, Ph.D., Member 
(C) Copyright by Derek R. Noether, 2005

All Rights Reserved 


\begin{abstract}
The construct of organizational culture has been used to interpret various aspects of organizational life, including organizational leadership and organizational change. The literature indicates that leaders can influence organizational change by attending to and modifying an organization's cultural dimensions. Much of this literature, however, is theoretical and speculative, and the empirical work that does exist has focused mostly on business.
\end{abstract}

The purpose of this case study was to develop an understanding of how leaders in a combined government and military organization used the notion of culture during a two-and-a-half year planned change initiative. The study explored the strategies and mental constructs those in positions of formal authority used to make sense of and influence the change process. The particular focus was on identifying any cultureoriented change strategies leaders use to overcome resistance to change. The study also examined how organizational culture shaped and constrained leaders' actions.

This study employed qualitative methods. Interviews with designated leaders of the planned change initiative were the primary data collection method. Document analysis and participant observation were used to triangulate interview data.

Several findings and conclusions emerged from the study. One of the more interesting findings involved the observation of resistance at the top of the organizational hierarchy, i.e. the level from which the change initiative had been promoted. Normally, resistance is conceptualized as something that occurs at the bottom rungs of an organizational hierarchy. In this initiative, in which middle managers were given considerable authority about what would be done to achieve goals mandated from the top, 
there was significant resistance coming from above as well as below. Both levels, in other words, were uncomfortable with the specific cultural change being implemented, and both levels attempted to minimize its impact.

This study should be useful to individuals who are charged with leading largescale change initiatives within their organizations and to scholars who analyze and write about the use of culture as both a facilitating and an inhibiting factor in planned organizational change. 
This dissertation is dedicated to my wife Nancy Noether

for her infinite patience, support and belief in me

"Many waters cannot quench love;

rivers cannot wash it away"

- Song of Songs 8:7 


\section{ACKNOWLEDGEMENTS}

I would like to thank God for the opportunity to complete this degree and the hope and endurance He has provided through the verse: "For I know the plans I have for you, declares the Lord, plans to prosper you and not to harm you, plans to give you hope and a future." Jeremiah 29:11

I would like to thank my family: To my wife Nancy-you have supported me through long nights and the ups and downs of getting a doctorate degree. You are the first to say, "I am with you to the end." To my daughter Ava-my morning star, your smile and laughter brings joy to my heart. To my dad-you have set an example in more ways than one; you inspire me to reach new heights and to become all that I am. To my momyou are no longer with us, but never forgotten. Thank you for teaching me what really counts-taking time to live and love others. To the rest of my family, your support and encouragement made this journey possible. Eric Noether, Chrissy Noether, Barbara and Larry Dixon, Tammy and Todd Barron-your love expressed through words, thoughts and prayers means more than you'll ever know.

I would like to thank Bob Donmoyer for countless hours of teaching me and our many early mornings at Peet's. You are truly gifted at what you do and I am fortunate to have spent this time learning from you. I would also like to thank the other members of my committee, Terri Monroe and Johanna Hunsaker for their guidance and insights.

I would like to thank Joyce Dutcher, my mentor, supervisor, colleague and friend. This degree would not have been possible without your support.

I am also grateful to the many teachers and friends who have shaped and influenced my life and allowed me to learn from their examples. 


\section{CHAPTERS}

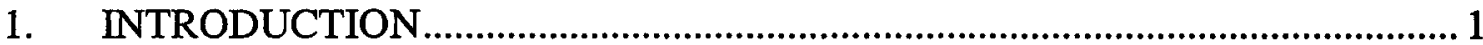

Background to the Study ......................................................................... 1

The Emergence of Planned Change Initiatives ................................. 1

The Failure of Planned Change Initiatives....................................... 2

Utilizing the Construct of Organizational Culture to Account for

Resistance to Change ...................................................................... 3

Resistance, Organizational Culture and Leadership ....................... 5

Statement of the Problem ........................................................................... 6

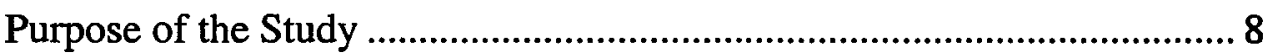

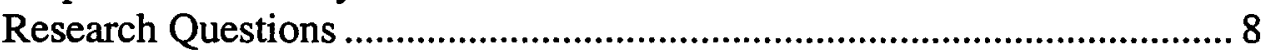

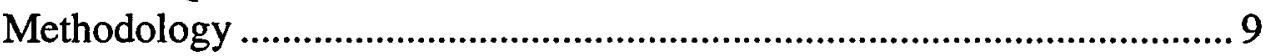

Significance of the Study ..................................................................... 11

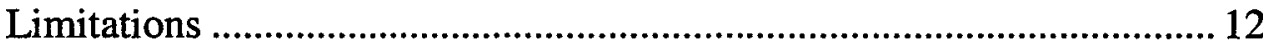

External Validity ....................................................................... 12

Internal Validity ........................................................................... 13

Organization of the Dissertation ............................................................... 15

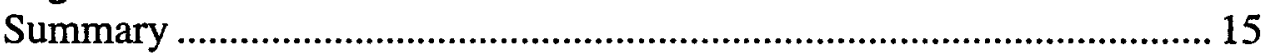

2. LITERATURE REVIEW ........................................................................... 17

The Recent History of Private and Public Sector Change .......................... 17

The Origins and Nature of Organizational Change........................ 17

An historical perspective ..................................................... 17

Recent developments....................................................... 19

Organizational Change in the Private Sector ................................... 20

The Recent History of Public Sector Organizational Change:

The Effort to Reinvent Government................................................. 23

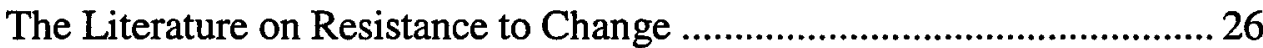

The Two General Perspectives Used to Study Resistance............. 27

Examples of Work Influenced by the Organizational Perspective 27

Examples of Work Emerging from the Individual Perspective .... 30

Phenomenological view of individual change resistance.. 30

Stage-oriented literature ........................................................ 31

Causal frameworks used to understand resistance ............. 31

Strategies used to overcome resistance ................................ 33 
Summarization of Organizational and Individual Resistance

Categories

Summary

The Emergence and Contemporary Use of the Organizational Culture Construct

The Origins and Definition of the Organizational Culture

Construct

A brief history of the emergence and use of the

construct of culture in the study of organizations

The evolution of the culture construct.............................. 38

Influential definitions of organizational culture

(including Schein's seminal definition)

Exemplary studies that used the cultural construct ............42

The Culture Of The Public (Government/Military)

Organizations

Military \& government culture ...................................... 47

Military culture at West Point .......................................... 48

Summary

The Role of Leadership in Influencing, Shaping and Changing Culture .. 51

The Concept of Leadership.... 51

Burn's view of leadership .............................................. 51

Greenleaf's view of leadership....................................... 52

Rost's views of leadership............................................. 53

Heifetz's view of leadership......................................... 54

Kotter's view of leadership ............................................. 56

Perspectives on How Leaders Influence, Shape and Change

Organizational Culture in General and Organizational

Resistance to Change in Particular.

General views of how leadership influences cultural change in organizations.

Schein's views of how leadership influences cultural

change in organizations

Trice and Beyer's views of how leadership influences cultural change in organizations.

Lewin's views of how leadership influences cultural change in organizations

Senge's views of how leadership influences cultural change in organizations

Specific procedures of theory and application for how leadership influences cultural change in organizations..... 65

Kotter's views of how leadership influences cultural change in organizations

Kotter \& Schlesinger's views of how leadership

influences cultural change in organizations

Bowman and Deal's views of how leadership

influences cultural change in organizations 


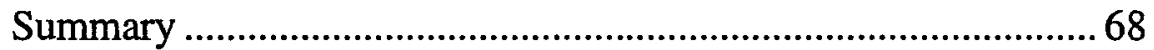

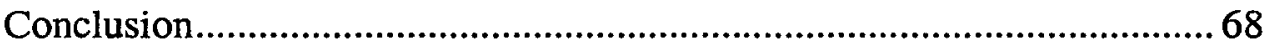

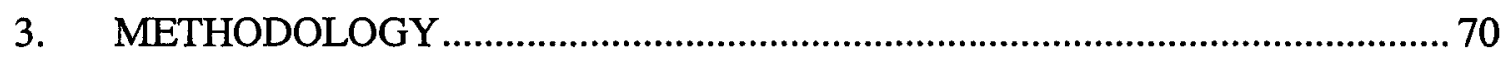

Research Methodology Overview........................................................70

Specific Procedures ...................................................................................72

Researcher Role.............................................................................72

Site Selection........................................................................... 74

Access .............................................................................. 74

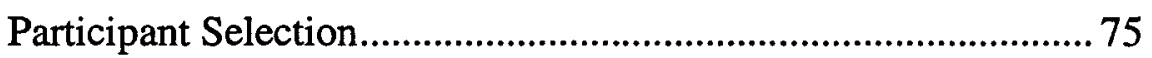

Data Collection.............................................................................. 77

Interview procedures ..........................................................77

Additional data collection methods....................................79

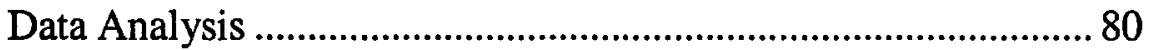

Individual case analysis.................................................... 80

Cross case analysis ........................................................ 82

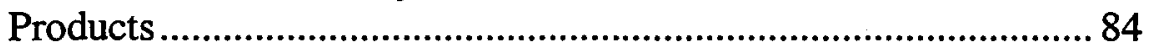

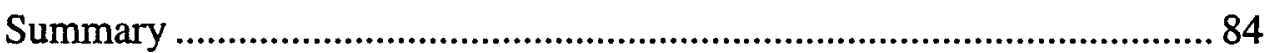

4. FINDINGS: THE STORY OF MAJOR ORGANIZATIONAL CHANGE AT SCSS-LIFE BEFORE, DURING AND AFTER THE FUNCTIONALITY

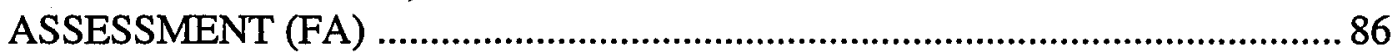

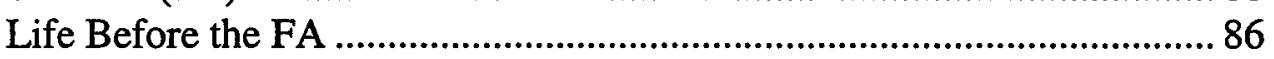

Assembling the Change Team........................................................ 87

The Main Characters ........................................................................ 88

Captain (CAPT) Nora Avian............................................. 88

Dr. Martha Ritter .............................................................. 88

Commander (CDR) Kelsey Vega....................................... 89

Senior (Sr.) Chief Nancy Lewin.......................................... 89

Lauren Maggin ..................................................................... 89

Rachel Christian ………........................................................ 90

Brenda Menton ............................................................... 90

Dedra Wesson .................................................................. 90

Summary ……................................................................ 91

A "Mixed" View of Change........................................................ 91

Negative views of the FA and their causes ......................... 91

Positive views of the FA: two variations ........................... 93

Life in the Real World................................................................ 94

A "Mixed" Breed: The Combined Military \& Civilian

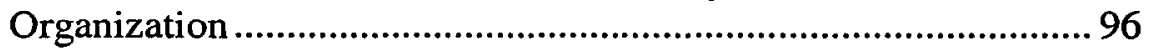

Us vs. them: a top-down view...........................................96

Different views on work and change................................. 97

The benefits of a mixed organization................................... 99

Lay of the land...................................................................... 99 


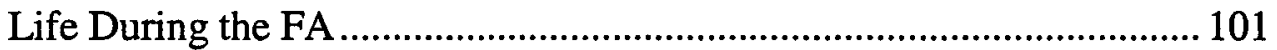

Significant Events in the FA ....................................................... 101

Decision to conduct the FA............................................102

Decision to hire a consulting company ............................ 103

Site visits with Base Commanding Officers (COs)......... 103

Insiders' Views about the Change Process .................................. 104

Groups that Played a Major Role in the FA ................................... 105

The role of the outside consulting team ............................ 105

Other groups that impacted the FA process ...................... 107

The Resistance Factor ................................................................... 107

Sources of resistance .......................................................... 108

Ancillary consequences of resistance.............................. 109

Change Agent Intervention Strategies......................................... 110

Communication strategies .............................................. 110

Confrontation strategies .................................................. 111

Consensus building strategies ........................................... 111

Other conscious and unconscious change strategies ....... 112

Organizational Culture: A Broader Perspective of

Organizational Change ................................................................ 113

A varied definition of organizational culture ................... 113

Different types cultures .................................................. 113

Life After the FA

If Walls Could Speak (Post-Reflections of the FA) ...................... 117

Change is threatening .......................................................117

Change is disappointing .................................................. 118

Change is difficult ............................................................. 118

Change is satisfying .......................................................119

The Role of Leadership and Culture in the FA ............................ 119

Lessons Learned in the FA.................................................... 119

Multiple change efforts .................................................... 119

Leadership support ........................................................ 120

Communication effectiveness ........................................ 120

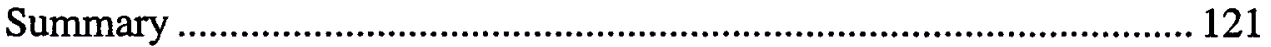

Conclusion................................................................................... 122

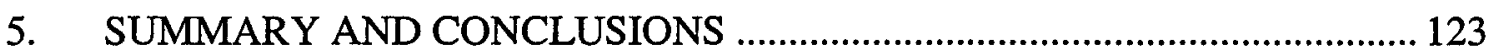

Brief Review of the Problem............................................................ 123

Overview of the Research Methodology................................................... 124

Review of the Major Findings in Terms of the Research Questions ...... 125

Research Question \#1 ................................................................ 125

Sub-Research Question \#1a ......................................................... 126

Sub-Research Question \#1b ..................................................... 127

Sub-Research Question \#1c ...................................................... 128

Research Question \#2 ............................................................... 129

Discussion and Interpretation of the Findings........................................ 130 
Blended Cultures-The Creation of a New Culture ..................... 130

Mixing Politics and Culture ..................................................... 131

Politics and Resistance to Change.......................................... 131

The Importance of (and Problems with) Cultural Awareness..... 132

Resistance From Two Directions ............................................. 133

Views of Gender, Power and Resistance ................................ 134

Views of Leadership and Culture.............................................. 135

Implications for Theory, Practice and Further Research........................ 135

Implications for Theory....................................................... 135

Implications for Practice ....................................................... 136

Implications for Further Research ......................................... 138

Methodological Reflection................................................................ 139

Personal Reflection ............................................................................ 141

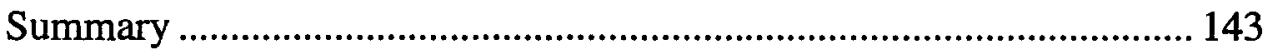

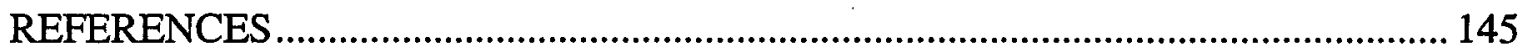

\section{APPENDICES}

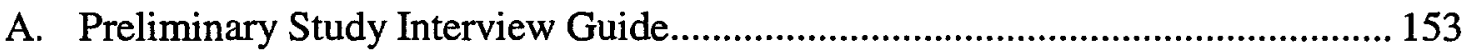

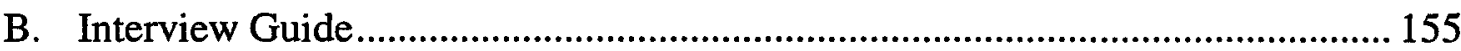

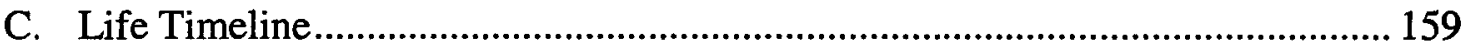

D. Functionality Assessment Timeline ............................................................ 161

E. Preliminary (Pilot) Research Study Permission Letter .................................... 164

F. Research Study Permission Letter.............................................................. 166

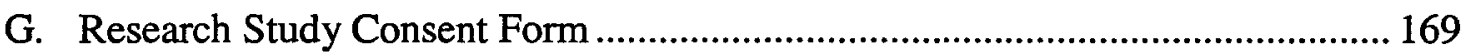

H. Research Study Consent Letter ............................................................. 172

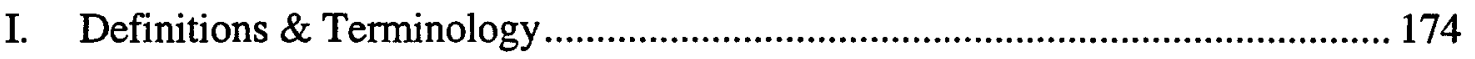

xiii 


\section{LIST OF TABLES}

Table 1. Cultural Change Mechanisms

p. 59

Table 2. Types and Dimensions of Culture Change

p. 62 


\section{LIST OF FIGURES}

Figure 1. Three Levels of Uniqueness in Human Mental Programming p. 43

$\begin{array}{ll}\text { Figure 2. Levels of Culture } & \text { p. } 45\end{array}$

Figure 3. Functionality Assessment (FA) Timeline p. 102 


\section{CHAPTER 1}

\section{INTRODUCTION}

Background to the Study

\section{The Emergence of Planned Change Initiatives}

The second half of the $20^{\text {th }}$ and the first part of the 21 st centuries have produced incredible change in the world of work (Herscovitch \& Meyer, 2002). Rapidly changing conditions in global and local markets, along with advances in technology, economic factors, government regulations and cultural forces, have prompted a significant increase in the rate of organizational change (Rousseu \& Tijoriwala, 1999; Winum, Ryterband, \& Stephenson, 1997; Cummings, 1995). The nature and pace of change is only expected to become more rapid and complex in the future (Bowman \& Deal, 1997, Kotter, 1995, 1996; Cummings, 1995; Burke, 1993). Not surprising, therefore, the topic of organizational change has become increasingly important in both the popular (e.g., Sternberg, 2002; Strebel, 1996; Kotter, 1996; Hammer, 1997; 1993) and the academic (e.g., Senge, 1999; Bowman \& Deal, 1997; Burke, 1993) literature about organizations.

In response to the environmental factors alluded to in the previous paragraph, continuous planned organizational reform is occurring in both the private and public sectors. A major motivation in the private industry has been the need to remain competitive in a changing global marketplace; this translates into reducing costs and becoming more efficient. Downsizing, reengineering, quality management, change management and organizational transformation are just some of the planned, large-scale reform movements that corporations have tried in order to create more efficient and competitive organizations. 
In recent years, the public sector also has begun to focus more intently on planned organizational change. A dissatisfied public that views government as increasing spending and decreasing service delivery has prompted change and reform in this sector of organizational life. In their 1992 book, Reinventing Government, for example, Osborne and Gaebler recommend that the sorts of change initiatives being undertaken by private industry also be adopted in the public sector. Supporting Osborne and Gaebler's view, Hughes (2000) points to the fact that growing discontent with overgrown bureaucracy, antiquated service systems, and out of control spending has led both private citizens and public officials to point to the need for government reformation.

The movement to reform and "reinvent". government has been embraced recently by President George W. Bush and previously by the Clinton and Gore administration in 1993. For example, when Clinton and Gore took office, their administration initiated the National Performance Review (NPR), an intensive six-month study of the entire federal government that focused on ways to reduce costs and improve services. In the remarks announcing the NPR, President Clinton stated, "Our goal is to make the entire federal government both less expensive and more efficient, and to change the culture of our national bureaucracy" (Gore, 1993, p. 460). This sentiment received broad bi-partisan support, as evidenced by congressional enactment of the Government Performance and Results Act (GPRA) in 1993.

\section{The Failure of Planned Change Initiatives}

Since the early 1990s, the NPR and GPRA have promoted formal public sector reform and improvement efforts at rapidly increasing rates. Interestingly, all of this has occurred even though the track record of formal reform initiatives in the private sector has been less than positive. In 1994 alone, for example, an estimated $\$ 30$ billion was 
spent on change-oriented personnel, consulting services and technology investments by U.S. corporations (Winum, Ryterband \& Stephenson, 1997), yet the literature suggests that most large scale reform efforts in the private sector fail (Senge, 1999; Schein 1993; Kotter, 1996; Strebel, 1996; Somerville \& Mroz, 1999, p. 75; Hammer \& Champy, 1993). There is less literature about the fate of change initiatives in the public sector, but the literature that does exist about public sector reform essentially mirrors the less-thanpositive picture that researchers have presented about private sector change initiatives (Hughes, 2000; Winum, Ryterband \& Stephenson, 1997; Champy, 1997; Gore, 1993). As a result of this bleak organizational change track record, there has been an increased interest among academicians and practitioners in exploring why change efforts fail. Although a number of factors undermine planned change efforts, resistance to change consistently surfaces as among the most significant (Oreg, 2003; Trice \& Beyer, 1993; Kotter, 1996; Senge 1990; 1999; Agocs, 1997).

Much of the recent literature on resistance has focused on individuals' response to change (Oreg, 2003; Herscovitch \& Meyer, 2002; \& Strebel, 1996). Trice \& Beyer (1993), however, note that resistance to change does not only take place at an individual level; it also occurs at a group and organizational level. The authors suggest that any of these levels may be impacted during change efforts.

\section{Utilizing the Construct of Organizational Culture to Account for Resistance to Change}

In recent years, organizational theorists have turned to the construct of organizational culture as a way to help understand and explain factors surrounding organizational change and resistance at the macro/organizational level (Bowman \& Deal, 1997; Schein, 1993; Trice \& Beyer, 1993). Some theorists have addressed the impact that culture inevitably has on planned change efforts. These theorists recognize that the 
concept of organizational culture serves as a helpful construct for understanding the success or failure of change initiatives (Detert, et. al., 2000). As Burke (1993) contends, large-scale system change has been explored before, but we are now beginning to understand that organizational culture serves as a primary lever for initiating and implementing organizational change. In other words, the way an organization's employees act and respond to change can be linked to its culture (Galpin, 1996).

Edgar Schein (1992) has made the linkage between organizational culture and organizational resistance even more explicit: "Organizational learning, development, and planned change cannot be understood without considering culture as a primary source of resistance to change" (p. xiv), Schein writes. He adds, "resistance to learning and change is a ubiquitous phenomenon often talked about but seldom understood".

Somerville \& Mroz (2000) also support this link between organizational culture and resistance to change. They suggest that even when leaders have understood the need for change and put in place a well-thought-out program (e.g., organizational restructuring, or process reengineering), "the organization and its culture usually thwart progress" (p. 75). Similarly, Detert, Schroeder \& Mauriel (2000), point to changing the culture as the one common denominator that led previous quality and change improvement efforts to fail. The authors suggest that most organizations had a 'flavor of the month' concept of change but unsuccessfully addressed the environment in which the organization tried to make the change. Like Schein (1992), they imply that most organizational change initiatives typically require some change in the culture. Galpin (1996) also argues that effective change requires changes in operations, systems, and procedures so that they are clearly aligned to the changed culture that is emerging fromand will be required to support- - the changes that are being made. 
Resistance, Organizational Culture and Leadership

Thus, there is a virtual consensus that failure to change the culture of an organization is one of the main reasons why most change initiatives fall short of reaching their goal (p. 84). This focus on the need to change culture has also led to an emphasis, especially in the organizational culture literature (see, for example, Bowman \& Deal, 1997; Schein, 1992; Hofstede, 1991; Peters \& Waterman, 1982), on the importance of leadership and the relationship between leadership and culture. Schein (1992), for example, contends that if leaders are to successfully overcome organizational change resistance, they must first understand the dynamics of culture (p.2). "Neither culture nor leadership, when examined closely, can really be understood by itself," states Schein. He also suggests that that a distinguishing characteristic between leaders and managers is the ability to create and change culture. The leader's ability to create, manage and destroy culture is one of the primary reasons that "leadership and culture are conceptually intertwined" (p. 370).

Schein (1992) argues that effective leaders manipulate culture to create and manage change in the organization. According to Schein, culture is created, developed and destroyed by those in formal authority positions. He suggests that developing one's culture to be adaptive to organizational change is the "essence and ultimate challenge of leadership" (p. 2).

Kotter (1996) also supports the notion that leaders play a critical role in the change process. He argues that successful change is a result of a leader-driven process that creates motivation sufficient to overwhelm sources of resistance and change in culture. Kotter believes that leadership involves a set of processes that initially creates organizations or adapts them to a significantly changing environment (p. 25). $\mathrm{He}$ 
indicates that the term culture refers to "norms of behavior and shared values among a group of people that persist over time." When new practices are created as a result of a transformation effort that are not compatible with the relevant cultures, they will almost always be subject to regression and resistance (p. 148). Therefore, understanding an organization's ability and readiness for change, and knowing how to overcome resistance, is a key function of leadership (see, also, Rosen, 1997).

Some have argued that the thinking of scholars such as Schein and Kotter represents an overly simplistic view of the relationship between culture and leadership (Detert, Schroeder, \& Mauriel, 2000; Senge, 1990; and Cummings, 1995). In fact, organizations are highly complex systems and this complexity suggests that the relationship between individuals' actions and their organizations' cultures would not normally be linear (Katz \& Kahn, 1966). Sternberg (2002), for example, provides a theory of organizational "modifiability" as another way to think about how leaders affect-and may not be able to affect-organizational change. Sternberg suggests that organizations differ in their capacity to change. Organization interventions may succeed or fail, based not only on what leaders do or do not do, but also on pre-existing levels of resistance in an organization and the organization's level of modifiability.

\section{Statement of the Problem}

There is a growing consensus within the literature about the relationship among organizational culture, understanding (and overcoming) resistance to change, and leadership. There is disagreement, however, about how these factors are related to each other. One reason for this confusion is the lack of empirical studies that specifically focus on how leaders use the culture construct to minimize resistance during formal change efforts. There are certainly many studies about the change process (e.g., Levesque, 
Prochaska, \& Prochaska, 1999; Cummings, 1995; Burke, 1993; Hammer, 1997; Champy, 1997; \& Kotter, 1996); there are many discussions about the phenomenon of resistance, some of which are grounded empirically (e.g., Oreg, 2003; Linstead, 1997; \& Agocs, 1997); there is a growing literature on the topics of organizational culture (e.g., Detert, Schroeder, \& Mauriel; 2000; Schein, 1993; 1992; Galpin, 1996; Hofstede, 1991) and leadership (e.g.. Schein, 1999; 1993; Heifetz, 1994; Burns, 1978) and some arm chair theorizing and "how-to" manuals that try to link the two topics (Freedman, 1997, Champy, 1997, Galpin, 1996). But an extensive literature search revealed virtually no specific studies that focused directly on how leaders use culture to minimize resistance during planned change initiatives. Furthermore, no literature was found that focused on leaders' use of culture within governmental and military organizations.

In addition, the majority of empirical research that has focused on large-scale, planned, organizational change has relied on quantitative studies that have used surveys to gather data (Oreg, 2003). After multiple searches of a number of different electronic databases using a number of key terms, very few studies were found that have qualitatively investigated change resistance using the construct of organizational culture in public industry. ${ }^{1}$ Thus, there is a need to understand, from a qualitative perspective, leaders' perceptions of how organizational culture influences change resistance in planned change efforts. There is also a need to examine this phenomenon particularly in public sector organizations.

1 Literature review searches were performed on the terms: "Change, Resistance, Culture, Government, Public Sector, etc." using psycARTICLES®, ERIC and Dissertation Abstracts $®$ (the Dissertation Abstract search was based on a 426 record search conducted on 10-25-03). 
The Purpose of the Study

This study begins to respond to the issues raised in the previous section. It will explore leaders' use of the construct of culture to anticipate and respond to resistance during a planned change initiative. The study also examined how these leaders' actions were shaped and constrained by the culture that already existed within the organization in which the planned initiatives occurred. In particular, the study explored the mental constructs leaders (i.e., individuals in positions of formal authority) used to make sense of and influence the organization's culture in order to promote the change initiative and minimize resistance to it.

This study was conducted in an organization located in the under-researched public sector. More specifically, the research was done in a setting that is a combined government and military organization. This sort of setting-with elements of the government's civil service rules and regulations (and the worker protection such rules and regulations provide) and the military with its emphasis on hierarchical controlprovided a robust environment for an empirically based study geared toward expanding our knowledge of the cultural dimension of organizational behavior and examining how leaders used the construct of culture to manage a large-scale change effort and minimize resistance to change.

\section{Research Questions}

During the course of this investigation, the following questions guided the study:

1. In what ways, if any, do the designated leaders of a large-scale planned change initiative use the construct of culture-either consciously or unconsciously-in thinking about and promoting change and, especially, in attempting to anticipate and respond to resistance to change. 
- What do designated leaders say about the role they played in a large-scale planned change initiative within a military and government-staffed organization?

- What culture-embedding mechanisms (e.g., language, mental schemas) and change strategies do designated leaders indicate they used to shape the organization culture in general and resistance in particular during the change process; to what extent do they themselves characterize these mechanisms and strategies in cultural terms?

- How are these mechanisms and strategies similar to, or different from, the various organizational culture and resistance constructs discussed in the literature?

2. How does the existing culture appear to shape and constrain what leaders do to promote change and minimize resistance during a large-scale change effort?

\section{Methodology}

The research for this dissertation involved a qualitative single-case study of leadership perceptions of organizational change resistance at a large combined military and government organization. This organization was selected not only because of the dynamic change occurring in military and government organizations in general, but also because it was a rich environment to study due to the changes that were occurring in this particular organization.

A qualitative research approach was used to study the perceptions of leaders who have experienced planned organizational change (Spradley, 1979). This study was a continuation and expansion of preliminary fieldwork and analysis conducted in prior study to add to the field's understanding of organizational change resistance. My prior role as a change management consultant within the organization studied helped me gain access to the organization in which the research was conducted. 
For this study, I purposely selected six participants from a government/military organization that had recently experienced a planned change effort. To counteract any sampling bias that might have been associated with my selection of the six interviewees, these interviewees were asked to identify anyone in the organization familiar with the planned change effort that sees the effort substantially differently than they do. This procedure resulted in two additional participants for the study for a total of eight individuals.

Data were collected primarily through interviews. The questions in the dissertation study interview guide were open-ended. The interview guide included follow-up probes that could be used to encourage interviewees to expand initial responses. To supplement the Interview Guide, two timeline analysis tools were used. The first timeline, the Life Timeline Analysis (LTA), represented the participant's life. The second timeline, the Functionality Assessment Timeline Analysis (FATA), was similar to the LTA but offered a tool for participants to reflect on events and dates that stood out about the FA change initiative. Although interviewing was the major source of data in this study, other data sources were used to triangulate interview findings. Documents related to the FA initiative were gathered, for instance. Additionally, notes I took in my consultant role in this organization were also used for triangulation purposes.

Each interview was audio taped and the tape was transcribed for data analysis. To ensure accuracy, participants were asked via email to review transcripts and provide changes or clarifications. During the individual case analysis, I relied on the research questions and the data themselves and the themes that emerged from these data to guide the purpose of this inquiry. After the individual cases were analyzed, I looked for patterns across the codes and categories of each of the eight cases. Once again, codes derived 
from the interview questions were used to organize the analysis initially; then the more emergent codes associated with each of the initial codes were compared and contrasted across the eight cases. Matrices (Miles and Huberman, 1984) were used during this part of the analysis process. To analyze and interpret the data, I used the process of analysis of narrative as discussed by Polkinghorne (1995).

A case study approach was used to organize and describe an analysis of narrative form of each participant's experience in the organizational change projects. Initially, I examined the experiences of each of these eight leaders individually as a case and utilized traditional case analysis procedures to organize and analyze my data. Later, an approach similar to a qualitative comparative analysis (QCA) approach was used to analyze findings across of individual experiences (Patton, 2002).

Significance of the Study

This study will begin to provide an empirical basis for assessing leadership's role in change resistance from an organizational culture perspective. For those engaged in such relationships, the research should help identify reasonable and realistic strategies and expectations. Organizational leaders should also have more of a basis than they currently have for approaching organizational change initiatives of a similar nature. More specifically, I hope to add to the literature that to date has given little attention to qualitative, change resistance studies in public industry. Through this research, I expect to further understand the strategies that leaders employ to manage change resistance and build acceptance. Additionally, it is my aim to illuminate some of the systemic issues and factors associated with organizational culture and change resistance. Finally, this research will attempt to provide a new way of thinking about the role of leadership in public industry in a dynamic world of increasing change. 


\section{Limitations}

This study sought to examine leaders' responses about their lived experience related to organizational change resistance. Some will be concerned that this study initially focused on the experiences of six individuals in a large-scale change initiative in one government/military organization. A few may be concerned that the organization's hierarchy is unique to the Community Support Services organization under study and not representative of other organizations. The fact that this study seeks to examine participant's views of the FA change effort "post-facto", that is, after its been conducted, may also give rise to concern. Additionally, others will be apprehensive that the study employed a qualitative approach. Finally, some may see the fact that the principal investigator previously served as a consultant on this project with the organization as a considerable limitation.

\section{External Validity}

While I acknowledge the potential legitimacy of the concerns expressed above, I would like to raise the following points: Although there is concern that social phenomenon has only limited application, the notion of generalizability and transferability in the study of an individual case study is applicable. As Donmoyer (1990) reminds us, the researcher is interested in individuals and not aggregates. More specifically, Donmoyer states, "it no longer makes sense to think of generalizability as synonymous with the use of large samples and statistical procedures designed to insure that the large samples accurately represent the population" (p. 181). The experience that one has in one situation, whether considered unique or typical, offers a basis to develop questions or, as Donmoyer describes, a "working hypothesis" to form questions to inform and apply those hypotheses to the new situation or experience as appropriate (p. 187). 
The advantages of the case study is gained through at least three characteristics including, (a) the ability to provide access to places or experiences otherwise not accessible, (b) providing a perspective from the researcher's view that might not otherwise be considered or seen, and finally, (c) increasing the others' openness to learning through a vicarious situation-i.e., the FA change initiative.

In the case of this proposed research study, these all, to some degree, apply. Additionally, the case can be made that through qualitative methodology and systematic rigor, external validity can be strengthened. The notion that the research will only focus on one government/military organization with a unique hierarchical structure does not limit the meaning and findings that emerge from this research study. Again, the focus is more on the depth and quality of research and the characteristics associated with the organization that may generate additional hypotheses, inspire new change resistance language, and introduce novel working schemas helpful when applied to organizations other than the one studied.

\section{Internal Validity}

The second point addresses the notion of internal validity. The fact that good qualitative data depends on the methodological skill, sensitivity, and integrity of the researcher is important to all qualitative research (Patton, 2002; p. 5). No research can provide complete internal validity. Qualitative inquiry methods, however, can provide opportunities for researchers to achieve empathic neutrality and provide an empirical basis for describing the perspectives of others (Patton, 2002; p. 53). Additionally, the role of observer-as-participant is well established in sociological literature. In qualitative research, the researcher is the primary instrument of inquiry for data collection and analysis (Merriam, 1998; p. 7; Patton, p. 14). However, there are costs associated with 
this approach, the researcher has already played the role of outside observer and consultant in the past with this same organizational unit, thus minimizing the potential for undue hardships.

Peshkin (1988) asserts that subjectivity is inevitable when conducting qualitative research. My previous role as a consultant to the organization studied could lead some to have concerns with subjectivity in this study since I served as the primary data collection instrument. Additionally, this may lead to other concerns associated with doing backyard research since I worked with an organization with which I was familiar. Glesne (1999) defines backyard research as studying one's own institution or organization. While my own consulting organization was not the focus of my research, concerns around this limitation may lead to critique of how I conducted qualitative research and analyzed data and findings. Concerning the issue of subjectivity, I carefully monitored others and myself throughout the process to maintain awareness of these potential problems. I used my research journal throughout the study to vigilantly monitor my thoughts and document all concerns that arose related to backyard research considerations, and structured my data collection and analysis steps to try to minimize possible effects. Finally, I used "triangulation of data sources and analytical perspectives" to increase the accuracy and credibility of findings (Patton, 2002; p. 93). According to Patton, every method, to some extent has limitations, therefore multiple methods are typically required (p. 247). 


\section{Organization of the Dissertation}

This first chapter provided the background to the dissertation. It discussed the statement of the problem, the purpose of the study, and the importance of studying culture and change resistance. In addition, the research questions were articulated. Finally, the significance and limitations of the dissertation were discussed. The second chapter reviews the relevant literature in the field of organization change, resistance, culture, and leadership, which laid the foundation for the study and informed the research. The third chapter outlines in detail the methodological procedures that guided the research process for this study. The fourth chapter presents the findings of the dissertation through a narrative analysis framework and borrowing loosely from a case approach. Finally, the fifth chapter summarizes the dissertation, provides succinct answers to the research questions, presents some methodological reflections, and reviews recommendations for practice as well as recommendations for future inquiry.

\section{Summary}

This chapter provided an introduction to the study about leaders' use of the construct of culture to anticipate and respond to resistance during a planned change initiative. The chapter began with a background to the study. The emergence of planned organizational change and the constructs of organizational culture, resistance, and leadership in the literature were discussed.

Next, a statement of the problem was provided and suggested that there is disagreement in the literature among how the constructs of organizational culture, resistance, and leadership relate to one another. The study's purpose and specific research questions were also presented. The particular focus was on identifying (a) any culture- 
oriented change strategies leaders use to overcome resistance to change and (b) specific ways in which the organizational culture shapes and constrains leaders' actions. The study's methodology was introduced. Specifically, I discussed how qualitative methods was used to collect and analyze data, primarily through interviews, in a combined government and military organization. The significance of the study was then presented. The study proposed to provide an empirical basis for assessing leadership's role in change resistance from an organizational culture perspective. External and internal validity concerns were discussed in the limitations section of the chapter. Finally, the organization of the dissertation was reviewed.

The next Chapter, the Literature Review, provides a brief review of the literature important to the study of organizational culture construct and its relationship to leadership and change. Specifically, the next section will present the recent history of private and public sector change; the factors surrounding organizational change resistance; the development of the organizational culture construct; and the role of leadership in influencing, shaping and changing culture. 


\section{CHAPTER 2}

\section{LITERATURE REVIEW}

This chapter is designed to orient the reader toward the topic of the study and, in the process, help to situate the dissertation within a larger intellectual context. This chapter will focus on four broad topics that appear to be relevant to the study conducted. These topics are: (a) the recent history of private and public sector change; (b) the factors surrounding organizational change resistance; (c) the development of the organizational culture construct; and (d) the role of leadership in influencing, shaping and changing culture.

\section{The Recent History of Private and Public Sector Change}

The opening section to the literature review explores the recent organizational change movement in both the private and public sector. The first section briefly discusses what the literature says about (a) the origins and nature of organizational change, (b) organizational change in the private sector, and (c) the recent history of organizational change in the public sector, particularly the movement to "reinvent" government.

\section{The Origins and Nature of Organizational Change}

The first part of section one will briefly discuss what the literature says about the origins, nature, and evolution of organizational change. Essentially, this discussion expands the discussion found in the "Background to the Study" section of Chapter 1.

An historical perspective. The early growth and advancement of organizational change theory and practice is often linked to the organizational development (OD) movement (Shafritz \& Ott, 2001, p. 147; Goodstein \& Burke, (1991). OD has its roots in scientific management dating back to the 1930s and the work of Fredrick Taylor. One of the best-known historical studies influenced by Taylor's notion of scientific management 
is the so-called "Hawthorne Experiments." The purpose of the experiments-which were conducted by the Elton Mayo team at the Hawthorne (Mayo, 1933) plant of the Western Electric Company beginning in 1927-was to find out if the relationship between quality and quantity of illumination influenced the efficiency of industrial workers.

The results indicated that, regardless of the differences in illumination at the plant, employee productivity improved. This improvement was later attributed to the increased attention that industrial workers received during the study (Roethlisberger, 1941). This focus on the human dimension of organizations and the so-called "Hawthorne effect" set the stage for advancing behavioral science, the change theory and the OD movement.

OD is defined as planned, organization-wide, managed change (Varney, 1996; Worren, et. al, 1999). OD uses intentional interventions to target organizational processes using behavioral science knowledge. Four core elements are associated with this strategy. These elements are: (a) planned interventions targeted at increasing organizational effectiveness, (b) heavy reliance on concepts and research from behavior sciences, (c) long-term and continuous effort, and (d) focused practice utilizing human relations variables (Worren, et al., 1999; French \& Bell, 1990; Varney, 1996;).

The notion of large-scale, planned organizational change became popular during the 40's, 50's, \& 60's through "National Training Laboratories" also known as "reinvention labs." As noted by Schein (1993), "the fundamental assumptions underlying any change in a human system are derived originally from Kurt Lewin" (p. 298). Lewin (1951) identified various stages of organizational change. His three stages of change include unfreezing, moving or changing, and then freezing again. Lewin's change model also focused on three levels within the organization: the individual, the interpersonal, and structures and systems. 
Lewin's concepts remain relevant today. The notion that change occurs in stages and that various levels must be examined when studying the change process have been utilized in this study.

Recent developments. In recent years, organizational development work, especially work inspired by the NTL, frequently focused more on Lewin's individual and interpersonal levels and ignored the importance of systems. Consequently, the notion of change management has tended to be used by those who manage and study organizational change concepts. Although the definitions of terms like OD and change management can vary-i.e., different individuals can use the same terms in somewhat different ways-the concept of change management normally implies a more comprehensive and systematic approach to organizational change, an approach focused on multiple systems and the interaction of these systems, while contemporary talk of organizational development tends to emphasize the individual and interpersonal aspects of organizational life and organizational change. Change management, in fact, has been defined as "a wide range of intervention strategies that may enhance human performance directly or indirectly" (Worren et al., 1999). Change management, in other words, covers a broad perspective that includes individual change as part of a larger strategic, enterprise transformation.

A key aspect of change management is the idea that the notion of organizational development, at least as it has come to be used, is only one component of a large organizational change effort. Other elements are strategy, processes, and technology; the primary objective being to integrate these components. Worren et al. (1999) support the notion that change management is broader than OD since it includes a wide range of interventions and approaches that cross over most organizational systems. One of the 
characteristics of change management that differentiates it from OD is that change management consultants work in teams, often with specialties in areas of strategy, IT, process analysis and organizational design.

In other respects, however, the change management concept seems to channel much of Lewin's original thinking as well as the Hawthorne experiments that gave rise to the OD movement. In an article published in Booz Allen Hamiliton's Strategy + Business Magazine, Jones, Staub \& Powers (2004) identify "10 Principles of Change Management." In the process of discussing their ten principles, the authors highlight the need to systematically address the "human side" of change, while working from the top of the organization down through every layer, and assessing the cultural landscape along the way (p. 4).

Other practitioners and researchers, including Senge (1999, 1990), Argyris (Argyris \& Schon, 1974), and Schein $(1999,1993)$, have contributed significantly to the field of change management. Collectively they seem to suggest that the notion of change management has the potential to integrate other planned change strategies including contemporary interpretations of the OD approach as well as other strategies alluded to in Chapter 1 (Shafritz \& Ott, 2001).

Organizational Change in the Private Sector

During the past few decades the private sector has focused on major reform efforts during the past few decades (Hughes, 2000; Kotter, 1996; Hammer \& Champy, 1993) in large part because of the perceived need to remain competitive in a changing global marketplace that has forced organizations to look for ways to reduce costs by becoming more efficient (Herscovitch \& Meyer, 2002, Rousseu \& Tijoriwala, 1999; Winum, Ryterband, \& Stephenson, 1997, Cummings, 1995). Indeed, even before the 
concept of change management became part of the nomenclature in the 1990s, a range of strategies began to be promoted as a way to structure and manage the change process. As noted in Chapter 1, these strategies included downsizing, reengineering, quality management, and, of course, organizational development. At times, many or all of these concepts have been subsumed under the change management concept, and are viewed as a kind of smorgasbord of strategies for engaging an organization in a systematic change process (Sternberg, 2002; Varney, 1996; Burke, 1993).

During the 1990s, the impetus for change brought on by global competition was especially strong. During that time, the ideas of three theorists-Hammer (1993), Champy (1997), and Kotter (1996)—became quite influential in the private sector. This portion of the review will focus on their ideas.

Michael Hammer is linked to the creation of the business process reengineering (BPR) movement (Champy, 1997). He later joined with Champy to more fully develop this concept. Hammer and Champy (1993) define BPR, which was developed from the disciplines of operations research and industrial engineering, as "the fundamental rethinking and radical redesign of business processes to achieve dramatic improvements in critical, contemporary measures of performance such as cost, quality, service and speed" (p. 19).

In many respects, BPR could be seen as a form of change management (which, in turn, could be seen as harking back to the original concept of OD inspired by Kurt Lewin). Hammer's unique contribution, however, is BPR's focus on orienting business improvement around customers' needs and maximizing customer satisfaction. Champy (1993) added a concern with articulating a clearly defined organizational change process (sequence of events) and organizational structure that are needed to help transform the 
organization. Champy (1997) also states that major organizational change programs must be top-down, vision-driven, and require broader participation in the design and implementation stages.

BPR also emphasizes that a business' senior management team members must be in agreement about the desired direction of change. More specifically, the emphasis is on agreement about three things: the business case for change, the scope and scale of the change, and a process for managing the change. Despite this emphasis on process-and the fact that process is part of the label they use to characterize their strategy-Hammer and Champy make clear that BPR requires that organizational change always be focused on the outcome and the customer instead of the mechanism or events. Stated another way, organizational change should be results-oriented rather activities-oriented.

Unfortunately, the results of BPR - and other change strategies employed during the 1980s and 1990s were often less positive than anticipated (Hughes, 2000; Champy, 1997; Kotter, 1996; Hammer \& Champy, 1993). Another influential change theorist during the 1990s, John Kotter, helps us understand why this occured. In the summer of 1994, Kotter wrote the article "Leading Change: Why Transformation Efforts Fail." The widely-cited article is based on Kotter's experience with several organizations using change initiatives to institute organizational transformation. Kotter's (1996) follow-up book, Leading Change, documents the problems of change and links leadership to successful organizational transformation.

Kotter (1996) identifies eight reasons why many change improvement initiatives have been disappointing and ineffective. These include: (a) allowing too much complacency; (b) failing to create a sufficiently powerful guiding coalition; (c) underestimating the power of vision; (d) under-communicating the vision by a factor of 
10 ; (e) permitting obstacles to block the new vision; (f) failing to create short-term wins; (g) declaring victory too soon; (h) neglecting to anchor changes firmly in the corporate culture.

Of the eight primary errors that he cites as reasons for failure, nearly all pertain to how the functions of leadership effectively guide organizational change (p. 21). For instance, Kotter establishes that having a sense of urgency is not enough, and in fact, having a strong, clear vision is the most important aspect of any successful change. He argues that one of the primary reasons that change fails, is that power of the vision is underestimated and under communicated.

The Recent History of Public Sector Organizational Change: The Effort to Reinvent

\section{Government}

While the contributions of Hammer, Champy and Kotter have focused almost exclusively on the private sector, this dissertation has focused on a very different sort of organization, i.e., that is a sort of hybrid of the public and private sector. This part of the review, will focus on literature about organizations that have not generally been addressed by Hammer, Champy, or Kotter. Although the differences between private and the public sector are great, there are many similarities that merit consideration and further exploration.

It must be noted that there is no literature about the sort of hybrid organization that was studied for this dissertation. Furthermore, until recently, there has been surprisingly little in the literature to help us understand the change process in public organizations until recently. 
The one possible exception to this is the area of educational change (see, for example, Fullan 1993; Miles \& Hubberman 1984; Sarason, 1996). The theoretical literature on school change, however, tends to be derivative of work in business (see, for example, the work on adapting the total quality management concept to schools (Fullan 2000 \& Sarason, 1996), while the more empirical work on school change describes a context which is radically different from the quasi-military organization that was the focal point for this study. Consequently the education change literature will not be reviewed here. Rather, the focus will be on literature about attempts to adapt some of the change management strategies discussed above to public organizations other than schools.

One of these attempts at adaptation was the recent effort to reinvent government. In the last part of section one I will briefly discuss Osborne and Gaebler's (1992) book Reinventing Government and the contributions it has made to changing the public sector, as well as Hughes (2000) and Holman's (1993) account of the impact of Osborne and Gaebler's reinventing government notion. (The reader may also wish to reread the sections pertaining to organizational change in the public sector included in the "Background-to-the-Study section" of Chapter 1.)

Osborne and Gaebler's (1992) book Reinventing Government sparked a new focus in organizational reform in the public sector. The authors' premise is that government must redefine itself and adapt to the times. The notion of bureaucracy has long been synonymous with government. Although the term bureaucracy had a positive meaning when it was originally introduced and connoted "a rational, efficient method of organization," the meaning of the term has a decidedly negative valance today, at least among the public. Osborne and Gaebler state that "people in government are not the 
problem, the system is" (p. 8). Put differently, the current bureaucratic state of government is no longer effective or viable. Even as they advocate looking to the private sector for models of reform, however, Osborne and Gaebler also emphasize that the government sector is not the same as private business and, hence, cannot simply mimic private business practices.

The authors suggest "ten principles of new government" that can serve as a guide to changing the existing state of government practices (and that are quite reminiscent of the principles associated with BPR). These are as follows: (a) promote competition between service providers; (b) empower citizens in the community; (c) measure performance by outcome; (d) be driven by goals or missions; (e) see your clients as customers; (f) prevent problems before they emerge; (g) encourage people to both earn and save money; (h) decentralize and encourage participatory management; (i) use market mechanisms; and (j) catalyze all sectors (i.e., public, private and voluntary) into action. These ideas promote two central ideas-government accountability and entrepreneurial action. In their final chapter entitled, "Putting It All Together", Osborne and Gaebler suggest the need for a new framework to understand and change government.

Other authors have reviewed Osborn and Gaebler's seminal work as well. Hughes (2000), for example, argues that the last two decades have been marked by significant organizational reform in the public, as well as the private sector. He credits Osborne \& Gaebler's work, Reinventing Government, with being the "driving spirit behind these reforms" (p. 256). Hughes makes the case that the workplace is in transition as a result of a competitive and changing marketplace. Discontent within the public sector has sparked a need for radical reform and change in the way government and the public sector 
operates. Hughes, however, does caution against unnecessary pain caused from reengineering and suggests ways to honor the "psychological contract"- a term initially coined by Levinson to refer to an implicit set of expectations between employer and employee that implied lifetime employment in exchange for loyalty and hard work (p. 257). He notes for example, that after a restructuring effort "leaders (should) strive to define and clearly communicate to employees the new organizational objectives as well as individual job requirements" (p. 267).

Holman (1993) also reflected on Osborn \& Gaebler's thesis. Holman agrees that government cannot be run the same as private businesses because they have different motivations, goals and missions. A somewhat different philosophical orientation and different organizational structures, however, do not mean that government cannot be more entrepreneurial, according to Holman. Holman (1993), in fact, states, "hierarchical, centralized and bureaucratized governments, designed and developed during the industrial era, do not work well in the rapidly-changing, information-based, knowledgerich 1990s" (p. 26). Both Holman and Hughes seem to agree that while Osborne and Gaebler's work has sparked a movement in the public sector for business reform, more work is needed to advance the cause.

The Literature on Resistance to Change

The literature about resistance to change is voluminous. To bring some order to this abundance of literature, I will organize this discussion around two general perspectives used to study resistance, and then summarize literature related to each perspective. 
The Two General Perspectives Used to Study Resistance

One perspective that has been used to study resistance could be labeled the organizational perspective. From this perspective, resistance is seen as a sociological phenomenon and as a response to the structural dimensions of an organization. The second perspective, which can be labeled the individual perspective, views resistance more psychologically than sociologically, and analyzes resistance from a phenomenological rather than a structural perspective. As its label implies, this perspective attempts to make sense of change resistance at the individual, or worker, level and employs an emic or "insider" point of view. Work that is classified from this perspective can display considerable variation.

Examples of Work Influenced by the Organizational Perspective

Certainly one of the most highly influential theories within the organizational perspective is the systems theory. The notion of systems, in fact, has been a key concept used in understanding organizational change in general, and resistance to change, in particular. Katz and Kahn (1966) define systems theory as basically "concerned with problems of relationships, of structures, and of interdependence, rather than with the constant attributes of object." They suggest that one important aspect of organizations is the need for both growth and conservation (i.e., maintaining enough of a steady state or "status quo" to keep an organization stable enough to be functional). One example of maintaining a steady state is the way the human body maintains a constant temperature of 98.6 degrees despite changes in the external environment. The authors describe this conservation process as dynamic homeostasis. Katz and Kahn argue that organizations also must experience homeostasis in order to stay healthy. 
Open systems are analogous to biological organisms in the sense that they interact and import energy from the environment and transform imported energy into some product. Open systems share several common characteristics that influence their ability to change, one of which, is negative entropy. According to Katz and Kahn, "the law of negative entropy states that systems survive and maintain their characteristic internal order only so long as they import from the environment more energy than they expend in the process of transformation and exportation" (p. 259). Put another way, open systems strive to reverse the entropic process in order to survive. Yet, there is also a need to simultaneously promote entropy so there is enough stability to maintain functionality within the organization. Indeed, the presence of at least a modicum of stability is a prerequisite for something being considered an organization. An organization cannot exist without some commonly held beliefs and agreed upon standard operating procedures. Thus, from the perspective of open systems theory, employee resistance is a necessary component of the ongoing tightrope walking act between change and stability that organizations must engage in to remain healthy.

Katz and Kahn indicate that open system theorists' concept of homeostasis borrows from Lewin's notion of "equilibrium," a term that Lewin uses to characterize what happens over time after an organization has experienced the "unfreezing" phase of a planned organizational change process. Edgar Schein (1992) also relates the notion of homestasis with Lewin's notion of equilibrium:

All human systems attempt to maintain equilibrium and to maximize their autonomy vis-à-vis their environment. Coping, growth, and survival all involve maintaining the integrity of the system in the face of a changing environment that is constantly causing various kinds of disequilibriums. (Schein, 1992; pg. 298) 
Katz and Kahn extend this thinking, and point out that as organizations adapt to their environments, they will attempt to cope with external forces by acquiring control over them. They argue that the underlying basic principle of organizational life is preservation of the organization's character. In other words, an organization will try to protect itself, or from a anthropomorphic perspective, it will attempt to protect its essential character during the move toward a new state of equilibrium. Thus, those who resist change prior to the establishment of a new equilibrium in an organization can be seen as being engaged in the highly important task of retaining an organization's essence and preserving the essential character of the organization even as novel aspects of the external environment are being accommodated. Once again, those who resist are seen as having an exceedingly important role to play in the change process.

Lewin (1951) also provided a stage theory to understand the organizational change process. Lewin's "unfreezing", "moving", and "refreezing" phases of planned organizational change suggests that change occurs as a result of turbulence in the stabilizing mechanisms, or force field, of an organization (p. 228). In other words, when the forces of change are greater than the resistance, change will result. To achieve planned change in the organization, Lewin suggested unfreezing the organizational equilibrium to create a surge of change and then refreezing the new equilibrium. Since Lewin's contribution to stage theory, numerous scholars have used this model to begin to understand change and resistance in organizations (see for example, Oreg, 2003; Kotter, 1996; Schein, 1993; 2000; Senge, 1990; \& Trice \& Beyer, 1993). 


\section{Examples of Work Emerging from the Individual Perspective}

Although organizational analysis in general, and systems theory in particular, provide a somewhat counterintuitive and, hence, intriguing perspective on the whole issue of resistance, most of the empirical literature about resistance takes a more individualistic stance. This empirical literature is capacious and reflects a wide variety of individualistic perspectives. Consequently, the vast empirical literature on change and resistance has been organized into the following categories: (a) the phenomenological view of individual change resistance (Kotter \& Schlesinger, 1993 \& Stebel, 1996); (b) stage-oriented literature (Levesque, Prochaska \& Prochaska, 1999 \& Lewin, 1951); (c) causal frameworks used to understand resistance (Rousseau \& Tijoriwala,1999; Senge, 1990; Bowman \& Deal, 1997); and (d) strategies that can be used to overcome resistance (Rosen, 1997; Argyris, 1990; \& Champy, 1997). Examples of the literature associated with each of these categories are presented below.

Phenomenological view of individual change resistance. While an organizational perspective, and, more specifically, a systems perspective, provides a functional explanation of the role of resistance in organizational life, literature included in this first subcategory operates out of and, consequently, provides a more phenomenological view of resistance to change. It does this by focusing on the specific reasons employees resist change. Kotter \& Schlesinger (1993), for instance, provide four of the most common reasons: (a) a desire not to lose something of value; (b) a misunderstanding of the change and its implications; (c) a belief that the change does not make sense for the organization; and (d) a low tolerance for change (p. 396).

Paul Stebel (1996) also writes from what is being referred to here as a phenomenological perspective of sorts, but he also links his phenomenological analysis to 
the traditional sociological concept of role. He suggests that part of the fundamental issue is that executives and employees see change differently. In this regard, senior managers generally see change as an opportunity to make improvements or advance the organization in a new way, while employees view change as a disruption of their normal work life. He suggests that managers must learn to see what it is that individuals expect to give and get out of their employment with the organization (p. 139).

Stage-oriented literature. Some individualistic literature has also focused on the stages of change. Levesque, Prochaska \& Prochaska (1999), for example, indicate that individuals experience five relatively distinct stages as they move through the change process within an organization. These stages include: (a) pre-contemplation, i.e., not intending to engage in action before the change occurs; (b) contemplation, i.e., intending to take some type of action before the change occurs; (c) preparation, i.e., intending to take action just before the change occurs; (d) action, i.e., making overt changes before change occurs; and (e) maintenance, i.e., overt changes made after planned change occurs.

Levesque, Prochaska \& Prochaska's stage theory differs from the change theory of Lewin that was discussed in the previous section of the review. The difference, of course, is that Lewin conceptualizes stages in organizational terms while Levesque, Prochaska \& Prochaska talk about the stages that individuals go through.

Causal frameworks used to understand resistance. Some literature has focused on establishing causal relationships as a means of understanding resistance to change. Rousseau \& Tijoriwala (1999), for example, point out the frameworks employees use to understand change are not well understood given the variety of ways that employees interpret reasons for change (p. 514). In a field study, authors Rousseau and Tijoriwala 
(1999) examined what are considered good factors or reasons for employees to want to change. For example, they noted the beliefs that other co-workers held about the change were influential. In other words, knowing how other employees felt or reacted to the change affected how they would adopt the change. Another factor was the amount of trust employees had in management and in the organization. These factors serve as a type of "mental model" that employees use to shape and define their interpretation of reality in a change context (Rousseau and Tijoriwala, 1999, p. 526; Bowman \& Deal, 1997; Senge, 1990).

Another example of the causal frameworks used to understand change is provided by Bowman \& Deal. Bowman \& Deal (1997) inform us that, from a human resources perspective, employees have good reason to resist change. Changes in routines and standard procedures diminish people's ability to perform with confidence and success ( $\mathrm{p}$. 323). The authors also indicate that organizational structures must be aligned in order to support changes in individuals. They conclude by articulating four causes of resistance. They state that resistance occurs: (a) when individuals' ability to feel effective, valued and in control is threatened; (b) when change upsets existing relationships and established working roles; (c) when change creates winners and losers; and lastly (d) when change causes a loss of meaning for people.

Rosen (1997) also explored casual reasons for change, and he, too, indicates that leaders need to pay attention to why and how employees deal with change. Rosen supports the notion that everyone resists change, primarily because of our human nature for control and predictability. To move through the protective barriers that all people put up, people need time to work through the change process. An effort must also be made to build organizational commitment and trust. Organizational commitment and trust occurs 
by building relationships one person at a time in order to help people feel engaged and committed to the organization's future (p. 310). Consequently, pre-planned or preprogrammed change initiatives are not likely to achieve high-levels of trust and commitment due to limited stakeholder involvement (Rosen, 1997; Cummings, 1995).

Argyris (1990) also uses a causal framework perspective and points out human defense structures play a major role in resistance to change. The author submits that deep-seeded defensive routines account for the seemingly hard to explain reaction of individuals resistance to change. These defenses play out in various ways. The first limitation of defenses is that an individual may not be willing to share feedback because of the lack of trust toward the organization. The second limitation results from the first because the organization never learns of the individual's causal reasoning behind their beliefs toward organizational change in the first place. Both of these limitations underscore how individual defensive reasoning creates consequences that are counterproductive to the subject's intentions (p. 374).

Champy (1997) adds that fear and cynicism are real feelings associated with organizational changes. The author identifies that fear comes from the real possibility of a significant change in job or possibility of job loss. He contrasts fear with cynicism which can come from distrusting that managers will indeed follow through with what they say will happen. The author supports the notion that cynicism and fear can be reduced through open conversations. If fear is legitimate it may not go away, but cynicism can be displaced if mangers act on what is said (p. 15).

Strategies used to overcome resistance. Finally, some of the literature on resistance has focused on ways to overcome resistance to change. Kotter (1996) provided eight-steps for creating an environment that is supportive for major change. The steps 
include: (a) establishing a sense of urgency; (b) creating the guiding coalition; (c) developing a vision and strategy; (d) communicating the change vision; (e) empowering broad-based action; ( $f$ ) generating short-term wins; $(\mathrm{g}$ ) consolidating gains and producing more change; and $(\mathrm{h})$ anchoring new approaches in the culture.

Freedman (1997) also articulated different approaches to overcoming resistance to change; his approaches are rooted in a socio-technical systems frame perspective. $\mathrm{He}$ notes that a common element in all change models has been the level and/or kind of attention that practitioners and theorists devote to managing resistance for change. Those least attentive to resistance believe that a change "system"-e.g., business process reengineering (BPR), a computer system, or total quality management (TQM)—will overcome resistance automatically. Time and again, this thinking has proven to be problematic. An example of a misguided kind of attention is attention focused on "fixing" individuals who resist. He suggests that this type of thinking is grounded in a more traditional and out-dated "mental model" held by most people about organizational change and resistance. Freedman's socio-technical perspective, on the other hand, offers another view of overcoming resistance to change. He suggests that complex transformational processes should be viewed and managed as a series of interrelated, stand-alone transitions. Freedman offers that this approach offers more "breathing space" between efforts and breaks up change into more manageable parts.

\section{Summarization of Organizational and Individual Resistance Categories}

In summary, it must be noted that the two change resistance perspectives that have been used to organize this section are ideal types. In reality, organizational and individual perspectives get merged in the literature all the time. This is a good thing because no single ideal type can account for and accommodate the complexity of 
organizational life or even the phenomenon of change resistance. The ideal types are helpful, however, in simplifying our thinking about the theories and research that attempt to make sense of the complexity of organizational life, they also are essential tools for critique.

Indeed, when we look at the literature through individual and organizational lenses, something quite interesting appears: The literature is skewed toward an individual rather than an organizational view of resistance. Kotter \& Schlesinger (1993), Stebel (1996), Agocs, 1997; Levesque, Prochaska \& Prochaska, 1999; Rousseau \& Tijoriwala, 1999; and Senge, 1990, all operate primarily from individual perspective. Although the individual perspective provides a useful view of change resistance that cannot be overlooked, it represents only one side of the change resistance phenomenon. The organizational resistance perspective offers a view of the other side, and also a more macro view of change resistance (Oreg, 2003; Herscovitch \& Meyer, 2002; Trice \& Beyer, 1993). Trice and Beyer (1993) support the idea that resistance to change does not only take place at an individual level and argue that it is also important to look at resistance as a group or organizational phenomenon. The authors suggest that any of these levels may be impacted during change efforts. In fact, the authors provide a list of "common sources of resistance to change" and suggest that these are different at the individual and organizational level. At the individual level, these include: (a) fear of the unknown, (b) self-interest, (c) selective attention and retention, (d) disruption of habits, (e) dependence on authority, and (f) need for security. At the organizational level, the sources of resistance include: (a) threats to a group's power, (b) lack of organizational trust, (c) different group perceptions and goals, (d) social disruption, (e) resource limitation, (f) fixed investments, and (g) inter-organizational agreements. 
In recent years, organizational theorists have turned to the construct of organizational culture as a framework to help understand and explain factors surrounding organizational change and resistance (Bowman \& Deal, 1997; Schein, 1993; T Beyer, 1993, Akin \& Palmer, 2000) at the macro/organizational level. This construct, of course, was a centerpiece of the research that will be reported in Chapter 4 of this dissertation. Summary

The first section of Chapter 2 reviewed what the literature said about the origins, nature, and evolution of organizational change. This section presented the evolution of organizational change from its roots in scientific management and organizational development to modern business process reengineering, change management, and organizational transformation theories. Studies about the recent history of public sector organization change and specifically, Osborne and Gabeler's notion of reinventing government, were discussed. Organizing the vast organizational change and resistance literature into two broad categories—organizational and individual change-helped examine change at two different levels and was central to the review of literature for this study. Additionally, sorting the literature in this way highlighted the lack of change and resistance literature from an organizational perspective. This review essentially expanded on the discussion from the "Background to the Study" section of Chapter 1.

The following section explores the emergence and contemporary use of the organizational culture construct and will examine three aspects of this literature including the origins and definition of the organizational culture construct, attempts to use the notion of culture help make sense of organizational behavior and change, and what the literature says about the culture of the public government and military organizations. 
The Emergence and Contemporary Use of the Organizational Culture Construct

This section of the literature review on the emergence and contemporary use of the organizational culture construct will elaborate on some key concepts and ideas discussed in the "background to the research" section above. Despite the relatively brief history of the use of culture as a construct in the organization field, the amount of literature on the topic is still substantial. This section will examine three aspects of this literature: (a) the origins and definition of the organizational culture construct; (b) attempts to use the notion of culture help make sense of organizational behavior and change; and (c) what the literature says about the culture of the public (government/military) organizations.

The Origins and Definition of the Organizational Culture Construct

Although the concept of organizational culture is a relatively new construct in the literature on organizations, theorist such as Edgar Schein (1992) emphasize that the concept has had a "long and checkered history" (p. 3) (See, also, Detert, 2000). A brief account of the organizational culture concept and how its definition has evolved, will begin this section. Then, a brief history of the emergence and use of the construct of culture in the study of organizations, will be followed by an examination of evolution of the culture construct and how organizational culture has grown to encompass other meanings beyond its original meaning. Finally, a number of influential definitions of organizational culture will be introduced, including Schein's seminal definition.

A brief history of the emergence and use of the construct of culture in the study of organizations. Over the past three decades, culture has emerged in organizational theory as an important construct for understanding organizational behavior in general, and the change process in particular (Detert, Schroeder, \& Mauriel, 2000; Strebel 1996; Schein, 
1992; Hofstede, 1991; Rousseau, 1990). The concept of organizational culture originated in several fields of study. The notion of culture was initially used in the discipline of anthropology—or, the study human societies. Initially, anthropology's focus was on socalled tribal or primitive societies (Hofstede, 1991). The norms and standard operating procedures in these cultures were so obviously different than the norms and standard operating procedures in our own environment, that a name was required to characterize the source of these differences. That name, for anthropologists, was culture. The construct of culture has since been appropriated—and adapted—by numerous other fields and disciplines ranging from psychology and sociology to political science (Schein, 1993; p. 369). Eventually, organizational theorists also began to employ the construct to talk about organizational life.

The term culture also has a number of other meanings associated with it, including a way to designate sophistication (e.g., we talk of sophisticated people as being "cultured"), national identify (e.g., we talk of "American culture" or "Arab culture"), and the ways a business or organization operates (e.g., we talk of competitive cultures) (Schein, 1993; p. 369; Hofstede, 1994; 1991; p. 5). Despite this widespread use and growing acceptance of the concept in popular culture, the business and organization fields have only recently embraced the concept (Hofstede, 1991; p. 18).

The evolution of the culture construct. Once the notion of culture began to be used by those who study and attempt to make sense of organizations, it began to be associated with two other concepts: climate (e.g., practices of an organization including individual motivations and specific behaviors) (Michela, \& Burke, 2000; Dennison, 1996; Schneider, 1990; 1970; 1968) and environment (e.g., the pervasive characteristics that define how members of an organization interact with each other) (Schein, 1992; Deal \& 
Kennedy, 1982). At times, each of these terms has been used as a synonym for the term culture. While organizational climate is, in many respects, similar to what theorist mean when they use the term organizational culture, some theorists argue that the two concepts are different from organizational culture.

In the last decade or so, organizational culture has been used generally to indicate the "climate and environment practices that organizations develop" (Schein, 1993; p. 369). Schein emphasizes that the climate concept refers to situational variables that influence an individual's motives and specific behaviors. These situation variables are subject to change much as weather conditions (i.e., the literal meaning of climate) can change and, consequently, the employee attitudes can also be changed relatively easily. By contrast, organizational culture is more a sociological rather than a largely psychological construct, and references the more enduring and pervasive beliefs, routines and rituals of an organization (Schein, 1992, 1993; Hofstede, 1991).

Another term that is often used interchangeably with culture is environment (Hofstede, 1991). Within the organization literature, the term organizational environment is frequently used to refer to the pervasive characteristics in an organization that influence and help define how members of an organization behave and interact with one anothher. This focus on pervasiveness, of course, suggests that the meaning of environment is quite similar to the meaning of culture, as that term has been used in the organizational literature. The notion of culture, however, places the human dimensions of organizational life front and center (Deal \& Kennedy, 1982, Schein, 1992, 1993). For this reason, and because the culture construct is more frequently used within the organization literature, I have chosen to use the term culture in this dissertation. 


\section{Influential definitions of organizational culture (including Schein's seminal}

definition). Theorists, researchers, and practitioners have long discussed and debated the definition and meaning of organization culture. Although many definitions exist, a few tend to be influential and frequently quoted. These include:

- Culture is a system of publicly and collectively accepted meanings operating for a given group at a given time. This system of terms, forms, categories, and images interprets a people's own situation to themselves. (Pettigrew, 1979; p. 574)

- Culture refers to the knowledge members of a given group are thought to more or less share...A culture is expressed (or constituted) only through the actions and words of its members....Culture is not itself visible, but is made visible only through its representation. (Van Mannen, 1988; p. 3)

- Culture is always a collective phenomenon, because it is at least partly shared with people who live or lived within the same social environment, which is where it was learned.... (Hofstede, 1991; p. 5)

- Organizational culture is the collective programming of the mind which distinguishes the members of one organization from another... (Hofstede, 1994; p. 180)

- Cultures are collective phenomena that embody people's responses to the uncertainties and chaos that are inevitable in human experience. These responses 
fall into two major categories. The first is the substance of a culture-shared, emotionally charged belief systems that we call ideologies. The second is cultural forms-observable entities, including actions, through which members of a culture express, affirm, and communicate the substance of their culture to one another. (Trice and Beyer, 1993; p. 2)

- The way we do things around here. (Deal and Kennedy, 1982, p. 4)

Of all of the numerous definitions of culture, Edgar Schein's view of organizational culture is perhaps the most widely accepted. Schein (1992) indicates that organizational culture is:

A pattern of shared basic assumptions that the group learned as it solved its problems of external adaptation and internal integration, that has worked well enough to be considered valid and, therefore, to be taught to new members as the correct way to perceive, think, and feel in relation to those problems (p. 12).

Although the concept of organizational culture is described somewhat differently in the literature, most researchers agree that culture relates to a system of shared beliefs, assumptions, norms, values, symbols, understanding and knowledge held by its membership (Schein, 1993; 1996; Hofstede, 1991; Galpin, 1996 \& Detert, Schroeder, \& Mauriel, 2000; Hammer, 1997). They also mostly agree with Schein that culture is exemplified — and can be accessed by examining — artifacts (symbols or practices), values, and the beliefs (underlying assumptions) that members share about appropriate 
behavior (Detert, 2000). Therefore, Schein's definition and his view of organizational culture served as a kind of conceptual framework for this research study.

Exemplary studies that used the cultural construct. The literature shows how organizational theorists have used the notion of organizational culture as a frame to interpret and understand an extensive range of organizational behavior (Bowman \& Deal, 1997, Detert, et. al., 2000, Schein, 2000; 1992; Cook \& Yanow; 2001). In this section, I will review some of the studies and literature that have popularized the study of organizational culture. Specifically, the following highly influential and frequently cited works will be reviewed: Peters and Waterman's In Search of Excellence (1982); Deal \& Kennedy's (1982) Corporate Culture: The Rites and Rituals of Corporate Life (1982); Hofstede's Cultures and Organizations (1991); and Schein's Organizational Culture and Leadership (1992).

Peters and Waterman's (1982) seminal work, In Search of Excellence, provided ground-breaking research on organizational culture. The researchers looked at forty-three of Fortune 500's top American companies in an attempt to discover what characteristics made these organizations successful. As a result, they determined that the primary key to success shared by the organizations studied was their focus on strategy and organizational structure ("hardware"), and shared values and culture ("software"). Peters and Waterman went on in the study to suggest that organizational culture was the most prominent component of successful organizations. They argued, "Without exception, the dominance and coherence of culture proved to be an essential quality of the excellent companies" (p. 75). The findings from their study helped forge the importance of culture in organizational research. 
Deal \& Kennedy's (1982) study on corporate cultures also helped focus attention on an area of business that had typically been ignored in previous studies. In contrast to the structural elements of organizations (e.g., organization structure, formal processes) that researchers normally had examined in past studies, Deal and Kennedy looked at the symbolic and ritualistic aspects of corporations. After collecting data from nearly 80 companies, they revealed that all organizations have some form of culture, whether weak or strong, and that culture has a powerful affect on every aspect of the organization.

Scholars have also looked at organizational culture and change from an international perspective. For example, in his book Cultures and Organizations, Hofstede (1991) related the notion of culture to software for the mind. In this regard, culture influenced how one would think and behave in organizations. Hofstede focused on three levels of uniqueness in human mental programming that include personality, culture and human nature.

Figure 1. Three Levels of Uniqueness in Human Mental Programming

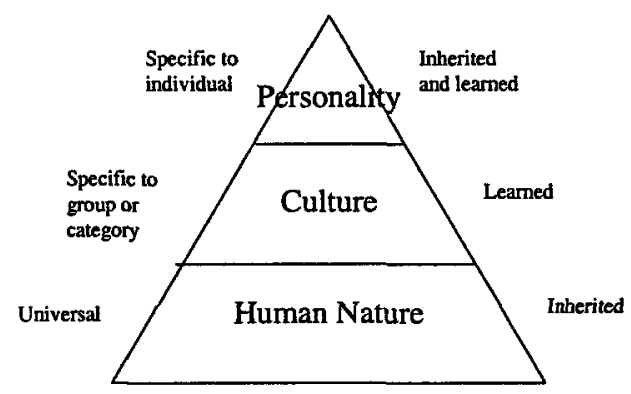

Note: From Hofstede, 1991. Cultures and organizations. McGraw-Hill Book Company, (p. 6).

Hofstede's view of mental programming, highlighted by differences between human nature (inherited) and personality (inherited and learned traits), demonstrated levels of culture. He pointed out that cultural traits have traditionally been attributed to 
inherited traits because scholars did not know how to explain these differences (p. 6). Hofstede also examined the various layers of culture. Through his study with IBM and over 50 countries that he researched, he found that people belonged to different groups and categories at the same time. The layers, for instance, could include: a national level, a regional level, an ethnic level, a religious level, a gender level, a social class level, and an organizational level (p. 10). As a result of studying the impact of national culture within IBM's organizational cultures, Hofstede (1991) found evidence for dimensions of uncertainty avoidance, collectivism versus individualism, femininity versus masculinity, and power distance. While Hofstede (1994) agrees that national culture studies have only limited application for understanding organizational cultures, his work is regularly mentioned by scholars in providing further insight into the organizational culture construct (Ashkanasy, Wilderom \& Peterson, 2001; Robbins, 2001; Schein, 1992). Edgar Schein (1999, 1996, 1993, 1992), the eminent MIT psychologist turned organizational theorist, is often cited for his contribution of understanding how organizational culture influences human behavior. Schein's (1992) work, suggests that the best way to think about and analyze an organization's culture is to understand the similarities that exist at various levels in an organization's belief system. Schein referred to different cultural layers as "the degree to which the cultural phenomenon is visible to the observer" (p. 16). He suggests that these levels range from tangible to intangible levels. 
Figure 2. Levels of Culture

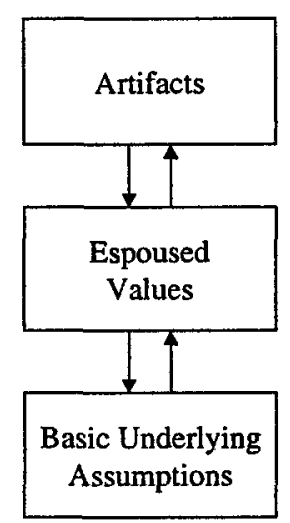

Note: From Schein, E.H. (1992) Organizational culture and leadership. San Francisco: Jossey-Bass Publishers (p. 17).

Schein argues that artifacts are the first level and consist of what is visible at the surface of an organization, such as the organization's "language" or "products." He points out that this level is easy to see, but hard to understand. The next level is espoused values. This level refers to the strategies, goals and philosophies supported by leaders of the organization. At this level, a set of values becomes embodied as part an ideology that serves to guide events and behavior, but "may be out of line with what they will actually do in situations where those values should, in fact, be operating" (Schein, 1992, p. 21). The third level is referred to as basic assumptions. This level is "taken for granted" and is often so strongly held by the membership of the organization that different ways of thinking or acting are almost "inconceivable". In this regard, basic assumptions are similar to what Chris Argyris introduced as "theories-in-use" (Argyris \& Schon, 1974, Argyris, 1993). Schein sees these basic assumptions as concepts that are very hard to recognize so they are "extremely difficult to change." This helps explain why resistance in organizational change is so difficult to manage since it is hard for people for people to see and understand how the change affects their basic assumptions. As Schein states: 
The human mind needs cognitive stability. Therefore, any challenge to or questioning of a basic assumption will release anxiety and defensiveness. In this sense, the shared basic assumptions that make up the culture of a group can be thought of at both the individual and group levels as psychological cognitive defense mechanisms (p. 23).

Schein links the notion of various levels of culture to resistance to change in organizations. He points out that when managers or leaders try to change the behavior of subordinates they "often encounter resistance to change at a level that seems beyond reason." He contends that this is in part because an attempt to influence change on the surface may not be as effective if deeply held beliefs and assumptions are at work.

The findings from Peters and Waterman's, Deal and Kennedy's, Hofstede's, and Schein's studies have enhanced our understanding of the organizational culture construct and its relevance for making sense of the phenomenon of resistance. Other contemporary organizational scientists and scholars also have added insight about how organizational cultures function and how this functioning impacts the phenomenon of resistance. For instance, Galpin (1996) sees organizational culture as a primary lever for initiating and implementing organizational change. He argues that effective change requires changes in operations, systems, and procedures to be clearly aligned to an organization's culture. In other words, most theorists described above seem to share the perspective that organizational change cannot take place without taking into account the interconnectedness of an organization's systems and preparing these systems for change. The Culture Of The Public (Government/Military) Organizations

In the last part of this section, I will look at the culture of public sector (i.e., government, military, and combined government/military) organizations. Almost no 
literature exists on the subject of change and resistance in combined government/military organizations. Therefore, I will highlight the long, established history associated with government and military organizations. Specifically, I will point out what the literature says about how military and government culture influences and guides behavior in organizational change efforts.

Military \& government culture. As described earlier in the background chapter and the discussion of organizational culture in this chapter, major cultural reform movements have set the stage for government and military reform (see for example, Reinventing Government, Osborne and Gaebler (1992); Business Process Reengineering, Hammer and Champy (1993); Leading Change, Kotter (1996); and Change Management (Worren, et al., 1999). Although parallels exist between private and public sector organizational culture, many would argue that the public sector has different goals and purposes that distinguish its culture from the cultures of for-profit businesses (Linstead, 1997, Ouchi, 1981). In the early 80s', William Ouchi (1981) examined different cultural characteristics associated with different types of organizations, including private sector and public sector organizations. His findings demonstrate that these different types of organizations are both similar and different (p. 434). The similarities include the expectation of long-term employment and even an unspoken desire for a lifetime relationship. Conversely, Ouchi also found that the United States military culture was different from other large, multi-national corporations. He points out that military and government organizations differ from public sector organizations in terms of their emphasis on hierarchy and bureaucracy. In fact, Ouchi calls military and government organizations "type Z" organizations. Ouchi (1981) defines type Z organizations as organizations that have achieved a degree of consistency in their culture, similar to clans. 
He suggests that the only way to change behavior in type $\mathrm{Z}$ organizations is to change culture. However, culture changes slowly because the members of a type $\mathrm{Z}$ organization hold deeply rooted values and beliefs that tend to maintain the status quo. Therefore, the implication for any culture change in public sector organizations is bound to be a time intensive and lengthy process.

In addition to Ouchi's comparison study, there also has been at least one study that has looked in depth at military culture in its own right. While military culture has not been given much attention in the literature (and joint military and public organizational culture hardly none at all), Murray (1999) argues that culture matters, and should be examined to understand its effects and influence on military organizations. Murray (1999) submits that military culture is shaped by natural cultures as well as factors such as geography and historical experiences that shape American military. Although typically described as unchangeable, military culture is susceptible to the influences of human affairs such as changes in leadership, military education, doctrinal preferences and technology. All of these result in the evolution of the culture of military organizations. Murray (1999), however, goes on to suggest that the effects on military culture are slow and gradual and may not be evident for years. One example of this is the early German battlefield successes of World War II that are traceable to changing cultural patterns in the German army dating back to the 1920 's. When the Germans were forced to reduce their army size by the Treaty of Versailles, the German officer corps changed their culture to emphasize performance in leadership positions and intellectual achievements.

Military culture at West Point. One military organization that has been studied extensively is West Point. West Point is a long established organization that has embodied and shaped the culture of American military. From the time when George 
Washington first proposed the idea of a military academy in 1783, West Point has developed military leaders and helped construct an enduring military culture for the United States.

Recently, a number of researchers and organizational theorists have focused their attention on West Point. For example, Ruvolo and Bullis (2003) examined the lessons learned from a failed culture change initiative that occurred at West Point. Just prior to a leadership succession at the academy, a department head had cultivated an open atmosphere of acceptance and learning. Some members of the greater community were threatened by this perceived antithetical "warrior spirit" culture and, as a result, brought in a new department head with an outstanding reputation as a warrior. To the surprise of many, within ten months, the department was in turmoil, morale and productivity were down, and the new department head was relieved of his duties. Although several "lessons learned" can be gleamed from this senior leader derailment case study, perhaps the most important point is that change failed largely because of the incongruence between traditional and non-traditional military culture. According to Ruvolo and Bullis:

At times the emphasis has been on training, following orders, and being prepared for military activity while at other times education, independent thinking, and individual development have been emphasized. (p. 161)

The authors conclude that change is difficult because of the propensity to hold on to this deep-embedded culture.

Others have argued that different factors can influence the enduring culture of the military. For example, the events and impact of September 11, 2001 ("9/11") on military organizations has been significant. While it is difficult to assess the long-term impact of 9/11, Noonan and Hillen (2002) point out that the terrorist's attacks to the World Trade 
Center will change the nature of war and how military and government organizations will respond in the future. In summary, it is clear that change is difficult in military and government organizations where culture is deeply-rooted and particularly resistant to change.

Summary

This section of the literature reviewed the emergence and contemporary use of the organizational culture construct. Despite the relatively brief history of the use of culture as a construct in the organization field, this review reveals that the amount of literature on the topic is vast and growing. This section examined three aspects of the culture literature including the origins and definition of the organizational culture construct, how theorists use the notion of culture to help make sense of organizational behavior and change, and what the literature says about the culture of combined government and military public organizations. Schein's influential definition and notion of culture were presented. In particular, Schein's phenomenological view of different layers of culture, and, specifically, the underlying assumptions and beliefs that an organization's membership holds, seemed to be particularly important to understanding how culture influences human behavior and change resistance and were also reviewed in this section.

In conclusion, the literature substantiates the need for a modern concept of culture to help understand cultural change. From this review it became clear that almost no literature exists on the subject of cultural change and resistance in combined government and military organizations. Additionally, most theorists reflections on the subject of culture suggest that the role of leadership is intertwined and is an essential construct to help understand organizational culture. This next section explores some of 
the relevant conceptualizations about what the literature says about the role of leaders in influencing, shaping and changing organizational culture.

The Role of Leadership in Influencing, Shaping and Changing Culture

This section will discuss what the literature says about the role of leaders in influencing, shaping and changing organizational culture. Once again, some of the topics raised in the "background to the study" section of Chapter 1 will be developed more fully. This section will be organized around the following topics: (a) the concept of leadership and (b) how leaders influence, shape and change the culture and organizational resistance to change.

\section{The Concept of Leadership}

The first part of this section will focus on what the literature says about the concept of leadership. Leadership is one of the most researched concepts in organizational theory (Leonard, 2003; Goleman, Boyatzis, \& McKee 2002; Ridgway, 2001; Dess \& Picken, 2000; Sims, 2000; Conger, Spreitzer, \& Edward, 1999; Horner, 1997). In addition, in the last half of the $20^{\text {th }}$ century, significant attention has been given to the study of the relationship between leadership and the construct of change. Burns (1979), Greenleaf (1970), Rost (1991), Heifetz (1994) and Kotter (1996) have made some of the most notable contributions to the study of leadership and change.

Burns' view of leadership. Despite the extensive attention given to the topic and study of leadership and its contributions to the change process, Burns (1978) argues that leadership is "one of the least understood phenomena on earth" (p.2). Burns seminal work, aptly titled Leadership, has laid the foundation for practitioners and scholars to further understand and explore the leadership construct. 
Burns (1978) suggests that leadership involves a process of exchange between leaders and followers. He states, "Leadership over human beings is exercised when persons with certain motives and purposes mobilize, in competition or conflict with others, institutional, political, psychological, and other resources so as to arouse, engage and satisfy the motives of followers" (p. 18). Burns argues that this is done in order to attain the goals mutually shared by leaders and followers.

Another prominent theme in Burns' work is the distinction between management and leadership (Also see Heifetz, 1994, p.15 and Rost, 1991). Burns (1978) describes managers as transactors and leaders as transformers. He states that managers are focused on maintaining and running organizations by following the organizations rules and procedures. He refers to this managerial activity as transactional leadership. Burns contrasts transactional leadership with what he calls transformational leadership, a type of leadership that occurs when one or more people influence one another so that leaders and followers raise each other to "higher levels of motivation and morality" (p. 20). Burns also argues that transformational change is associated with real change. He describes real change as the creation of new conditions that generates changes in motivation and goals; real change also sets in motion ongoing change (p. 441). Burns' definition of leadership in general, and his distinction between transactional and transformational forms of leadership, seem significant for making sense of the process of organizational change.

Greenleaf's view of leadership. Greenleaf (1970), another commonly cited researcher, provides a similar view of leadership, albeit with somewhat different language and a different focus. Greenleaf, for example, supports the notion that leadership cannot be adequately understood without considering the relationship of 
leaders and followers. In fact, Greenleaf offers a unique view about who leaders are and what they do in organizations, one built around the notion of servant leadership. According to Greenleaf "the servant-leader is servant first... [Servant leadership] begins with the natural feeling that one wants to serve, to serve first. The conscious choice brings one to aspire to lead" (Greenleaf, 1970). A servant-leader focuses on others' highest priority needs and helps them to become more knowledgeable, autonomous and more like servants themselves (Northouse, p. 309). While many characteristics can be associated with the notion of servant-leadership, Greenleaf emphasized ten essential traits: (a) listening, (b) empathy, (c) healing, (d) awareness, (e) persuasion, (f) conceptualization, (g) foresight, (h) stewardship, (I) commitment to the growth of people, and (J) building community. These traits serve as the foundation of Greenleaf's thinking about leadership. For Greenleaf, the ultimate test of servant-leadership is "do those served grow as persons; do they, while being served, become healthier, wiser, freer, more autonomous, more likely themselves to become servants (Greenleaf, 1970; see also Ferch, 2004).

While there does seem to be some similarities between Greenleaf and Burns on the notion of the leader and follower relationship, there is a subtle distinction. Burns tends to emphasize the leader's positional authority while Greenleaf's emphasis on the leader's servant status intentionally minimizes whatever power a leader has by virtue of his or her position.

Rost's views of leadership. Like Burns, another influential leadership theorist, Joseph Rost, emphasizes that leadership must be distinguished from management. Through his in-depth analysis of leadership, Rost (1991) points out that scholars and practitioners historically have explored leadership from multiple perspectives. Several 
leadership theories emerged in the literature including: trait theory (also referred to as "great man theory"); group and behavior theories; contingency theory and situational theory (Rost, p. 17). Rost (1991) argues that these theories and models primarily focus on an industrial paradigm, and do not sufficiently account for the essence of leadership. He contends that the study of leadership in most of the twentieth century can be summed up as a misguided study of "leadership as good management" (p. 94).

Rost notes that over 220 definitions of leadership had been documented in the literature by the end of the $20^{\text {th }}$ Century. He suggests that this proliferation of definitions is one of the primary reasons the discipline of leadership studies has had a problem of “definition ambiguity and confusion" (p. 6). Rost, himself, endorses Burns' (1978) definition and concept of leadership that was discussed above. Specifically, Rost (1991) defines leadership as "an influence relationship among leaders and collaborators who intend significant changes that reflect their mutual purposes" (Rost, 1991, p. 102). He notes that there are "essential elements" to this definition including leaders and followers in an influence relationship with one another developing shared purposes with the intention of real (i.e., transforming) change.

While a debate continues over the leadership and management distinction and its overlapping aspects, scholars generally agree that leadership and management can be distinguished (Burns, 1978; Kotter, 1996; Rost, 1991). This distinction will be useful in this dissertation's attempt to analyze how a group of leaders used culture to promote organizational change.

Heifetz's view of leadership. In recent years, Heifetz (1994) has added yet another influential definition of leadership that is compatible with the Burns' and Rost's notions but also extends their perspectives. Like Burns and Rost, for example, Heifetz defines 
leadership as the act of mobilizing people to face problems (Heifetz, 1994; p. 20). But there are also some unique subtleties with the Heifetz definition to which one must attend. These subtleties can be seen by looking more closely at the words Heifetz uses in his definion.

Heifetz's definition, for example, emphasizes that leadership is best described as an activity rather than a position of authority or a personal set of characteristics. This point is not as clear in either Burns' or Rost's writing. Indeed, each of them tend to conceive of leaders as people who hold leadership positions. Heifetz, on the other hand, emphasizes that leadership exists in multiple positions in a social structure; whether one is a president or a clerk, both have the potential to lead.

Heifetz also uses the word "mobilize" in his definition of leadership to connote motivating, organizing, orienting, or focusing attention to a goal or problem. On the surface at least, this assumption, seems consistent with the leadership theories of Burns and Rost, but Heifetz also distinguishes between two different sorts of challenges leaders and followers face, and he suggests that leaders, in fact, mobilize people differently to meet each type of challenge. Heifetz labels these two types of challenges technical and adaptive.

A technical challenge involves daily operational issues and, consequently, technical leadership is concerned with handling such issues. As such, technical leadership is more or less analogous to Burns' notion of transactional leadership and Rost's notion of management (a concept that Rost suggests is not even encompassed by the notion of leadership).

By contrast, adaptive involves addressing "the conflicts in the values people hold, or to diminish the gap between the values people stand for and the reality they face" 
(p. 22). Stated simply, adaptive work means leadership helping people to face tough problems. This meaning, of course, seems more or less compatible with Burns' notion of transformational leadership and Rost's view of leadership as opposed to management. Heifetz's view of adaptive work includes the notion of resistance to change. Using a living systems perspective, Heifetz sees adaptive work as requiring sustained periods of disequilibrium for change to occur. He points out that during this state of disquilibrium, resistance is often a common response that prevents people from adapting to change. Heifetz labels this resistance to disequilibrium as work avoidance and suggests that work avoidance is often unconscious and is similar to the defensive routines that are found in individuals, groups and organizations. He concludes that one of the major challenges of leadership is learning how to "counteract the expected work avoidances and help people learn despite resistance" (p. 37).

Kotter's view of leadership. Finally, Kotter (1996) articulates a definition of leadership that places little to no emphasis on the notions of mutuality and shared leadership, notions that were central to the thinking of Heifeitz, Rost, Greenleaf, and Burns. Rather, Kotter suggests that leadership is A set of processes that creates organizations in the first place or adapts them to significantly changing circumstances. Leadership defines what the future should look like, aligns people with that vision, and inspires them to make it happen despite the obstacles. (p. 25)

Like Burns and Rost, however, Kotter does distinguish between management and leadership, though the way he does this is decidedly different and consistent with his more leader-centered view of organizational life: "Management is about coping with 
complexity," Kotter writes; "leadership, by contrast, is about coping with change" (1991, p. 103).

Although additional definitions and conceptualizations of leadership could be cited, this literature review is already long and complex. The discussions of the major theorists' ideas presented here should be sufficient to capture most of the key ideas about leadership that have been written about during the past 50 years.

Perspectives on How Leaders Influence, Shape and Change Organizational Culture in General and Organizational Resistance to Change in Particular

The next section reviews what the literature says about how leaders influence, shape and change organizational culture in general, and resistance to change, in particular. This section will be divided into two parts. The first will focus on general theory, and will build on the notion of culture that was introduced in earlier parts of this chapter, and review the concept of cultural leadership for change provided by four theorists : (a) Schein, (b) Trice and Beyer, (c) Lewin, and (d) Senge. The second part of this section will focus on specific procedures that leaders might use to change a culture and mute resistance, and will discuss the views of two theorists: (a) Kotter, (b) Kotter \& Schlesinger, and (c) Bowman \& Deal.

General views of how leadership influences cultural change in organizations. Two theorists, Schein, Trice and Beyer, who provide broad-spectrum views of cultural change will be discussed first, followed by two people who are not typically considered "cultural theorists", but who espouse views that are compatible with the cultural change notion. One is the sociologist Kurt Lewin, an historical giant in the organizational theory field; the other is the more contemporary theorist, Peter Senge. 
Schein's views of how leadership influences cultural change in organizations. As discussed in the background section of Chapter 1, increased emphasis has been placed on understanding the relationship between culture and leadership in recent years (Schein, 1992, Bowman \& Deal, 1997). While the notions of leadership and culture have been around for some time, the concept of cultural leadership is newer. Despite the attention given each of the constructs that make up the concept of cultural leadership, few theorists have connected the concepts of culture and leadership prior to Edgar Schein discussing such a connection.

In his book, Organizational Culture and Leadership, Schein (1992) explores the central characteristics of cultural leadership. Schein (1992), for example, makes the argument that leadership cannot be defined outside of culture. He states, "Culture creation, culture evolution, and culture management are what ultimately define leadership" (p. xv). For Schein, the most important functions of leadership can be boiled down to creating, managing and even destroying culture (p. 5). He states that "these dynamic processes of culture creation and management are the essence of leadership and make one realize that leadership and culture are two sides of the same coin" (p. 1). He contends that leaders, or those in formal authority, play a role in creating cultures when they create groups and organizations. Schein suggests "culture is one of the most difficult aspects to manage in a climate of perpetual change" (p. xiv). He asserts that culture creation takes place as an evolutionary process:

Culture begins with leaders who impose their own values and assumptions on a group. If that group is successful and the assumptions come to be taken for granted, we have then a culture that will define for later 
generations of members what kinds of leadership are acceptable. The culture now defines leadership (pp. 1-2).

In short, Schein associates leadership with creating and changing organizational culture (Schein, 1992, 1993; Gagliardi, 1986).

Schein suggests different ways leaders can promote organizational change depending on the stage of the organization. The strategies appropriate for organizations at different levels of development are summarized in Table 1.

Table 1. Cultural Change Mechanisms

\begin{tabular}{|c|c|}
\hline Organizational Stage & Change Mechanism \\
\hline Founding and early growth & $\begin{array}{l}\text { 1. Incremental change through general and specific } \\
\text { evolution } \\
\text { 2. Change through insight from organizational } \\
\text { therapy } \\
\text { 3. Change through promotion of hybrids within the } \\
\text { culture }\end{array}$ \\
\hline Midlife & $\begin{array}{l}\text { 4. Change through systematic promotion from } \\
\text { selected subcultures } \\
\text { 5. Planned change through organization } \\
\text { development projects and the creation of parallel } \\
\text { learning structures } \\
\text { 6. Unfreezing and change through technological } \\
\text { seduction }\end{array}$ \\
\hline Maturity and decline & $\begin{array}{l}\text { 7. Change through infusion of outsiders } \\
\text { 8. Unfreezing through scandal and myth explosion } \\
\text { 9. Change through turnarounds } \\
\text { 10. Change through coercive persuasion } \\
\text { 11. Destruction and rebirth }\end{array}$ \\
\hline
\end{tabular}

Note: From Schein, E. H. (1992) Organizational culture and leadership. San Francisco: Jossey-Bass Publishers (p. 304).

In general, Schein seems to share a similar view to Heifetz's notion of leadership and adaptive challenges. Clearly Schein's unique contribution is an emphasis on how leaders influence and change culture to be adaptive. According to Schein, "to develop the culture adaptively is the essence and ultimate challenge of leadership" (Schein, 1992; p. 
2). Although Schein does not specifically reference Heifetz in his definition, they both seem to be using the term adaptive in a similar way. The main difference here again is that Schein's model of cultural change appears to be operating from a positional leadercentric perspective and does not seem to account for a distributed model of leadership and culture change. Still, Schein's notion of cultural leadership continues to be highly influential, and other theorists also have begun to provide insights that often extend or compliment Schein's work about how leaders influence, shape and change the cultures of organizations (see for example, Hatch, 2000; 1997; Sims, 2000; Detert, Schroeder, \& Mauriel, 2000; Senge, 1999; 1990; Bolman \& Deal, 1997; Kotter, 1996; Heifetz, 1994; and Trice \& Beyer, 1993).

Trice and Beyer's views of how leadership influences cultural change in organizations. Trice and Beyer $(1993 ; 1991)$ also explore the notion of cultural leadership. Like Schein, they suggest that cultural innovation involves the duality of creation and destruction (Trice and Beyer, 1993). Also like Schein, the two authors argue that a cultural approach to leadership is unlike previous conceptualizations because it supports "the other side of leadership...(that is) how leaders influence the development... of culture in their organizations" (Trice \& Beyer, 1991; p. 255). Put another way, cultural leadership can help explain how leaders influence the interrelationships of behavior in organizations.

Trice and Beyer's (1993) unique contribution comes from attempting to define four types of culture-based leadership that are certainly consistent with Schein's thinking, but that package different dimensions of cultural leadership in a somewhat different way. Trice and Beyer's four types of cultural leadership are: (a) leadership that creates 
cultures; (b) leadership that changes cultures; (c) leadership that embodies cultures; and (d) leadership that integrates cultures.

The first type of leadership suggests that cultures are created from the vision of leaders in new organizations, a vision that then becomes solidified as organizational cultures. The next type suggests that cultures move toward change when the change is actively sought and consciously intended by the leader. The third type supports the notion that cultures are maintained and preserved when the leader attempts to uphold the mission, roles, commitments, and values of the organization. The last type focuses on organizational integration. Here, the authors suggest that leaders try to integrate and share power among various subcultures.

Trice and Beyer argue that these four types are not necessarily discrete because cultural leadership at any given time often exhibits two or more types simultaneously. Additionally, they suggest that many members often share cultural leadership, formally and informally, which may cause organizational dissonance (p. 286).

Trice and Beyer (1993) have distinguished between organizational change that is planned versus unplanned. The authors define cultural change as:

Planned, more encompassing, and more substantial kinds of changes than those which arise spontaneously within cultures or as part of conscious efforts to keep an existing culture vital. Culture change involves a break with the past; cultural continuity is noticeably disrupted. It is an inherently disequilibriating process (p. 40).

They define the types of cultural change by at least three different degrees of change: (a) revolutionary and comprehensive efforts to change the cultures of entire organizations; (b) efforts confined largely to changing specific subcultures or subunits 
within the organization; and (c) efforts that are gradual and incremental, but culminate in comprehensive reshaping of an entire organization's culture (p. 415).

Another important aspect of Trice and Beyer's work is their distinct perspective of seeing culture change as a range of processes with different characteristics. The authors' suggest that change processes can be described along four specific dimensions. These dimensions are pervasiveness, magnitude, innovativeness, and duration of a change process (p. 415). By analyzing these dimensions, managers and leaders involved in change efforts will have a better understanding of the complexity and scope of the change effort.

Table 2. Types and Dimensions of Culture Change

Types of Culture Change Placement on Dimensions

\begin{tabular}{ll}
\hline 1. Revolutionary, comprehensive & Pervasiveness: high \\
& Magnitude: high \\
& Innovativeness: variable \\
& Duration: variable \\
& Pervasiveness: low \\
2. Subunit or subculture & Magnitude: moderate to high \\
& Innovativeness: variable \\
& Duration: variable \\
3. Cumulative comprehensive reshaping & Pervasiveness: high \\
& Magnitude: moderate \\
& Innovativeness: moderate \\
& Duration: high \\
\hline
\end{tabular}

Note: From Trice, H. M., \& Beyer, J. M. (1991). Cultural leadership in organizations [Electronic version]. Organization Science, 2(2), (p. 149).

Trice and Beyer (1993) contend that "changing organizational culture requires not one change, but many changes in many different cultural elements...change efforts must encompass both ideologies and the accumulated cultural forms that express them" (p. 419). Therefore, using a process perspective, as suggested by Trice and Beyer, to 
understand organizational change may be helpful to understand and manage organizational change and to determine ways to mitigate resistance.

It is interesting to note that both Schein and Trice and Beyer seem to be operating with a much more leader-centered view of organizations than Burns, Rost, Greenleaf or Heifetz. Although the final point made about Trice and Beyer in the last sentence of the previous paragraph sounds a bit like Heifetz's notion of distributed leadership, it is fairly obvious that Trice and Beyer are talking about a much more limited definition of shared leadership than Heifetz's theorizing envisions. In addition, while Heifetz seems to view the fact that leadership is distributed positively, Trice and Beyer see as a complication and, hence, as something that is, at base, problematic.

Lewin's views of how leadership influences cultural change in organizations. Kurt Lewin offered a traditional view of cultural change before the term culture became widely used and accepted. Although the literature contains a number of change models that those who lead a cultural change process might use to guide their work, Lewin's (1951) work has been particularly influential among practitioners and researchers who have used the organizational culture construct (Detert et al, 2000; Schein, 1992). Central to Lewin's (1951) model of planned organizational change are the concepts of "unfreezing, changing, and refreezing"; these concepts imply that change happens when an organizations stabilizing systems are interrupted. According to Lewin, planned organizational change starts with "unfreezing" the organization in order to create an influx of change. This is followed by the second step of "moving" or making changes in the organization. The last step is "refreezing" and is the equivalent of resetting the organization with the new changes (p. 227-228). 
Lewin also introduced the term "force field" analysis to describe the powers that interact during a change process. He points out that the forces involved in the change are either positive (proponent of change) or negative (opponent of change). A force field analysis simply identifies the positive or negative forces involved in a change process to determine whether or not change will occur. For instance, when the forces of change are greater than the resistance, change will result. Several theorists have referred to Lewin's "unfreezing, changing, and refreezing" model and "force field" analysis for organizational change and specifically to understand change resistance. Although Lewin does not explicitly talk about these phenomena in cultural terms, they fit nicely with a cultural perspective of organizations.

Senge's views of how leadership influences cultural change in organizations. Although Senge's view of leadership does not primarily focus on cultural change in organizations, his ideas do seem to compliment and extend the views of other cultural theorists, particularly with regards to resistance to change. Senge $(1990,1999)$ argues that organizations are made up of interrelated systems. These systems influence and get influenced by members of the organization.

For Senge, "systems thinking" serves as a discipline for seeing the whole organization and understanding the subsystems that comprise it. Senge describes systems thinking as "the fifth discipline" because it underlies all learning disciplines. Systems thinking serves as a framework for seeing interrelationships and "patterns of change" in an organization (p. 451). Like Argyris, Senge sees "feedback loops" as an vital part of organizational learning, growth and change. According to Senge, there are two distinct types of feedback processes-reinforcing (or amplifying) and balancing (or stabilizing). 
He describes that leaders who attempt organizational change find themselves in a "balancing process" (p. 457). As Senge describes:

To leaders, it looks as though their efforts are clashing with sudden resistance that seems to come from nowhere. In fact, as my friend found when he tried to reduce burnout, the resistance is a response by the system, trying to maintain an implicit system goal. Until the goal is recognized, the change effort is doomed to failure. (p. 457).

Senge suggests that the leader must change members' habits or create new and different models in order to set the norm that the members of the organization will follow. He suggests that deep seeded values and beliefs in members' minds guide their behavior during organizational change initiatives. He states:

Whenever there is 'resistance to change,' you can count on there being one or more 'hidden' balancing processes. Resistance to change is neither capricious nor mysterious. It almost always arises from threats to traditional norms and ways of doing things. Often these norms are woven into the fabric of established power relationships. The norm is entrenched because the distribution of authority and control is entrenched.

Finally, Senge describes the process of leading organizational change as artful and delicate. He suggests that "rather than pushing harder to overcome resistance to change, artful leaders discern the source of resistance. They focus directly on the implicit norms and power relationships within which the norms are embedded. (p. 458).

Specific procedures of theory and application for how leadership influences cultural change in organizations. This next section, I discusses the contributions of three theorist that provide defined steps and procedures for how leaders can influence cultural 
change. Specifically, Kotter's ways to overcome resistance, Kotter \& Schlesinger's change influence strategies, Bowman and Deal's view of reframing organizational change.

Kotter's views of how leadership influences cultural change in organizations. In his landmark book, Leading Change, Kotter (1996) focuses on ways to overcome resistance to change. According to Kotter, change initiatives often fail because leaders ignore norms and values that could be considered the bedrock of an organization's culture. He proposes that "cultural renewal" can be the result of working systematically through an eight-stage change framework which includes: (a) establishing a sense of urgency; (b) creating the guiding coalition; (c) developing a vision and strategy; (d) communicating the change vision; (e) empowering broad-based action; (f) generating short-term wins; (g) consolidating gains and producing more change; and $(\mathrm{h})$ anchoring new approaches in the culture. According to Kotter, any successful change effort needs to be "anchored" into the culture. He warns, "When the new practices made in a transformation effort are not compatible with the relevant cultures, they will always be subject to regression" (p. 148). In other words, resistance will be a factor when change efforts do not account for the culture.

Kotter \& Schlesinger's views of how leadership influences cultural change in organizations. Although Kotter and Schlesinger offer views about leadership and change resistance that do not focus specifically on cultural leadership, they seem to extend the cultural literature in a helpful way. As noted earlier, Kotter \& Schlesinger (1992) suggest that as business environments become more competitive and organizations are forced to change, leadership will play an increasingly critical role in understanding and responding to organizational resistance. Several strategies have been proposed to help leaders 
influence the change process and outcome. These change influence strategies include: (a) education and communication; (b) participation and involvement; (c) facilitation and support; (d) negotiation and agreement; (e) manipulation and co-optation; and (f) explicit and implicit coercion. The authors also point out that other situational factors influence the effectiveness of these strategies. The amount and type of resistance that is anticipated, the position of the initiator in relation to the resistors, the people designing and implementing the change, and finally the stakes that are involved in the change initiative.

Bowman and Deal's views of how leadership influences cultural change in organizations. Bowman and Deal (1997) also examined culture and its role in organizations in their book Reframing Organizations. The authors generally support Schein's formal definition of culture that said culture is "a pattern of shared beliefs" but point out that there is controversy about the relationship between culture and leadership (p. 231). They argue that there is a lack of clarity about whether leaders shape culture or are shaped by culture. Bowman and Deal suggest that each organization develops different beliefs and patterns over time.

Bowman and Deal point out that major organizational change creates four different issues. First, it affects people's ability to feel effective, valued and in control. Second, change disrupts existing roles and working relationships yielding uncertainty and confusion. Third, change creates conflict between winners and losers, that is, those who benefit from the change and those who don't. Finally, change causes a loss of meaning for people on the receiving end of the change (Bowman and Deal, 1997). The authors conclude that successful change requires a well orchestrated, integrated design that responds to the needs for learning and alignment, negotiation, and grieving (p. 339). 


\section{Summary}

This last section presented some of the seminal ideas in the literature about the role of leaders in influencing, shaping and changing organizational culture that are relevant to this dissertation. Several important leadership theorists of the last half of the $21^{\text {st }}$ century-Burns, Greenleaf, Rost, Heifetz and Kotter-were discussed. Additionally, a review of the cultural leadership literature was divided into two parts: (a) general views of how leadership influences cultural change in organizations (i.e., Schein; Trice and Beyer; Lewin; and Senge) and (b) specific procedures of theory and application for how leadership influences cultural change in organizations (i.e., Kotter; Kotter \& Schlesinger; and Bowman \& Deal). These theorists view's provided both common constructs and specific steps that are helpful for understanding the process of creating and managing organizational culture and applications for overcoming resistance to change. Despite the apparent similarities and overlap among some of the theorists' views, some fundamental differences of note are discussed in the conclusion.

\section{Conclusion}

At a general level, there appears to be two different views about the notion of leadership—transactional/technical vs. transformational/adaptive leadership. Transactional/technical leadership is similar to Burns' view of transactional leadership, Rost's view of management, and Heifetz's view of leadership that focuses on technical challenges. The main focus of these views are that leadership contains a kind of intrinsic power that is equated with either positional authority or personal characteristics.

The contrast of this view is transformational/adaptive leadership. By transformational/adaptive leadership the literature seems to identify leadership as an act or process that is shared by many people to accomplish a collective goal or moral 
purpose. This view of modern leadership that has recently emerged emphasizes sharedleadership and "other-focused" leadership is similar to Heifetz's view of leadership, aspects of Burns' transformational leadership, and Greenleaf's view of servantleadership.

The importance of the distinction drawn in the literature between transactional/technical and transformational/adaptive leadership is how theorists have used each construct. One would expect that cultural theorists would use transformational and adaptive views of leadership for change. The literature presents a different view that seems to indicate cultural theorists views are more aligned with transactional/technical leadership. As a result, most of the literature to date on the subject has been generated based on this view of leadership. The implications for change resistance are significant. For example, rather than looking to a person in a positional leadership role or with specific personal characteristics to manage resistance in a large-scale change initiative, a transformational/adaptive leadership view takes a human-centered and distributed leadership approach to change management. The emphasis, from this perspective, is to try and understand why individuals resistant change and how to foster a community or culture that can adaptively respond to change.

Therefore, an overview of the relevant literature appears to support the rationale for my study about organizational change and culture. While this chapter examined previous research that is of particular importance to this study, the following chapter provides the methodology that guided my study. 


\section{CHAPTER 3}

\section{METHODOLOGY}

The purpose of this chapter is to provide a detailed overview of the research design and methodology for the study being reported here. The chapter begins with a brief overview of the research methodology employed, and then specific information is presented about the procedures of the study. This information includes discussions of: the site and participants; the steps used to gain access to the organization studied; the researcher's role in the study; and the data collection and analysis procedures. Finally, the procedures included to assure trustworthiness are discussed.

\section{Research Methodology Overview}

Spurred on by the National Performance Review (NPR) and the Government Performance and Results Act (GPRA) in 1993, the public sector pursued reinvention and transformation change initiatives. Based on what happened in the private sector, it is unlikely that all or even most of these public sector planned change initiatives have been successful. Clearly, organizational culture could be thought of as an intervening variable in any change initiative; in addition, leadership is a key contributor to the success or failure of a large-scale organizational change initiative (Lakomski, 2001; Hatch, 2000). I am interested in learning about leaders' perceptions about how they have influenced large-scale, planned organizational change. More specifically, in this study, I wanted to investigate how leaders in one organization undergoing a large change initiative say they used—and were constrained by-organizational culture in efforts to minimize resistance and maximize acceptance of organizational change.

The interpretative tradition of qualitative research (Spradley, 1979) was deemed the most appropriate by the researcher for studying the perceptions of leaders who have 
experienced planned organizational change. This study was a continuation and expansion of preliminary fieldwork and analysis conducted prior to-and with the goal of informing - the proposal development process; both the preliminary project and this expansion of it were designed to add to the field's understanding of organizational change resistance.

For this study, I selected six participants from a combined government and military organization that had recently experienced a planned change effort. Participants were chosen purposefully in order to "focus on selecting information-rich cases whose study will illuminate the questions under study" (Patton, 2003, p. 230). In this regard, I chose participants that I judged would provide information that would address the purpose of this study. The specific criteria employed to select these individuals are detailed below. In addition, to counteract any sampling bias that might have been associated with my selection of the six interviewees, these interviewees were asked to identify anyone in the organization familiar with the planned change effort that sees the effort substantially differently than they do. This procedure netted two additional participants for the study.

Data were collected primarily through interviews. Initially, I examined the experiences of each of these six leaders individually; I treated each of these individuals as a case and utilized traditional case analysis procedures that are described in detail in the next section to organize and analyze my data initially. I then used a qualitative comparative analysis (QCA) approach to analyze findings across cases (Patton, 2002). This cross-case pattern analysis was used to "retain the strength of holism embedded in context-rich individual cases while making possible systematic comparisons of ... [a number] of cases" (Patton, 2002, p. 492). My prior role as a change management 
consultant within the organization studied helped me gain access to the organization in which the research was conducted. The notes I took in my consultant role in this organization were used for triangulation purposes.

\section{Specific Procedures}

This study built on preliminary research that functioned, in essence, as a pilot for the work done in this dissertation study. This preliminary study was conducted in MarchApril 2003 to fulfill a requirement for the Advanced Qualitative Research Methods course at the University of San Diego. Two leaders of a government/military organization (i.e., members of the internal change team that had been designated by the organization to lead the FA effort while continuing to play their designated leadership/management role within the organization) that had recently undergone a major change effort were interviewed, and the data from these interviews were analyzed along with other data (e.g., relevant documents and artifacts) that were used primarily for triangulation purposes. The procedures used in the preliminary study were nearly identical to the procedures that were used in the subsequent dissertation study that are described below. A limited number of differences-some of which were responses to issues that arise during the preliminary work-will be highlighted in the discussion that follows.

The remainder of this section discusses the following topics: the researcher's role, site selection, access, participant selection, data collection, and data analysis.

\section{Researcher Role}

Glesne (1999) suggests that there are "predispositions" that qualitative researchers should carry with them into all research situations (p. 41). Glesne advises, for example, that qualitative researchers should be "ever conscious of [their] verbal and nonverbal behavior" and attend to their "behavior and it's impact" on participants (Glesne, p. 41). In 
both the preliminary study and the study being reported here, I attempted to use this advice as I played a number of different roles in the study: interviewer, participant observer, and learner.

In my primary role of interviewer, I used a range of strategies. These are detailed in the discussion of data collection procedures below. In addition to serving as an interviewer, I had, prior to the actual start of the study, worked as a member of the external consulting firm the group had hired to assist them with the change effort. Consequently, in some respects, it could be said that I also functioned as a "participant observer" (Glesne, p. 41), especially since I used notes written while functioning as a consultant to triangulate the interview data I had gathered.

Throughout the study, I also attempted to play the role of researcher as "learner" (Glesne, p. 41). I strived to keep a "sense of self from the beginning" and "reflect on all aspects of research procedures and findings" while in this role (p. 41). During interviews, for example, I approached each situation interested in learning about the participants and their perspective of the phenomenon under study. In this sense, I tried to encourage the respondents to speak freely and not to make them feel that I was an "expert or an authority." My own interest as a learner was to understand and explore perceptions about leadership, organizational change resistance, and culture. I should add that I approached playing the consultant role with a similar sort of mind set: Any good consultant, in my judgment, is a learner before he or she can function as a teacher. 


\section{Site Selection}

Both the preliminary and the pilot studies were conducted in an organization that is being referred to by the pseudonym, Southern California Support Services (SCSS). ${ }^{2}$ The SCSS, a U.S. Navy organization that is a somewhat unique blend of military and civilian personnel, is located in Southern California and was identified from my previous consulting work the SCSS was chosen because it embodies a number of characteristics that constitute a good environment for looking at leaders perceptions of a substantial change initiative in a large and complex organization.

The organization, for example, has over 2,000 employees, a multi-tiered hierarchical structure (e.g., executive level, management level, and staff level employees), and multiple departments (e.g., community support services division, housing division, food services, etc.) . The organization also is dispersed over a number of geographic locations. Even more important, the organization had recently completed a large-scale, planned organizational change initiative-the Functionality Assessment (FA). The FA took place over two and one-half years, from 1999 to 2002 . This change initiative involved five divisions in the SCSS organization and included significant reform in operations, staffing, organizational structure and facilities. The FA process is similar to other large planned change efforts commonly referred to as Business Process Reengineering (Hammer, 1993). (Please see Appendix D for definitions and additional explanations of terminology particular to the study.)

Access

As a former consultant to the Community Support Service organization, and current consultant and advisor to the Navy, I made use of relationships I had established 
with former clients. These clients served in a leadership role during the FA change effort and expressed interest in participating in a study of this nature. In order to conduct research in the SCSS organization, I contacted the organization's gatekeeper, i.e., "the person... who must give their consent before you may enter a research setting, and with whom you must negotiate the conditions of access" (Glesne, 1999; pg. 39). The Navy's Assistant Chief of Staff (ACOS) for the SCSS organization served in this role and gave permission on two occasions, once for the preliminary study and again for the dissertation, to conduct the study (See Appendix E \& F for the study approval letters).

\section{Participant Selection}

As mentioned above, within the organization itself, I used a purposeful, intensive sampling strategy to identify a group of potential participants (Patton, 2003). Specifically, I decided to target the members of the internal change team that had been designated by the organization to lead the FA effort with the assistance of a group of external consultants. ${ }^{3}$ The change team consisted of organizational members who performed a dual role that entailed serving as an internal change agents while continuing to play their designated leadership/management role within the organization. These roles included: Assistant Chief of Staff (ACOS), Director of Bachelor Housing, Director of Military Family Housing, Director of Moral, Welfare \& Recreation; Director of Food Services, and Director of Marriage and Family Services. The person who played the last role also served as the FA Director.

2 The Southern California Support Services (SCSS) organization had a different organizational name identity before the Change Study.

3 The term leadership has been extensively used by academics and practitioners and can vary widely in its meaning and intent (Burns, 1978; Rost, 1993). For purposes of this study, leadership refers to those serving in a formal position of authority in the organization. Thus, the candidates for participation in the study made up the team of individuals that was designated to lead the FA change initiative. 
During the preliminary study, two of six team members were randomly identified and asked to participate; during the dissertation study, all six members were asked to participate and all six agreed to be interviewed. The original plan for the dissertation study was to interview only the four additional team members who had not been interviewed in the preliminary study and to use the preliminary study interview data in the dissertation work. However, after I decided to substantially revise the interview guide used in the preliminary study in order to hopefully net richer and more detailed information (See Appendix A for the Preliminary Study Interview Guide and Appendix B for a copy of the Interview Guide that was used in this study), I decided to re-interview two original members from the preliminary project.

In addition, to guard against sampling bias, I decided to employ an additional sampling technique, a version of snowball sampling (Patton, 2002; p. 237). At the end of each of the initial six interviews, I asked interviewees whether there was any member of the organization who had a substantially different view of the change process than the one they had just articulated. Several participants identified other participants that had already been interviewed or were slated to be interviewed. Four different people were named by three different leadership team members. Two of the four had either moved or retired and were not available for interview. I then made arrangements to interview the other two identified persons.

Access to the six leadership members - and to the additional two participants identified by snowball sampling techniques-was facilitated by my previous consulting role with the organization that assisted with the change effort. The contact procedures used in the dissertation study were the same as the procedures used in the preliminary study. Potential interviewees were contacted by phone. During the phone conversation, 
the study was described and the person was invited to participate in the study. After individuals agreed to participate, I made arrangements to meet with each participant in person to explain the informed consent form and, after an explanation was provided and a participant's questions were answered, to have the participant sign the form. After the form was signed, the interview was conducted.

All readily agreed to participate when I contacted them. That meant that I was able to interview the entire leadership team (as opposed to selecting interviewees randomly as was done in the preliminary study). The leadership team had members from all five-business divisions within the organization.

The two additional interviewees identified during the snowball technique were managers within the organization who were familiar with the FA change initiative. They worked in two different divisions within the company.

\section{Data Collection}

Interview procedures. As has already been noted, the primary data collection strategy used in this dissertation was interviewing. An Interview Guide approach was used (Patton, 2002; p. 343) in the study. With this approach, possible questions are defined in advance, but not necessarily asked in precisely the way they were formulated in the guide or in the exact order. By using this approach, I retained the freedom to explore topics and create something resembling a natural conversation with the participants. The interview guide approach, however, also provided a degree of structure even as I attempted to make the interview "feel" as natural as possible within reasonable limits. Among other things, the guide helped insure that our "conversations" did not deviate too far from the topic of the research and that key questions did not get ignored. 
In addition, the use of preformed questions - unless there was a good reason to deviate from them-minimized inappropriate variance across interviews.

The questions in the dissertation study interview guide were open-ended. Openended questions gave each participant considerable opportunity to frame and structure his or her response. Questions began with the general and moved to more specific topics. Initially, for example, I asked participants to describe their experience of the FA and their perceptions of the role they played. Later, the guide listed more specific questions focused on the respondent's strategies for influencing resistance to, or acceptance of, organization change during the FA.

The interview guide included follow-up probes that could be used to encourage interviewees to expand upon cryptic or overly general responses. In addition, the guide had space in which I could record notes about things that were observed during the interview or later reflections about behaviors exhibited by interviewees. These notes supplemented the transcriptions from tapes of the interviews. (The taping and transcription process is discussed below.)

As already noted, experiences with the guide developed for use during the preliminary study led to a revised guide that was used during dissertation study. Specifically, the Interview Guide asked for more information about the person's background, including their prior leadership experiences. This additional information allowed me to assess the different perspectives I heard in context and, consequently, to construct a richer understanding of each case. The Interview Guide questions were also rearranged to introduce research questions in a more logical sequence, while still allowing for flexibility to address "unscripted" discussions that emerge during the 
interview. A copy of the Interview Guides for both the preliminary study and dissertation study can be found in Appendices A and B.

To supplement the Interview Guide, I used two timeline analysis tools. The first timeline, the Life Timeline Analysis (LTA), represented the participant's life. A blank timeline was presented to participants at the beginning of the interview and participants were asked to notate key events and milestones that have occurred in their life up to this point. The timeline included a single blank line with a portion above the timeline to provide dates and a portion below to list the milestones and events. This format provided participants a chance to reflect freely and provide background and insight into particular events hat occurred in their personal life prior to the FA experience. The second timeline, the Functionality Assessment Timeline Analysis (FATA), was similar to the LTA but offered a tool for participants to reflect on events and dates that stood out about the FA change initiative. As was the case with the personal life history timeline, participants were given a sheet of paper with a single blank line on it. In this case, however, because there were some key events such as the official start of the project and its official conclusion, participants were also allowed to see a timeline prepared by me that listed some key events that were a matter of record. This partially filled-in timeline, as well as the two open-ended timelines, are included in Appendices D and C.

Additional data collection methods. Although interviewing was the major source of data in this study, other data sources were used to triangulate interview findings. Documents related to the FA initiative were also gathered. These documents included information about the organization's history, the staff, financial records, processes, structure, systems and strategies. As a former consultant to the organization during the FA change effort, I had access to these documents. In addition, as part of my consultant 
role, I had taken notes during meetings I attended and while interviewing staff. These notes also functioned as another source of triangulation.

Also, after I had traded in my consultant role for the role of a researcher, I used a research journal to document my observations, my reactions to, and my reflections on interviews. Glesne (1999) recommends using analytic notes to record things that occur; she refers to these as memos to oneself. She notes that "reflective and analytic thoughts may come to you during participant observation and other times too" and it is important to record these thoughts (p. 53). When recording journal notes, I heeded the advice given by Patton (2002) and relied on personal reflexivity as one of the strategies I employed throughout the study. In this regard, I reflected on my own self-awareness and on my political and cultural perspective throughout the research process (p. 299). Such reflection seemed especially important in this study because of the role I, and the company I work for, had previously played within this organization's change initiative. Data Analysis

Individual case analysis. As was suggested above, data analysis was done in two stages. Initially, the responses of each individual were treated as an individual case and analyzed accordingly. Each interview was audio taped and the tape was transcribed for data analysis. To ensure accuracy, participants were asked via E-mail to review transcripts and provide changes or clarifications. (E-mail was also used during a later part of the analysis process to clarify something that was unclear in the interview transcript.)

During the individual case analysis, I relied on two principal sources for categories with which to organize and analyze the case data recorded after these data had been reviewed and, if necessary, modified by the relevant interviewee. The first source 
were the research questions that guided the inquiry and reflected the purpose of the study. The second was the data themselves and the themes that emerged from these data.

This second source of categories (and also the relatively open-ended nature of the research questions) suggest that, at least to some extent, I approached analysis with a grounded-theory sensibility oriented toward building rather than testing theory, though, of course, the literature on organizational culture and resistance influenced the initial conceptualization of the study and its research questions. During analysis, therefore, I attempted to be both systematic and creative, in an effort to understand participants' viewpoints and to use these viewpoints to establish building blocks for theory (Patton, 2002; p. 127).

Operationally, this translated into, first, transforming the interview guide questions - which were created from my research questions-into coding categories, and using these categories to do an initial coding of the data (i.e., the transcripts themselves and the notes that had been written on the interview guides during and after the interviews). Then, I sought subcodes within each of the general codes that had been created from the interview guide questions by reading and rereading the data that had been associated with each of the first cut codes. In time, themes and patterns emerged and these themes and patterns were translated into new codes to further categorize the data that had been put into the preliminary coding categories. This process was similar to what Patton (2002, p. 453) describes as content analysis, a process of qualitative data reduction steps to make sense of the voluminous data and sifting out the key meanings and patterns.

The various FA initiative documents were used to triangulate the various categories and their contents that had been developed to organize the information that each interviewee provided. For example, documents that illustrated the organization's 
structure were used to understand the reporting relationships between FA leaders and other organization leaders, managers and staff. I also reviewed a newsletter, the FANewsletter, which provided a monthly update of FA activities, progress being made on the project, and a section devoted to FA questions and concerns. Additionally, I reviewed presentations and documents that focused on the methodology or approach being used to execute the FA project. Various other documents were also consulted including program financial information, personnel lists, strategic plans, and business plans. All of these documents, or what Edgar Schein (1992) refers to as artifacts, were consulted to shed light on the "visible" level of the organization and use to triangulate interview data and understand the specific language and events unique to the FA initiative (p.17).

Cross case analysis. After the individual cases were analyzed, I looked for patterns across the codes and categories of each of the eight cases. Once again, codes derived from the interview questions were used to organize the analysis initially; then the more emergent codes associated with each of the initial codes were compared and contrasted across the eight cases. Matrices (Miles and Huberman, 1984) were used during this part of the analysis process. Specifically, the data matrix contains a top row for participant pseudonyms and left column for key categories based on the interview guide and research questions. At least some of the matrices contains direct quotes from participant interviews. Other matrices contain researcher comments on categories and themes. I used a word processor, ATLAS.ti® and Microsoft Word ${ }^{\circledR}$ to help organize and relate information in the matrices. Atlas.ti was used to uncover complex phenomenona hidden in text in an exploratory way. This tool provided a means to extract, code, compare, explore, and reassemble meaningful pieces from extensive amounts of data in 
creative, flexible and systematic ways. The data analysis matrix is provided in Appendix E.

A combination of two analysis approaches, which Polkinghorne (1995) refers to as the analysis of narrative and narrative analysis, were employed. Primarily, I used the technique of analysis of narrative to make sense of the interview responses and experiences described by participants. Polkinghorne (1995) describes this technique in the following way:

[In] analysis of narratives, researchers collect stories as data and analyze them with paradigmatic processes. The paradigmatic analysis results in descriptions of themes that hold across the stories in or taxonomies of types of stories, characters, or settings...Thus, analysis of narrative moves from stories to common elements. (p. 12)

The narrative analysis approach was used to arrange the chronology of events and organize many of the research findings.

Throughout this narrative, I have used pseudonyms for both the organization and the central actors/characters in the story. For Institutional Review Board (IRB) issues related to confidentiality, the other members of the leadership team who participated in the study are mentioned by pseudonym name or position. The information provided by these actors-along with the information gleaned from the analysis of documents and participant observation in the organization-was synthesized (Polkinghorne, 1995) into one story. The multiple data sources used to construct the case "story" presented below helped link events chronologically and thematically and also made it possible to triangulate data and the interpretations of data implicit in the story. 
The eight participants (leaders) who are referred to here as: CDR Kelly Valencia, Dr. Mary Rotterman, Sr. Chief Norma Lewis, Linda McGinn, Ruth Christopherson, Barbara Montoya, Damaris Wilson, and CAPT Nancy Avila.

Products

A case study approach was used to organize and describe in analysis of narrative form each participant's experience in the organizational change projects. The first part of analysis included a case approach of individual cases to explore emergent qualitative findings. Using a technique similar to what Patton (2002) describes as a qualitative comparative analysis approach (QCA), the second part of analysis analyzed data across cases. The analysis from this study serves as the written product of my dissertation and a qualitative framework for guiding follow-on research.

\section{Summary}

This chapter of the dissertation provided an overview of the methods employed in this study. Detailed steps were described about the study and how the research questions would be explored through scientific inquiry and methodological rigor. Specifically, this chapter outlined the steps employed in this research study.

General procedures and guidelines for this research study were informed by a preliminary study. Changes to the research study included selecting four additional participants, identifying two more participants through a snowballing technique, changes to the interview guide and modifications in data analysis procedures.

This chapter also discusses my role in the study, criterion for site selection and access to the organization. The process of participant selection and how data was collected was outlined, and a review of the products from this dissertation study 
concluded the second phase. Finally, a brief sketch of the dissertation's organization was presented.

The next chapter presents the findings of the research study. This section discusses the story of major organizational change at SCSS. Specifically, the chapter analyzes the narratives of eight primary characters and their experiences before, during and after the Functionality Assessment (FA). 


\section{CHAPTER 4}

\section{FINDINGS:}

\section{THE STORY OF MAJOR ORGANIZATIONAL CHANGE AT SCSS-LIFE}

\section{BEFORE, DURING AND AFTER THE FUNCTIONALITY ASSESSMENT (FA)}

This chapter presents the findings regarding the ways in which leaders use and are constrained by organizational culture to respond to resistance to change. The primary methodology used to describe the contents of this study was analysis of narrative (Polkinghorne, 1995). This qualitative approach was discussed in more detail in Chapter 3 , which focused on the methodology.

This story is about leaders' perceptions of change and the influence that culture has on resistance to change throughout a two and half year organization transformation effort. Specifically, I looked at how leaders thought culture influenced change and resistance during the Functionality Assessment (FA) at the Southern California Support Services (SCSS) organization. ${ }^{4}$ As with most stories, the FA change effort has a beginning, middle and an end. To help guide the story and configure the primary themes, I used three sections to organize the main themes and findings of the research. The three sections focus on: (a) life before the FA; (b) life during the FA; and (c) life after the FA. Each section is described in detail below.

\section{Life Before the FA}

This first section, "Life Before the FA," provides an overview of the team, central character descriptions, initial views about the FA and the key characteristics of this particular mixed military and government culture.

\footnotetext{
$4 \quad$ As discussed in the Chapter 3, the SCSS is a large combined military and civilian U.S. Navy organization located in Southern California.
} 
Assembling the Change Team

The primary actors in the FA are central to recounting the story of change in the SCSS organization and are a central focus of this narrative. The FA leadership team consisted of managers from the various support service organizations that made up the overall SCSS organization. As discussed Chapter 3, the change team consisted of organizational members who performed a dual role that entailed serving as internal change agents while continuing to play their designated leadership/management role within the organization.

The FA team make-up went through different staff during the project. At the onset of the FA, the team consisted of three men and five women. All were Caucasian and in their 40 s or 50 s. The civilian/military ratio of the team was 3 to 5 . All team members had worked predominantly in public sector organizations for most of their professional lives; some, however, had worked primarily in government while others had had experience in military organizations.

During the FA study, one of the men left the organization to take another job, and two of the men retired. When they left, the civilian/military ratio within the team and the age and work experience of participants did not change, but there was a significant change in the gender of the team. All three of the men who left the organization were replaced by Caucasian women, and each of these women assumed the FA team responsibilities that their male predecessors had had prior to leaving the organization. Thus, over time, the FA team became entirely female. Consequently, the story of the leadership of the FA change effort is largely the story of these women's leadership. 


\section{The Main Characters}

The personalities and background of each FA team member are important components of the FA story. This section provides brief descriptions of each team member and some telling data about each person that emerged from the interviews and observations.

Captain (CAPT) Nora Avian. CAPT Avian held the highest military position in the SCSS organization. Her position was roughly equivalent to the position of CEO in private industry. The only difference is that, in the military chain of command, she did not report to a board of trustees; rather she reported to an even higher ranking officer, the chief of staff.

Physically, Nora ${ }^{5}$ was hardly imposing; she had a small frame and was barely five feet tall. Nevertheless, her high military ranking and enthusiasm captured people's attention and demanded respect. Nora, in fact, had a reputation among the team and throughout the organization for making quick decisions. This characteristic was very evident during the FA process.

Although Nora was not the FA team lead, she did serve as the ultimate authority in the organization for making final decisions regarding FA changes and recommendations. Interview data also indicate that Nora's authoritative leadership approach to staff, process, operation, and finance decisions often intimidated staff and employees; these data also were triangulated by observations of the FA process.

Dr. Martha Ritter. Dr. Ritter was the designated FA team lead for the FA change project. She has "been working for the Navy for over fifteen years in social service

5 A military officer is typically addressed by their formal title and last name (i.e., CAPT Avian), however, as a result of working closely with the FA team I had developed rapport and felt comfortable addressing them by their first name. 
programs" and was the resident expert for large change projects. Prior to coming to work for the Navy, she "owned a consulting business" on the east coast. Mary had an entrepreneurial approach to the FA and pushed other team members hard to make significant changes and achieve savings for the Navy.

Commander (CDR) Kelsey Vega. CDR Vega replaced the male Bachelor Housing manager that left the organization and she joined the FA team. Kelsey was an up-andcoming junior career military officer. She knew how to get respect from personnel at all levels in both civilian and military organizations. Kelsey described a situation which occurred early in her career of standing up to a male military officer who was not showing her respect, "This is still the military, where you will salute me and call me by my military name." She was not afraid to roll-up her sleeves and to do the hard work of organizational change and lead the way, even when she was challenged by the different views of other team members wanting to protect the "status quo" in the organization. Kelsey took full responsibility for the outcomes associated with her actions.

Senior Chief Nancy Lewin. Senior Chief Nancy Lewin became a team member when a senior male military member was transferred to a position out of state. She often focused on the human aspect of change and reminded the leadership team of this quality when sensitive personnel decisions were being made. Nancy's focus was on doing the best thing for the sailor and for the organization.

Lauren Maggin. Lauren supported the Military Family Housing division. She assumed the head role over the division when her boss, who, like Kelsey Vega, retired and moved overseas; she assumed all of their predecessor's responsibilities including his responsibilities as a member of the FA leadership team. Lauren was skeptical of the change effort throughout most of the FA and often tried to protect her employees from 
change. Lauren saw that military and government approached FA issues differently and usually sided with the government. Lauren had been a government housing employee since the beginning of her career.

Rachel Christian. Rachel, who headed the Morale, Welfare and Recreation (MWR) department, was one of the only FA team members to have worked in private industry. Her private industry experience gave her a different perspective of the FA from other leadership members. Rachel understood the business aspects of the FA and often attempted to present multiple views of FA change issues to military and government leadership members. She valued the outside advice provided by the consultant team and promoted their viewpoints within the FA leadership team.

Brenda Menton. Brenda became head of the Food Services organization in the early part of the FA change initiative after the prior head retired. Brenda had work experience in the private industry before coming to the Navy. Brenda's prior work experience, like Rachel's, made her more sensitive to the business "bottom line" often associated with private industry. Nevertheless, Brenda was protective of the way that her department conducted its business and took issue when told another way to run her business.

Dedra Wesson. Unlike the other members of the FA team, Dedra did not have a formal leadership position in the organization. Rather, she supported Dr. Ritter in the Social Services department. Dedra was selected to the FA team based on her two previous experiences with large-scale government change efforts. Dedra was skeptical about the consulting team that assisted with the FA (i.e., the organization I was a part of) and often challenged recommendations based on her previous change experiences. 
Summary. The eight individuals briefly described in this section made up the FA team. Their combined experiences and unique personalities were key components of the FA change story being recounted here. Other key components are described below.

\section{A "Mixed" View of Change}

Each the team members thought of the FA effort differently. While everyone agreed that the FA was a significant "change effort" for the SCSS organization, each individual tended to see the FA as either a negative or positive initiative. Certain individual's views shifted about the initiative during the process. What follows, however, is a summary of the thinking that different subgroups articulated at the start of the FA initiative.

Negative views of the FA and their causes. Even before the FA started, the majority of the team members had negative views about the change initiative. Team members identified various factors that accounted for their negative perceptions: (a) negative experiences with other change efforts in the past; (b) a history of unsuccessful change in SCSS organization; and (c) the Navy's approach to rapid organizational change; and (d) turnover in military leadership positions. Each of these views is discussed in some detail below.

Most members recalled negative experiences with other significant change events that occurred during their careers in the Navy and saw the FA through the lenses these earlier change initiatives had created. Several members had worked in the SCSS organization prior to FA and remember undergoing "regionalization." Regionalization was described as the process the Navy went through to consolidate and standardize similar services (e.g., recreation, food, counseling, and housing services) that were provided to service men and women across all SCSS organizations in the South Western 
region of the United States. Regionalization required major personnel and organizational structure changes. As CAPT Avian recalled, "We went through regionalization and people went away." These changes created a separation between central headquarters and remote SCSS sites, referred to as "Metropolitan" (Metro) and "Over-the-Horizon" $(\mathrm{OTH})$, respectively. The regionalization initiative stood out in leaders' minds because it was a major change event that affected the entire region (e.g., employees were required to move, employees' jobs changed, and many staff experienced stressful change and uncertainty). Although the outcomes from regionalization helped reduce government costs and standardize services between organizations, most people in the SCSS organization felt that employee morale suffered as a result of the tremendous adjustment. As a result, most of the FA team members saw regionalization as a failure and wondered if the FA would play out in similar ways.

Several members also were skeptical about the history of effective change within the SSCS itself. Some members reflected on their earlier experiences with unsuccessful change initiatives and described the feeling as, "Oh, no, here we go again." A few of the members who had been in the organization for more than five years, viewed the FA as an attempt to "fix something [that wasn't broke]." Although these views were not equally shared by all members, it was generally agreed that the Navy in general, and the SCSS organization in particular, did not have the best track record when it came to organizational change.

The Navy's continuous and rapid approach to organizational change also surfaced as a reason why the organization had struggled with past change initiatives. Those who stated that the Navy was changing too rapidly, and too often, felt that the Navy's change approach was ineffective in accomplishing the goals of change initiatives. This view was 
shared by at least one of the team members who explained that the Navy had undergone organizational change for as long as she could recall. She warned that "too much change too quickly... is hard for the organization to absorb." Others agreed that the Navy's approach of continuous change, or one change happening on top of another, was simply more than the organization could sustain.

Another reason why leaders seemed apprehensive about the FA was related to the ongoing turnover in military-occupied leadership positions in the SCSS organization. Military staff requirements necessitate military personnel to rotate or turn-over typically every three years. This constant turnover of personnel already caused ongoing disturbance throughout the organization, independent of specific change initiatives. Some members, including a military Commander, saw this constant change in military leadership as "disruptive to the organization." Not surprisingly, these individuals did not welcome an additional change initiative and the additional disruptions it would cause.

Positive views of the FA: two variations. Despite the dissenting views characterized above, some members of leadership team viewed the FA positively. They saw that the FA provided an opportunity to bring needed changes to the SCSS organization. Although the organization had gone through regionalization and made some changes a few years earlier, the FA provided what one member called a "fresh perspective" and more encompassing change that would, from this member's perspective, help improve the services offered to SCSS's customers.

There were also some leadership team members whose thinking could be characterized as positive, but who were not especially enthusiastic about the FA project. From their perspective, the FA was better than the consequences of not doing anything. Those who felt this way viewed the FA as a way to avoid an even worse fate-changes 
mandated by the Navy. From their perspective, the decision to conduct the FA study, at least in part, was seen as a way to avoid an alternative government change effort that might have more drastic consequences.

\section{Life in the Real World}

One theme that was discussed by the team members during interviews was the relative effectiveness of the SCSS organization when compared to comparable private industry organizations. The vast majority of team members thought that private organizations were more effective, had more freedom, and respected their employees more than the SCSS organization did. Team members often referred to private industry organizations as the "real world" versus life in the military or public industry. One military member, for example, said that "in private organizations, as opposed to working in the military, private organizations rely on results...to achieve their goals." Team members also attributed other benefits to private industry's focus on profit and "bottomline" results. One team member, for instance, said: "The [private] organization worked as a team in harmony, with as little turnover and with as much productivity as possible so that [the organization] achieved where they were going." The leaders and managers in these "outside" organizations were seen as being "less intrusive into the process" and just saying, "Here is your goal." This was not seen as being the case in the SSCS organization.

The concept of competition and good leadership skills were seen as missing in the government workplace. Dr. Ritter commented that "there's less competition [in the military and public sector organizations]"; she also noted that, in private industry, competition drives performance and results. In the private industry, she said, "Your folks knew what they needed. They felt empowered to help you get there. They were part of a 
team. You were a good leader...you achieved your goals and you helped the company make it's profit."

Another civilian team member who had also worked in private industry said, "It's different here because there isn't as much emphasis put on the total quality leadership skills...the total package of a leader." As a result of this organization's less than holistic approach, one team member described feeling a little lost and confused "working in this environment...there's too many cook's in the kitchen. I don't even know how to define who is the leader."

A somewhat different perspective was exhibited by certain other team members. These members did not necessarily view the public sector as being superior to private industry, however. Rather, they felt that the mixed military and civilian organization was a more challenging environment to operate in than private industry and, consequently, believed that those who successfully negotiated this more challenging environment were more savvy and competent than their counterparts in the private sector. As one person put it, "Explaining [the ways we do business], is always interesting to [private industry] because I don't think [they] think we do business as they do." Another team member shared a similar view when she said the following:

I tried to infiltrate the outside because I felt like they were further advanced in technology and in ideas [that gave them the] competitive edge in San Diego. So I tried to bring somebody in from the outside. They found it very hard. truthfully they couldn't cope. The rules were so tight, rules were so much tighter than on the outside. 


\section{A "Mixed" Breed: The Combined Military \& Civilian Organization}

Another theme emerging from the analysis of the interview data related to the unique characteristics of a hybrid organization. Team members described an organization that was very different from both an all-civilian or an all-military organization. One civilian described the type of organization as "the melding of different cultures." Similarly one military member suggested that "the two groups really do come from two different worlds... and that there are things in common and there are things that are not."

Not surprisingly, civilian and military team members held different views about each other. These different views created a number of dynamics around issues of equality, authority, and values. These dynamics are characterized in the remainder of this section and in the discussion about culture and its impact on the FA initiative later in this chapter.

Us vs. them: a top-down view. The issue of civilian equality in a military organization was something FA members commented on and was described as an "us vs. them" attitude. One civilian member said that the military had the view that I'm ultimately in charge and you are subordinate. It's very much a subordinate mentality in the military with the civilian workforce. There's an attitude that the civilian can be replaced as easily as a hammer in a toolbox. It's just another tool in the box.

Another civilian member expressed a similar view when she stated, "I've gotten used to it...but you know where you stand as a civilian within the organization; more like a second-class citizen." She went on to note that "there's always pressure to conform to the military environment and you're not always able to be yourself, which is not a good thing for a lot of people." 
To some extent, the above views might be seen as simply a reflection of the topdown nature of the military, an organization which is, after all, built around the chain of command. A civilian member of the team, however, did speak of variation even within military contexts. She noted: "Sometimes the military accepts and teams with their civilian workforce better than others-from the president's administration on down, how they value and enforce the relationship and the equality of the civilian and military workforce varies in different situations." In the SCSS, however, civilian members perceived both that they were being treated as second class citizens and working for a very top-down organization.

Different views on work and change. Military and civilian team members held different views of each other with regards to work and change in the organization. One military member commented that "civil service really has huge job security. It is hard to fire them. They are definitely an eight to four kind of group." From the civilian side, FA members also viewed the military work culture as unique. "It's a different perspective. Theirs is more of a temporary kind of lifestyle, and so some of the [issues] of management...are arrived [at] from a different perspective than...from the civilian side."

Team members also pointed out that because of their different views of work and different statuses within the work culture (e.g., the security provided by civil service protection), military and civilians respond differently to organizational change. Military work requires a job change every two to three years, and sometimes a relocation or completely new job. In general, FA team members who were from the military side of the organization felt that, because of this characteristic of their work, military personnel are more used to change than their civilian counterparts are. Even civilian members took note of this characteristic. One civilian commented, for example, "It [frequent change] can be 
a benefit because you get a fresh look at an organization every two to three years...and sometimes status quo is not necessarily the best way to go." However, several FA civilians saw a downside to the transient nature associated with the military work culture. Since the military were always rotating jobs, there is usually a "lack of continuity at work," one civilian team member noted. Some members also felt that this lack of continuity contributed to a loss of organizational memory and continually imposed a steep learning curve that can be really disruptive to the organization (LM). One military member also admitted that the Navy's way of business requires military to be constantly on the move in order to advance in the organization. She noted that military personnel 'can't just sit in the cubicle being a military person. You've got to be the hamster on the wheel or you're not promoted." These fundamental differences in work perspectives created tension between how military and civilians viewed the FA.

On the other hand, civilian personnel are seen as much more stable at work. Some FA members saw this stability as being positive; others saw it as negative. One interviewee who viewed civilians' stability as positive, for example, said, 'The good side is that you've got a knowledge base there and a lot of experience that the organization can take advantage of." The Assistant Chief of Staff (ACOS) and head of the SCSS organization said much the same thing when she noted that they're [civilians] just as good as any military person, and in some ways they're better; because one becomes the expert in their fields and their functions... without them this organization would not function. They made it...they were the backbone of it and it was not the sailors...it wasn't the marines...it was the civilians and I was proud to work with them. 
CDR Vega, another military team leader, on the other hand, pointed out some of the downsides of stability. She suggested that civilians can "plod along in the same job for twenty to forty years. It's very comforting to them." According to this FA team member, change is difficult for civilians. She stated, "So when you try to change something that they've been doing for the last twenty years, [it's], "Don't mess with my cubicle!" [They get] extremely comfortable, and they can't be fired." Military members pointed out that this type of attitude makes it hard because there is constant change in the Navy. One civilian also shared this less-than-positive perspective of civilian stability. She stated that "when you have a civilian workforce with not a lot of change... you can get stuck in a rut."

The benefits of a mixed organization. Some members of the FA team held a positive view about working in a combined military and civilian organization. They felt that having an organization made up of military and civilians provided the best of both worlds. As one military officer said about the FA, "I rather enjoyed it because, as I got to know people —and you got to really work with...a lot of different backgrounds-I just got a lot of good input... [and] I think it was very helpful." One civilian member also saw the advantages of military change and civilian stability and called it "a good pairing." Still another civilian viewed the relationship as positive and said, "I think it's very much a workable arrangement; we have a mutual respect and we work very well together."

The lay of the land. Both military and civilians held similar views about ways to be successful and ways to avoid problems in the SCSS organization. Most members agreed that, in order to be successful, you needed to support the leader's vision and be open to change. Aligning with the leader's goals was important even in the midst of uncertainty and in unsteady times. As one person put it, "[You need] to be able to keep 
that focus while being tasked in what seems to appear to be pulled in many different directions." One member suggested that you did this by saying, "Yes sir." She added that these two words seem "to be by far the most valuable two words that you can own in order to be successful in this organization; it only took me fifteen years to figure this out."

According to many interviewees, another key to being successful was being able to adapt to change. "They have to be willing to change," one military member of the leadership team noted; "it's a constant change these days [and] it's a brand new way of doing business. You just have to be on board with that not only to survive but to help the organization survive."

Some members mentioned additional notions of how to be successful in the organization. For some, following the rules and knowing the politics of the organization were good ways to avoid encountering problems at SCSS. One woman, for instance, talked about "making sure that you know what the law and the rules are because there are still procurement issues and go-to-jail-type things that you certainly need to know and be aware of." Another woman also highlighted the need to be political and understand the rules that govern the SCSS organization. She suggested that having at least knowledge of politics is good because if you are sensitive you know the rules to go by. This person also indicated that it is important to "make friendships...I don't mean friendships where you're trying to manipulate but I mean... finding a way to connect with people in a caring kind of way." Another team member stated, "You need a book about how to be political. If you're not political, learn what that means." 
According to at least two other members, communication was the most important way to stay out of trouble. One of these persons stated, "You have to communicate...communication has got to be the key." The other woman commented If you can't talk to that captain on the base and think you're going to run a program, a successful program, forget it. You have to talk to the command. You have your commander in chief, you have your XOs, $\mathrm{COs}$ and you need to communicate with them...everybody has to be on board with what you're doing and how you're doing it. That's the only way I could see to be successful—-total communication. ${ }^{6}$

Life During the FA

The second part of the chapter, which I have titled "Life During the FA," explores (a) the main events of the FA, (b) how the team and organization responded to these events, (c) the different views about the leadership team's responses, and (d) examples of resistance to change that occurred at various points during the change process.

\section{Significant Events in the FA}

As was noted in Chapter 3, during each interview a copy of an FA timeline, with a limited number of key dates and events highlighted on it, was presented to the interviewee (See Figure 3.0). These can be described in three distinct phases that members readily understood. The first four events made up the "AS-IS" phase. ${ }^{7}$ This phase included the announcement of the study, the official "kick-off" (i.e., start) of the FA, a data collection period, and a benchmarking period. The second phase was the "TOBE." 8 This phase included three primary events: a redesign of the organization, visits

\footnotetext{
$6 \mathrm{CO}$ refers to the Commanding Officer of a ship or base; XO refers to the next in command to the $\mathrm{CO}$

7 The "AS-IS" refers to the baseline or current state of the organization.

8 The "TO-BE" refers to the designs and plans (i.e., blueprint) for the future state of the organization.
} 
with the Base Commanders, and revisions to the "TO-BE" plan. The third phase was the implementation of the design and included developing an implementation plan and a performance metrics plan and executing the plan. The following timeline depicts the major events described above.

Figure 3. Functionality Assessment (FA) Timeline

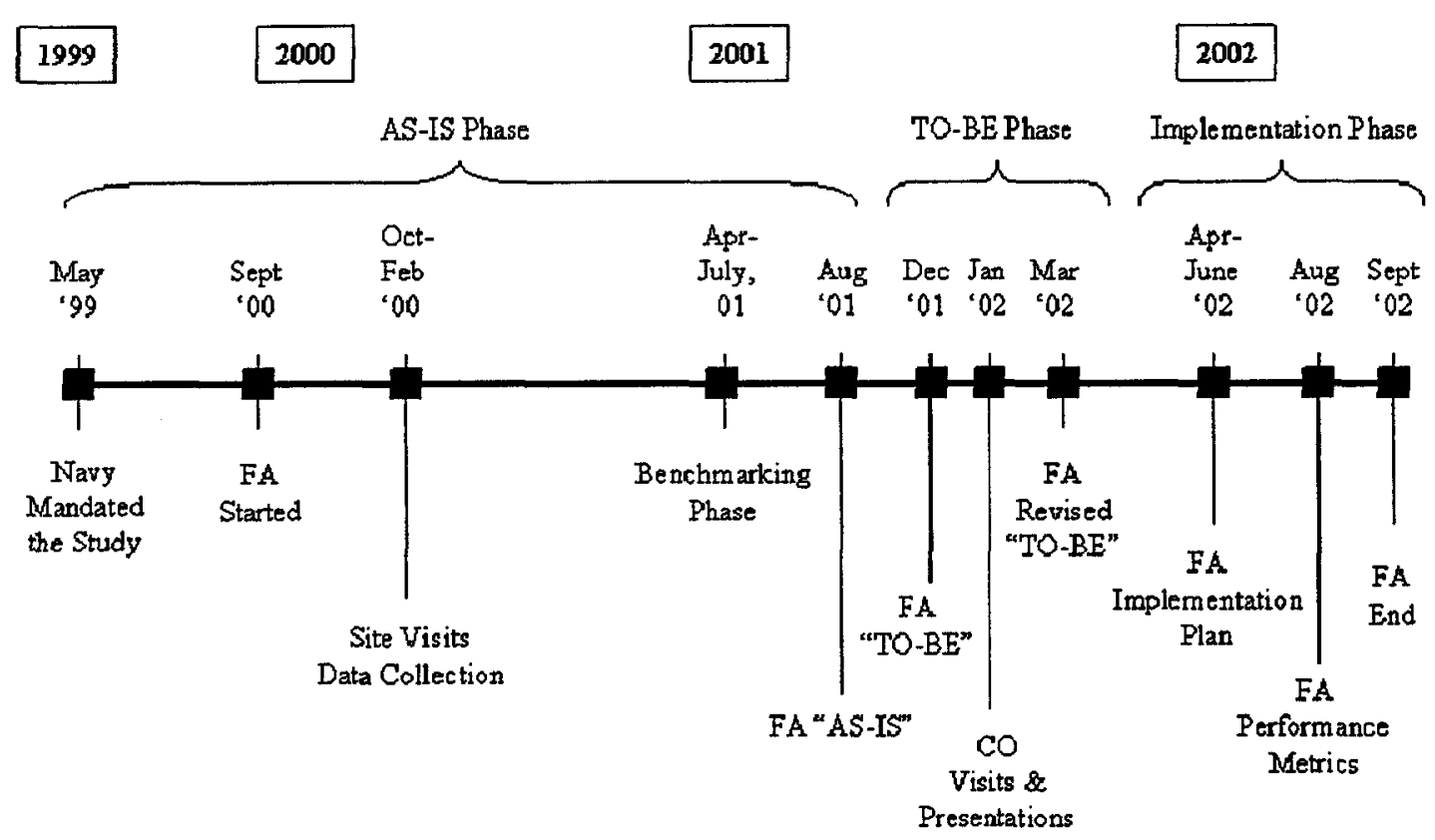

Team members were asked to discuss their perspectives of the major milestones listed on the timeline and to add additional milestones that they believed were important and then discuss these events. Most team members agreed that three major events stood out as particularly important to the FA. One was the decision to conduct the FA study. Another related event was the decision to hire an outside consulting company to assist with the change effort. The third event was the resistance that team members experienced during the Base Commander site visits. These events are described further.

Decision to conduct the FA. The decision to conduct the FA change effort was described by most team members as a significant event. Following the Navy's decision to formally study the SCSS organization, the SCSS organization was given a choice to 
either conduct a Functionality Assessment (FA) or a Commercial Activity (CA) study. The FA meant that SCSS would essentially study itself as opposed to an outside organization making change recommendations. Several of the SCSS leaders, who also became members of the FA team, chose to conduct the FA study. According to Dr. Ritter, "In ' 99 we submitted our proposal to do an FA from the [Navy] fleet." The process of getting the FA started was very long and time consuming. Rachel recalls, "[When] we started out, we had a lot of meetings with Dr. Ritter heading up most of those [meetings], and I was identified as the MWR [Morale, Welfare \& Recreation] team lead at that time. I just remember numerous meetings, briefings with folks and employees as to what was going on and how long the time period would be."

Decision to hire a consulting company. The decision to hire an outside consulting team to assist with the FA change effort was highlighted during the interviews by team members as another important event in this study. Team members had different reactions to bringing an outside consulting company in to assist with the FA. For some members, the consultant support was appreciated. Rachel mentioned, "We brought you guys on board in September. I put that it was a very good thing because we certainly needed the support and then we worked with you to develop the [plan] of where we go from here." Others were less positive about the consulting company's help. One individual expressed that the consulting team did not provide the right type of support for this large-scale, change effort. She critiqued, "I didn't really see that much of a focus on change management." Additional observations from other FA members are described in more detail later.

Site visits with Base Commanding Officers (COs). Another major event discussed by team members during this study's interviews were the site visits with the Commander 
Navy Region Southwest base COs. The FA team met a significant amount of resistance when they presented the FA plan to the base COs. According to the FA lead, "We allowed the COs in the Navy Region Southwest at that time to drive the cart instead of us [driving the cart]. They stayed out of the way only to sabotage it later on and say, 'I didn't agree.' And that was the whole passive aggressive nature of the study.... We were ambushed at the end, because they could nod their head and let us believe that we were going along on the right track, but we really never pinned them down and put the responsibility on their back."

Insiders' Views about Change Process

Members of the team described different perspectives of what they saw and heard from other team members and employees during the FA the change process. According to most people who were interviewed, most employees generally recognized the need for organizational change and agreed with it on the surface, but beneath the surface they were often skeptical and opposed to change. Team members indicated that employees were likely to say, "I know I have to make changes, and I know I need to make sure they're significant changes, because there is a mandate and an expectation that there will be a certain amount of reengineering that will cause [the SCSS organization] to be able to reduce [cost] significantly, but I don't know that I really agree [with these changes]."

One member doubted that the FA would make real change in the organization. According to her, "When [the FA change effort] was happening; a lot of us were very unsure that this was going to take effect or really mean anything. I'm not sure that in food service that we were heading in the right [direction]; we met with a lot of opposition. [The Command leaders] didn't like it." 
Overall, the effectiveness of the FA was viewed differently by various stakeholder groups in the organization. From one member's perspective, "It depends on who you talk to." She mentioned that some people would say that "we didn't do a very good job in the FA." This same person admitted that this is was a "very hard pill for me to swallow because I happen to believe that we did do a very good job within the FA." Groups that Played a Major Role in the FA

FA team members discussed the various groups that impacted the FA change process. According to one member, "There [were] plenty of people who were involved." In general, team members mentioned internal support groups (i.e., SCSS departments), external customer groups (i.e., the Base Commanders), and an outside support group (i.e., my consulting team). Team members were generally positive about the role that insider groups played in the FA. The other two groups mentioned will be discussed in the next part of this section.

The role of the outside consulting team. Several team members commented on the role that the outside consulting organization had in the FA. Overall, most team members held a positive view about the consultants' role in the SCSS organization and their impact on the FA. Many team members indicated that the consulting team was helpful and supportive during the change process. According to one member, "The Booz Allen people were very professional. That was the general consensus, everybody felt the same way." Another member suggested that the SCSS organization would not have been able to conduct the FA without the help and support of an outside consulting team. She stated: I don't think it would have unfolded at all if it hadn't been for your organization. We knew nothing of conducting an FA and we needed 
your guidance to kind of carry us along. Again, to be very honest, sometimes you pushed us but that was necessary and I think we would have become stuck in a few different places.... So looking back on it I think we needed that.

A few team members, however, offered a contrasting perspective. These team members commented that they didn't always feel that the consultants fulfilled the role that they were expected to play. This perception was attributed to the experience level of the Booz Allen team and the strong personalities of the SCSS leadership. One female member observed, "I think some of the players involved in the FA functionality assessment on the contractor's side were influenced by some of our people." From her point of view, some of the "best decisions" weren't made because some folks in the SCSS organization "influenced them." In other words, there was a perception that the consultants did not do their job because they were persuaded by others in the organization who resisted the change that was being suggested.

Another person felt that the Booz Allen team didn't push hard enough during some aspects of the change process. This person stated:

I think in general the team assigned was understandably timid because of the personalities of the leadership they're dealing with. I really feel like it was doing what was being told rather than giving hardball responses and pushing the management here to do a real FA.

This same person noted, "Under many circumstances I felt kind of like the team backed down and became cautious. Kind of like you were being political about it." Still, in contrast, others felt that the consultants were effective in their approach and helped push organization members to make difficult and unpopular decisions. For example, one 
woman recalled a meeting with a consultant, "he really pushed the bar and he brought some stuff that we really never dealt with and never dealt with again but he really opened [the SCSS organization] up for more critical thinking and revision."

Other groups that impacted the FA process. Finally, a few team members described different views from the ones mentioned above. One team member had a different view of the groups that were involved in the FA. This person dichotomized the groups into those that supported the FA and those who did not. She stated:

I believe that you had two groups of people. You had the Base COs and the Site Manager's who were on one team and you had those of that were trying to lead the FA effort on the other team and we didn't always see eye-to-eye on things and we saw that when we had to go back and change a lot of things from our original to be plan.

Another team member also mentioned the impact of the Base COs in the FA. According to her, "the COs or the site managers over the bases maybe should have been more involved. I don't think we would have had as much controversy if they would have been involved."

One other team member described three different groups that she felt were significant to the FA process. She described the differences between subordinates, peers, and superiors. She stated that "my subordinates are supportive. My peers are not supportive. My superiors I think are supportive of it, but there's so many other things happening now with the change in the Navy."

\section{The Resistance Factor}

Nearly all team members felt that there was resistance experienced during the FA. Resistance was generally described as a group or individual who was opposing the 
change that was being made. Although resistance occurred in different ways, FA members described various sources of resistance experienced during the FA.

Sources of resistance. When people talk about resistance, they normally are talking about a bottom-up phenomenon: Those who must implement initiatives developed at the top of the organization are either unenthusiastic or downright hostile and behave in ways that can sabotage the innovation. Here the situation was somewhat different. Team members generally agreed that push back from the top was a major source of resistance during the FA. One member of the organization described this resistance and lack of support from the top as "roadblocks" that the FA team experienced along the way. The leader of the FA team also agreed and commented, "I think the greatest resistance, or maybe it was a lack of action, was by upper echelon COs [Commanding Officers]-they did not want to make the [cost, people, and programs] cuts that needed to be made and that was with the leadership." Another FA team member explained that the COs resisted change because "they were reluctant to give up what they want on their base." From her perspective, "[the COs] supported each other, no matter what-kind of like a club." Another FA team member recalled experiencing push back and resistance from her supervisor. She commented, "I just didn't feel that he was willing to open up his mind enough to change...it was more comfortable to stay status quo than it was to step outside of that box, to truly do something different."

Resistance did not only come from the top, however. Another interviewee suggested that there was even resistance from within the FA team. She recalled, "There was not complete buy-in to thoroughly look at the programs with an open mind and to develop better ways to do business." From her perspective, the FA team was "having to swim through sharks to try and accomplish a goal that we weren't really getting 
supported for fully." Furthermore, some of these sharks, according to her, were members of the leadership team.

According to some interviewees, one consequence of the top-down and lateral resistance described above was that some areas were not adequately looked at during the FA. A few team members felt that there was a concerted effort from those higher up in the organization to protect certain programs and areas from undergoing change. One team member stated, "There were lots of resistance to sacred cows and manipulation in what the outcome was to look a certain way." Another member suggested that "there were certainly areas within several of the programs where there was either a spoken or an unspoken protection of that area getting a thorough look."

Ancillary consequences of resistance. FA team members also observed particular effects that change resistance had on the organization. Some members described that sick leave and personnel issues increased. One member recalled, "We had personnel issues that we've never had before. Employees arguing over, you know, trivial things...almost tattling, childish kind of things." This same team member provided an explanation of why employees exhibited this type of behavior. She concluded, "I guess it's a natural reaction...to the fear, the unknown and, you know... it's people's livelihood and when that's threatened it creates a huge issue in an organization." Other effects from change resistance were also mentioned, but were more subtle. Overall, team members described a general feeling of what they characterized as "push-back" (e.g., resistance) from both the top of the organizational hierarchy and the bottom. In addition, within the unit itself, they reported greatly lowered morale. 


\section{Change Agent Intervention Strategies}

Most FA members described an intentional role that they played to influence change and resistance during the FA study. Although different types of interventions were used, I will call attention to a few of the most common interventions discussed by team members.

Communication strategies. In general, most team members mentioned their efforts to use communication as a strategy to manage change resistance within the SCSS organization. One member described the need to "get the word out early" about the FA changes. Another member supported this approach and explained that it was important to communicate early in the process and throughout the entire effort to address employee concerns about change. She explained that "the rumors got out very quickly and people thought we were taking jobs away and taking people's positions away." Therefore, team members' decision to communicate early was both a response and a preventative strategy to "get rid of these rumors that were just floating."

Members also used different methods to communicate horizontally and vertically in the organization. For example, one member had meetings with organizational leaders once a month to provide a status of the FA change process, discuss planned events and to hear feedback. Another member stated having regular meetings with employees to "try to keep them well informed." She explained, "I think sharing information is a very vital thing and I tried to do that through those meetings that I had on a periodic basis." The interviewee also used training programs to help employees with the change process. For instance, the training programs assisted employees with "how to deal with stress, how to deal with change, and how to write a resume...so that employees felt as if they weren't being left without any options." 
Confrontation strategies. Another strategy used was confrontation. One member stated, "I confronted everyone" with organizational changes. She explained, "I would bring it out, lay it on the table, look at it...try to find out if there was any possibility that we were going to be able to break through that resistance and get some support for it." She also described "socializing" (i.e., sharing and familiarizing) the proposed changes "up and down the chain [of command]" in order obtain support and understand where there was resistance. As she recalled, "I worked very aggressively on trying to get at these pockets [of resistance]." Another team member was even more direct in her approach when faced with "push-back" (i.e., resistance) from employees in the organization. She explained that "[resistance] is not an option. You can't put your head in the sand and if you're not use to change then maybe you'd better think about going." As a result of this type of intervention, she explained, "Some employees left the organization and some people waited until I left."

Consensus building strategies. Another approach taken by a few FA members was to develop consensus about the changes among the leaders within the SCSS organization. This approach, while adequate early on, was not very effective later on and met with considerable resistance from organizational leaders (i.e., Base Commanders). As the head of the FA team recalled:

I think I was pretty straightforward, diplomatic and attempted to build consensus until it got to a point of the final briefing and where I had to stand fast and say, 'we went through this, we spent all this money and now you all are backing off.' They weren't going to change their minds. I couldn't do it with kindness. The old [adage] 'kill them with kindness.' So, take the honey away and what do you have left? 
Other conscious and unconscious change strategies. FA members described using other strategies and mechanisms to shape the organization's culture. For instance, one FA member described using the notion of culture and mental schemas to influence the "attitude of the people" and to "make people change their minds to see it our way-the way that the FA team looked at it." A few FA members described putting themselves in the place of others to think about what they might be experiencing. One FA leadership member stated, "I always looked inside myself and said, 'okay, let me think about this. Now I am still doing what I believe, which is taking care of the sailor.' That was important to me." One other woman shared, "It has made me personally take a step back and try to look at things in a different light...it's kind of like, well maybe there's another way to look at this or another way to react. It has helped me."

A few FA members added that, in addition to, or in lieu of, using conscious and planned intervention strategies, they also used unconscious and automatic strategies. These FA members attributed this difference mostly to their experience with similar large-scale change initiatives. As one member put it: "It was automatic and it was planned because of having done these before-this was my third study by the time this came up, so it was from a lot of lessons learned."

Overall, despite the different strategies employed, several team members admitted being surprised by the type of resistance that they experienced during the FA. As one member explained, "I wasn't prepared for the insidious sabotage that was going on in this process." Some members attributed this change resistance to the organization's culture. The impact that organizational culture had on individuals in the organization is discussed next. 
Organizational Culture: A Broader Perspective of Organizational Change

The SCSS and Navy's organizational culture played a significant role in the FA according to team members. This section will discuss FA members' definition of organizational culture, perspective of different types of culture in FA initiative, and view of how the culture impacted the organization.

A varied definition of organizational culture. Although FA members were familiar with the concept of organizational culture, the specific definitions they attached to the term often were somewhat different. Some of the descriptions of organizational culture included "a complete way of doing business," the "environment you are trying to create for yourself," the "attitude of the people," the "organization's being and the innards" and "a new way of thinking." Despite these differences, there seems to be an underlying similarity with each other and also with the view of organizational culture promoted by Schein (1992), a view that was discussed in Chapter 2.

Other people's definitions do not fit so neatly or tidily under the Schein umbrella. One team member, for example, equated culture with politics. She said, "When I talk about culture, it's political."

Different types cultures. FA members acknowledged that there were at least three different types of organizational culture-government, military, and private industryoperative in the organization that was being studied. The first two types of cultures were present because this was, in fact, a hybrid organization which was part governmental and part military. The culture of the private sector came into play in three ways. First, the change initiative that had been undertaken was inspired by and modeled after similar sorts of change initiatives in the private sector. Second, a number of FA team members 
had come from the private sector and brought private sector values with them. Third, the consulting team brought in the private industry perspective.

According to interviewees, each of the three cultural contexts influenced the organization in general and the change process in particular. Government culture, for instance was described as "bureaucracy." One member explained, "We look at making things hard by imposing more rules and more paperwork and more regulations." She contrasted government and business culture and said that they were at "opposite ends." She suggested that "the government culture does not look at things in a business way. We don't look at it in terms of how much it costs or how can you do it cheaper." (Of course, this sort of thinking was precisely what the change initiative was attempting to promote.)

The military culture was different from government and private industry cultures. One member explained that "the [military] culture was like 'don't tell us to run like a business'. The military is not a business."

The head of the FA described the military culture as static and enduring. She commented:

There is such a long tradition in the Navy and the culture has been there for a long time. You and I are not going to change that except little by little.... Tradition will be tradition, will be tradition. That's what this culture is. The culture being, "I'm in charge and that's all there is to it so shut up and listen to me and do what I say."

Other members also held the perception that military culture is very "top-down," "hierarchical" and follows a "chain-of-command" structure. Others commented about the "temporary" nature of military staff who transfer positions every few years. They pointed out that this characteristic affected the way that military staff viewed work and business. 
Team members also viewed private industry differently than government and military organizational cultures. In general, private industry, or civilian culture was seen as being more focused on the "bottom-line" and is "results-oriented." Employees that work for private industry are more "competitive" and "driven by profit." The FA members equated this view of business with the outside consulting company and the mindset they used to implement change in the SCSS organization.

Finally, some members commented about the combined SCSS government and military organizational culture. One member suggested that there "doesn't seem to be an overlap [between the two cultures that make up the organization]." Another interviewee commented that "it's very much a subordinate mentality in the military with the civilian workforce." Others agreed that the military had more authority and power than civilians in the organization. Overall, FA members concluded that government, military, and private industry had different organizational goals that affected each of their cultures. Impact of culture. Most team members agreed that the organization's culture influenced how leaders and employees thought about and responded to organizational change. As one interviewee put it, "The culture can make you perform one way or the other." A different person noted that leadership played an important role in the culture and needed to make changes to the culture in the SCSS organization. She suggested that "the whole culture had to change and it had to change at the top first."

Others felt that military culture, in general, and Navy culture, in particular, caused organizational leaders to respond to change in a certain way. For example, one FA team member commented, "I don't think [organizational change] really had anything to do with the FA. I just think the whole change culture is extremely difficult for military because they are such a culture of tradition." This notion that the military's culture as a culture of 
tradition was supported by other team members too. The head of the FA agreed that "[SCSS and Navy leadership] maintain the culture that's been there for eons but needs to change." This perspective is also consistent with Schein's (1992) notion of leadership that creates and maintains organizational culture.

Some people on the FA team saw culture as a way to influence people to change in a particular way. One FA member who joined the team later explained that the concept of culture was useful in communicating change throughout the organization. She stated, "I think [culture] was helpful in making people change their minds to see it our way. The way that the FA team looked at it and wanted us to be."

Lastly, some of the FA members saw organizational culture as a facilitating and constraining force. A few members felt that culture was a useful construct to think about and communicate change throughout the organization. As one person put it, "[Culture] was helpful to making people change their minds." Others, however, felt that culture, and particularly military culture, limited what could be done in the FA change process. Some members of the FA team spoke about the military's hierarchy and chain of command as factors that "blocked" change in the organization. One FA team member commented, "The whole change culture is extremely difficult for military because they are such a culture of tradition." Even military members of the FA team felt this way. For example, one military team member stated:

I'm very used to an extremely structured environment, someone telling me what to do and then I can do it. With the FA, I had to come up with the ideas myself and then convince these people who have never changed, that change is now good. 
In summary, the various conceptualizations of culture discussed above affected how FA leadership members defined and viewed organizational culture. More specifically, the characteristics and contexts of the three cultures discussed (i.e., government, military and private industry) influenced how organizational members thought about culture and responded to organizational change.

\section{Life After the FA}

In many respects, an organization is a living entity. Organization members come and go and, through various experiences, change over time. The SCSS organization and its membership also changed as a result of the FA initiative. This final section, "Life After the FA," reviews how the organization was affected by the FA initiative. Specifically, I will review participants' post reflections of the FA, the role of leadership and culture in the FA, and finally, lessons learned from the FA. If Walls Could Speak (Post Reflections of the FA)

FA members reflected on their perceptions of how the organization changed after the FA. Overall, members of the FA team held mixed views about how the FA impacted the organization and how others in the organization viewed this initiative. A few key themes emerged from interviewee reflections on their experience of the FA and are discussed below.

Change is threatening. In general, the FA was seen as a threatening experience for many of the SCSS organization's members. As one person stated, "The FA was threatening...people lose their jobs." Another FA member felt the same and mentioned that "[change] causes fear. The change, the downsizing, the possibility of losing jobs, you know that kind of thing creates an uneasiness in the organization." Others shared the perception that even if the intention of the change initiative is good (e.g., improving 
efficiency or improving the "bottom-line"), employees felt that their job security was threatened and out of their control. One person commented, "They're the worker bees. The rest of us are the ones that are designing and thinking about how we want the organization to look in the future."

Change is disappointing. FA team members expressed some disappointment with the FA process and the results. In particular, team members expressed "disappointment" that after a long and "painful process," not all of the recommendations were "implemented." As one FA member recalled, "When you finally work your way to the TO-BE you expect that the TO-BE is going to be fully implemented full force." Another team member remembered hearing people say that "we didn't do a very good job in the FA, which is a very hard pill for me to swallow because I happen to believe that we did do a very good job within the FA." Still others were disappointed because the final change recommendations made by the FA team and an outside consulting organization to the leaders in the SCSS organization were not fully accepted. As one interviewee recalled, "It was kind of disappointing because I felt that it was a good business decision that the FA team came up." This same person concluded, "It was almost like... why did we do this?"

Change is difficult. FA members described the change process as "long and painful." This sentiment was reflective not only of the change process but of the organizational culture that FA members were trying to change. One interviewee recalled her experience of trying to change the organization and stated, "I've been at this a very long time." Another person recalled, "the change culture is extremely difficult for military because they are such a culture of tradition." One FA member observed another reason that change was difficult in the SCSS organization culture. She explained, "It's 
kind of the culture sometimes that if things don't go exactly as planned or whatever it becomes, 'let's find out who we can blame or go after to hold them accountable."

Change is satisfying. After the FA dust had settled, some of the original recommendations were accepted in the long run. As one person put it, "Some of the things that we suggested have now come to life... we've had to consolidate, combine, even close things down that originally people didn't want to do." The leader of the FA recalled, "I would say that actions speak louder than words. The original plan was right on the mark." In summary, some of the things that leaders and employees "fought us on" were accepted in the end.

The Role of Leadership and Culture in the FA

Several FA members reflected ex post facto on the role that leaders played in the FA initiative; and specifically, on the connection between leadership and culture. One team member indicated that culture "needs to be a group of people working together. There has to be a leader and the leader may change. Respect and communication has to be key... and that's also a part of culture." Another interviewee suggested that "culture is in the environment and very much dictated by the leader." This idea of culture is similar to Schein's (1993) notion. Schein also felt that culture was created by leaders and also influenced leaders actions and thinking (see Chapter 2).

Lessons Learned in the FA

Several FA members described lessons learned and things that they would have done differently during the FA initiative. The views of the FA leaders cluster around a few main themes.

Multiple change efforts. Some FA members commented on the challenges associated with overlapping change initiatives. People felt that there were too many 
changes occurring in the organization at one time. (The FA was only one of a number of change initiatives happening simultaneously and previously.) As one person stated, "I think there can be too many changes going on at one time. I think that's disruptive to the organization because you kind of lose focus." She concluded that "change is not necessarily bad, but too much change too quickly is hard for the organization to absorb."

Leadership support. FA members consistently suggested that they would have gotten more support for the FA change initiative and results if they would have gotten "buy-in" from SCSS leadership up front. For instance, the lead FA member reflected on what she would have done differently in the FA. She stated, "I would have gotten more official buy-in on the steps along the way to developing the TO-BE that held the COs feet to the fire." She added, "We allowed the COs in the region to drive the cart instead of us. They stayed out of the way only to sabotage us later on and say 'I didn't agree'." The FA lead concluded, along with others, that this behavior was indicative of the "whole passive aggressive nature" of the FA change initiative that we were "ambushed at the end."

Communication effectiveness. Lastly, there was a perception that the FA team leader did not communicate effectively with the Base Commanders and other naval leadership. One interviewee recalled, "I found the best thing to do is go to the bases, sit down and meet with the CO." She further described, "I met with all the COs of the bases and I told them everything that we were doing all the time."

FA members shared the perception that effective communication was key to change resistance. One member indicated that employees were very appreciative of her communicating changes during the FA. She stated that "they appreciated that they were being kept in the loop" and that "they were being given information." She explained, "In fact, several people said to me, 'it doesn't have to be good news as long as it's news'." 
In some cases, FA members discussed using a different language to communicate changes to employees. One member used "different language to explain what I was doing until I could interject the language of business." She further explained, "I would explain the goals of the study and the culture of the bureaucracy and government way of doing business...I would just translate things in another language."

\section{Summary}

This chapter presented the findings of the research study. Specifically, this chapter reviewed the story of major organizational change at the SCSS including life before, during and after the functionality assessment (FA).

The section, "Life Before the FA," presented the change team's main characters and provided their view of the FA. Aspects of a combined government and military organization were discussed. Comparisons were also made between the way a combined government and military organization works and the way private industry works.

Next, in the "Life During the FA" section, FA member's experiences were discussed. The section presented a review of: (a) significant events in the FA, (b) insider's views about the change process, (c) groups that played a major role in the FA, (d) the resistance factor, (e) change agent intervention strategies, and (f) organizational culture.

In the final section I presented FA member's reflections on "Life After the FA. This section included post reflections of the FA. The role of leadership and culture were discussed and briefly compared to the literature on the topic. Finally, I presented lessons learned in the FA. 


\section{Conclusion}

The findings of the study were based primarily on eight interviews of leaders with formal positional authority in the SCSS organization. In addition, secondary data analysis of documents, artifacts, participant observations, were used to triangulate the data and enrich the story. While this chapter provided the sort of details about the change process and people's perceptions of it that implicitly answer the questions posed at the outset of the study, these questions are explicitly addressed in the next chapter. 


\section{CHAPTER 5}

\section{SUMMARY AND CONCLUSIONS}

"We do not know what the world of tomorrow will really look like except that it will be different" (Schein, 1993).

In some ways, stories never end. They only provide reflections of who we are and what we aspire to change or leave unaltered in our lives. In large part, the real discovery of this research study may have been making conscious what might have largely been unconscious in the SCSS organization, the experiences of the participants, and of my own perceptions.

This chapter will provide a brief summary and an extended discussion of the findings reported in the previous chapter. It begins with a brief review of the purpose and methods. Then the findings will be summarized; the research questions articulated in Chapter 1 will be used to organize this summary. After the summary of findings is presented, the study's findings will be discussed and the methodology will be critiqued. Finally, I will discuss the implications that the study has for theorizing about culture change and resistance and I will make recommendations for practice, and suggestions for further research.

\section{Brief Review of the Problem}

The construct of organizational culture has been used to interpret various aspects of organizational life, including organizational leadership and organizational change. The literature indicates that leaders can influence organizational change by attending to and modifying an organization's cultural dimensions. Much of this literature, however, is 
theoretical and speculative, and the empirical work that does exist has focused mostly on business.

The purpose of this case study was to develop an understanding of how leaders in a combined government and military organization used the notion of culture during a two-and-a-half year planned change initiative. The study explored the strategies and mental constructs those in positions of formal authority used to make sense of and influence the change process. The particular focus was on identifying any cultureoriented change strategies leaders use to overcome resistance to change. The study also examined how organizational culture shaped and constrained leaders' actions.

This study employed qualitative methods. Interviews with designated leaders of the planned change initiative were the primary data collection method. Document analysis and participant observation were used to triangulate interview data.

Overview of the Research Methodology

As mentioned, this dissertation research used qualitative methods to study leaders' perceptions of organizational change resistance at a large combined military and government organization. For this study, I interviewed eight participants. Although interviewing was the major source of data in this study, other data sources (i.e., notes I took in my consultant role and documents related to the FA initiative) were used to triangulate interview findings.

A combination of two analysis approaches, which Polkinghorne (1995) refers to as the analysis of narrative and narrative analysis, were employed. The narrative analysis strategy was reflected in the use of chronology to organize many of the research findings. Within this general chronological structure, however, there was more traditional coding and categorization, i.e., Polkinhorne's analysis of narrative approach. 


\section{Review of the Major Findings in Terms of the Research Questions}

This summary of the findings is organized around the research questions that were articulated in Chapter 1 and answered implicitly in Chapter 4. Here, the implicit answers will be made explicit.

\section{Research Question \#1}

In what ways, if any, do the designated leaders of a large-scale planned change initiative use the construct of culture-either consciously or unconsciously_in thinking about and promoting change and, especially, in attempting to anticipate and respond to resistance to change.

The evidence suggests that most members of the FA leadership team used the construct of culture to think about organizational change. At times the use appeared to be conscious; at other times the culture construct appeared to influence thinking in a more unconscious manner.

Several members of the organization described how thinking in terms of culture was useful for understanding different perspectives in a mixed government and military organization. For instance, one FA leadership member stated, "The government culture does not look at things in a business like way. It's a bureaucracy." The lead of the FA team described applying her understanding of the SCSS culture-which was really a composite of three different cultures (i.e., military, government, and private sector) to anticipate resistance and encourage change in the organization. She recalled using experiences from her own "indoctrination into the military and government bureaucratic culture" to develop a "workable model that this group could understand, grasp and embrace." 
Other ways leaders on the FA team used culture during the change initiative are addressed in the following sub-research questions.

Sub-research question \#1a

What do designated leaders say about the role they played in a large-scale planned change initiative within a military and government-staffed organization?

FA members played various roles to actively promote change vertically (i.e., with those above and below them in the organizational hierarchy) and horizontally (i.e., with other organization leaders at comparable levels in other departments of the organization) during the FA change initiative. Team members used terms like "communicating change," "training employees," "confronting staff" and "educating leaders" to describe and discuss their various change roles. For instance, one person recalled, "The implementing, where we actually let people go and had to socialize and do everything...it was very much a leadership issue."

Interviewees also focused on their roles in terms of overall change effectiveness. In large part, members felt that the change role they played in the FA was not very effective (or at least did not have substantial impact at the time). This was attributed, at least in part, to resistance to change. For example, one person reflected on her role during the FA. She stated: "I had missed several opportunities in the building of the TO-BE to get incremental buy-in.... I had not been able to keep it from happening and intervene soon enough." Another woman recalled the letdowns of playing a change role during the FA. She stated, "I had to push and really do a lot of promoting [change]...While I was not successful, I certainly gave it a lot of energy and effort." 
Sub-research question \#1b

What culture-embedding mechanisms (e.g., language and mental schemas) and change strategies do designated leaders indicate they used to shape the organization culture in general and resistance in particular during the change process; to what extent do they themselves characterize these mechanisms and strategies in cultural terms?

Most members of the FA team acknowledged using varied change strategies to influence organizational change during the FA initiative. Several of these change strategies are discussed in Chapter 4 and include: communication, confrontation, consensus building, and other conscious and unconscious change strategies.

Once again, team members reported mixed effectiveness with these strategies. For example, although communication was a commonly used strategy to influence change, a few members explained that the change strategies used could have been more effective. One person recalled that a coordinated "communication plan" was needed to ensure that employees and leaders knew what was happening during the change process. She stated, "The fact that the COs were surprised...they were really never involved. There was never any real communication plan to get the customers involved." Once again, according to interviewees, the organization's culture and resistance from employees-but also from leaders at the top of the hierarchy where the change effort had initially been promotedwere factors in constraining the FA team members effectiveness. 
Sub-research question \#Ic

How are these mechanisms and strategies similar to or different from the various organizational culture and resistance constructs discussed in the literature?

For the most part, the mechanisms and strategies people used to influence culture change and resistance seemed to be consistent with the literature. For example, communication is often talked about in the literature as an important mechanism for organizational change (Jones, Aguirre, and Calderone 2004; Sternberg, 2002; Kotter, 1996; Argyris, 1993). Members of the FA team also agreed that "communication was key" and reported using various communication strategies (i.e., newsletters, e-mails, websites, and face-to-face meetings) during the change initiative. Several FA members described conducting numerous meetings with employees and leaders to increase awareness of and deal with organizational change issues. As one member stated, "I had several meetings with employees to try to keep them well informed."

Other change strategies and constructs were also talked about by the FA team leaders, however, these strategies appeared to be incomplete when compared to the change and culture literature. For example, Kotter (1996) suggests that change initiatives often fail because leaders ignore norms and values that could be considered the foundation of an organization's culture. He proposes using a multi-step change framework to systematically work through change. The FA team also used some of these same steps, for instance "building a case for change" and "communicating the change message," when conducting the FA initiative. However, the FA team appeared to omit some of the other critical steps that Kotter recommended, such as, "creating the guiding coalition" and "anchoring new approaches in the culture." In hindsight, the fact that some 
of these strategies were only partially followed, or even omitted, may help explain why participants felt the FA initiative had limited success.

Another way that the strategies and mechanisms used were connected to the literature was through politics. Several of the FA team members acknowledged how other leaders in the organization used their power to influence change in the FA study. This perspective is similar to Bowman and Deal's (1997) notion of using a political framework as a way to see and understand power, conflict and coalitions within in the organization (p. 163). In general, leaders in the SCSS organization used notions similar to Bowman and Deal's (1997) view of the political lens "to influence behavior, to change the course of events, to overcome resistance, and to get people to do things they would not otherwise do" (p. 165). In other words, the team members used political strategies to influence change in the organization. In fact, in this organization, the culture was a highly political one. This suggests that it may be helpful, at times, to amalgamate the sorts of frames Bowman and Deal talk about in their book. There will be more on this point below.

Research Question \#2

How does the existing culture appear to shape and constrain what leaders do to promote change and minimize resistance during a large-scale change effort?

FA members consistently referred to the existing SCSS organizational culture as a major factor that affected how leaders influenced change in the organization. As one team member put it, "I just thought [culture] limited what we could do in this environment. The scenario of the people during that period, I could tell pretty early that not much could come out of this [change initiative]. I mean the potential was grand." Other team 
members also described how the existing organizational culture shaped and constrained what leaders were able to do during the FA. The situation in this particular organization was made even more complicated by the fact that there were distinctly different organizational cultures operating in the composite organization.

Discussion and Interpretation of the Findings

There are a number of intriguing issues embedded in the findings that were just summarized and that were presented in more detail. Here, several of them will be discussed.

Blended Cultures - The Creation of a New Culture

Another interesting finding that came out of the study involved the various cultures that merged together and created a much more complex culture. Typically, culture is thought of as a single entity or construct (Schein, 1999; 1993; 1992; Detert, Schroeder, \& Mauriel, 2000; Senge, 1999; 1990; Bolman \& Deal, 1997). In this study, however, culture consisted of at least three distinct cultures, i.e., government, military, and private industry. A fourth culture, although not overtly discussed by participants, could be identified as the consultant culture. This blended view of culture is different from Schein's view that suggests a single leader drives culture (Schein 1992, p.5; 1993). According to Schein (1992), "culture creation and management are the essence of leadership" (p. 1). However, this varied view of culture may be more indicative of most organizational cultures. If this is, in fact, the case, it may be necessary for those who promote change initiatives to gain greater awareness of the various cultures at play in the organization, and to develop strategies that address the specific change issues related to those particular cultures. 


\section{Mixing Politics and Culture}

One of the perplexing issues that I faced during the study was when I tried to account for organizational culture. Although several of my research questions focused on how interviewees defined and thought about organizational culture, the construct took on various meanings and seemed to almost become a secondary theme in the research. I tried to understand why this was the case. In large part, when participants reflected on ways that culture influenced change in the FA, they associated culture with politics. In some ways, the various cultures and political structures intertwined in the SCSS organization; the culture, in short, was dominated by politics and political considerations. This amalgam of politics and culture, to a large extent, influenced and constrained the thinking and strategies leaders used to influence change resistance in the organization.

\section{Politics and Resistance to Change}

As discussed, the culture of the studied organization was highly political and powerful political groups often were the source of resistance to change. This was due, at least in part, to the mixture of various cultures and their competing objectives that, in turn, created an environment in which conflict was inevitable and power was a viewed as a key resource. For instance, often when FA members recommended a "new way of doing business" to military leaders they met with "push-back" (i.e., resistance). This was partly because the proposed idea had developed outside the military hierarchy and partly because of the threat that COs would loose power on their bases if they were perceived as closing down golf courses, bowling alleys or other services. The political culture of the organization often resulted in the military leaders trying to protect their existing power by constraining, blocking, or interfering with the FA initiative in order to keep things "status quo." 
This perspective highlights some of the hidden motives and agendas that leaders of the organization seemed to hold. Developing an awareness and understanding of the political framework of the organizational culture and the strategies to influence this framework may be a critical step for change agents. In retrospect, neither the consultants nor the "insiders' on the leadership team focused on this issue sufficiently. The Importance of (and Problems with) Cultural Awareness

The members of the leadership team who, arguably, were most effective were those who knew the culture of the organization well (including its rather definitive subcultures) and who also had had prior experience with change. Leaders who were familiar with the SCSS organizational culture relied on their prior experiences to make change decisions. They often were able to anticipate what needed to be done and seemed to know how to do it. For example, knowing the chain of command was essential to knowing who to talk to about particular issues and whose approval was required to do certain things. One FA member stated, "You have to follow the chain of command and don't push too hard on issues. If you disagree with something you can make it known but then back off."

On the other hand, this cultural awareness also at times hindered FA participants effectiveness. Having prior knowledge of the SCSS culture appeared to affect participants differently. Knowing what the organizational culture was like and what resistance would likely occur could become a self-fulfilling prophecy. One individual said that she was more assertive through the change process because she was new to the organization and did not really understand the culture. She explained, "In some respects, I maybe naively was willing to push harder for some change than maybe someone that had more experience or maybe would just be more conservative... within that environment." 


\section{Resistance From Two Directions}

One of the more interesting findings in the study involved the observation of resistance at the top of the organizational hierarchy, i.e., the level from which the change initiative had been promoted. Normally, resistance is conceptualized as something that occurs at the bottom rungs of an organizational hierarchy (Hatch 2000; Champy, 1997; Hammer 1997; Agocs 1997; and Kotter, 1996). In this initiative, in which middle managers were given considerable authority about what would be done to achieve goals mandated from the top, there was significant resistance coming from above as well as below. Both levels, in other words, were uncomfortable with the specific cultural change being implemented, and both levels attempted to minimize its impact.

Conceivably, as organizations increasingly attempt to provide both direction from the top and discretion at the grassroots level, the top-down resistance observed in this case may become more commonplace. If this is, indeed, the case, it may be necessary for those who promote change initiatives from the top to be more explicit about the degrees of freedom middle managers have and, then, to honor the commitments they have made once decisions are made at the middle management level. Resistance to change is difficult enough to overcome when it comes from one direction; it is exceedingly problematic when those who encouraged a change initiative in the first place work to undermine it.

Schein's (1992) view of culture is helpful to understand the type of upward and downward resistance experienced by FA team members. Schein, for instance, suggests that culture is made of up different levels. According to Schein (1992) basic underlying assumptions, i.e., the deepest level, are often "taken for granted" and "extremely difficult to change." Most members associated the difficulty of leading change in the organization, 
in large part, to trying to change how leaders thought about organizational change. One FA team member recalled, "When you are working with base COs they believe that the installation is 'their team' and they don't want to have to close anything or have to reduce hours of operation on 'their watch'." These underlying assumptions and beliefs, at least in part, help explain why FA members experienced "push-back" from different directions and why resistance to change is so difficult to mange.

Views of Gender, Power \& Resistance

The fact that the team was mostly staffed by women and that they met with considerable resistance from male-dominated components of the organization during the FA is important to reflect on. The challenges that woman face in organizations seemed to be even more pronounced in this predominantly male military organization. For example, in some interviews, women alluded to the difficulty of being heard during the FA. In other instances, a few women even described that they were viewed as being masculine if they pushed too hard for change. In general, these women associated these challenges with the fact that they were trying to influence high ranking military men who "just wouldn't change their minds." This view of change resistance in the FA may also have broader application. In some ways, the difficulties that women on the FA team faced reflects some of the same challenges that women and minorities face in other organizations. This suggests the need for those who lead change efforts to be aware of these power dynamics and ways they can be overcome. One final point: Interestingly, the head of the FA initiative, a woman who had what might be characterized as more masculine than feminine, discounted the role that gender played in generating resistance to implementing the plan that had been developed. 


\section{Views of Leadership and Culture}

Finally, several FA members also reflected on the role that leaders played in the FA initiative and also on the connection between leadership and culture. One team member stated, "Culture is in the environment and very much dictated by the leader." This notion of the leader's role in the creation and maintenance of organizational culture is consistent with Schein's (1993) thinking about leadership and culture (see Chapter 2).

As has already been alluded to, FA members also discussed the influence of those at the top of the hierarchy in inhibiting the change effort. In short, in this organization, at least, positional power mattered both within the unit undergoing change and in the larger organization.

Implications for Theory, Practice, and Further Research

\section{Implications for Theory}

The purpose of this dissertation was to contribute some empirical grounding to the theoretical literature of organizational culture construct by studying an outlier organization in which change is a constant. In some ways, the constantly changing environment of the government and military organization studied made the organizational change process both easier and more difficult to accomplish. On the one hand, the FA team utilized these opportunities. On the other hand, the changing organization made it more difficult to obtain support from leaders that were changing jobs or leaving the organization.

In some ways, the unique nature of the combined government and military organization seemed to have played a significant role in the change process. Most of the strategies used in private sector did not appear to be easily employed in the government and military organization studied. This may be due, at least in part, to the political nature 
of the organization. The literature indicates that the mechanisms typically employed in planned change initiatives, such as process reengineering, restructuring, and organizational transformation, are somewhat similar across different cultures (Sternberg, 2002; Levesque, Prochaska \& Prochaska, 1999; Strebel, 1996; Hammer, 1997). This study, however, suggests that what works in the private sector may not comfortably translate to the public sector, at least the public sector in which military culture plays a significant role. FA leadership team members certainly supported this perspective and indicated that planned change efforts in the SCSS organization should not be treated the same way as planned change efforts in the private sector.

To summarize, theory about planned change that glosses over contextual factors may be problematic. At least in this study, context and politics mattered and, consequently, context quite possibly should be given greater attention in theorizing about change and the phenomenon of resistance.

\section{Implications for Practice}

In addition to the theoretical implications outlined above, there are also implications for practice emerging from this study. This study, for example, sensitizes leaders in other organizations to think about organizational change from a complex cultural framework. Leaders that promote change initiatives are encouraged to think about the interaction of various subcultures and how each subculture is uniquely affected by change. This change relationship (i.e., interaction), particularly with the unique characteristics of a combined government/military organization, has important implication for leaders of organizational change.

Another implication for practice is related to the change process itself. Leaders that promote organizational change are typically focused on change and resistance from a 
top down perspective. Many of the change strategies endorsed in the literature and used by change leaders also suggest a downward focus on organizational change. This study highlights the need for change practitioners to be aware of the need for upward change as well as change strategies that are focused downward and across the organization.

Additionally, the politics in the organization created an organizational culture that made it more difficult for change agents to accomplish their assigned task. This suggests that the role of change agents needs to be expanded to identify and understand the underlying political framework that guides decision-making in an organizational change initiative. Change agents may need to employ particular strategies to influence those who have positional power in the organization. This study also suggests that different tactics and strategies may be required for woman, minorities, and other groups with limited authority/power that play this change agent role.

In summary, traditional views about culture and resistance may not be entirely accurate—or at least generalizable in various contexts. In this study, the interaction of different subcultures was an important variable for leaders of the FA change initiative. Also, the way that resistance to change emerged from leaders at the top of the organizational structure has particular implications for leaders of large-scale, planned, change initiatives and should be further examined.

\section{Implications for Further Research}

This study focused on only one organization and one change initiative team. As a result, it has a some unavoidable limitations common to single-case or " $n$ of 1 " studies. In time, it would be useful to have other case studies of different organizations that are undergoing a major organizational change initiative. The type of organization should also be expanded to include military, government, and private sector organizations. 
Ultimately, a cross-case analysis can be conducted using a grounded theory approach to culture, leadership and change using different settings and across multiple organizations.

Another implication for future research is related to the notion that organizational culture influences an organization's ability to change. For example, are some organizations better suited and able to change than others due to the culture of the organization? Sternberg (2002), for instance offers an interesting perspective of organizational change-modifiability. The primary premise is the culture of the organization needs to be modifiable to begin with in order to change. Further study in the area of modifiability and adaptability would provide greater insight into the change and culture phenomenon.

Additionally, future studies that explore the phenomenon of change should focus on organizational resilience (see, for instance, Linstead, 1997 and Jones, Aguirre, and Calderone, 2004). More recently, organizations are undergoing change efforts on a continuous basis, and in some cases, organizations are experiencing multiple change initiatives simultaneously (Rousseu \& Tijoriwala, 1999; Winum, Ryterband, \& Stephenson, 1997; Cummings, 1995; Burke, 1993). In this particular study, several interviewees mentioned the difficulty of managing multiple change efforts. Further research would be useful to understand the impact of continuous and multiple change initiatives and may be helpful for those who are in change leadership roles.

Other studies could be conducted at other organizations that examine the different impacts of change both during and after a major change initiative. In the case of the SCSS organization, it was clear that post-reflection on a two-year long change initiative had particular advantages and disadvantages. One the one hand, having some time elapse after the FA initiative was useful for members of the change team to reflect on their 
experiences. On the other hand, particular observations and insights specific to how members felt during the change process may have been reported differently by participants. Additionally, a longitudinal study might provide further understanding about the leaders' views about change and culture. A change study focused on sustainability might also reveal whether the effort resulted in changes to the underlying assumptions of the organization's culture and were impacting in the long-run.

Finally, future case studies should look at the role of woman, minorities, and consultants that perform a change agent role in the organization. More research is needed to understand the different perspectives and strategies employed in change initiatives across various organizational cultures.

In summary, additional research is needed to study the phenomenon of organizational change. Various research designs in different organizational settings should be explored to more fully understand the complex nature of organizational culture and change.

\section{Methodological Reflection}

As discussed in Chapter 3, a combination of two analysis approaches, which Polkinghorne (1995) refers to as the analysis of narrative and narrative analysis, were employed. The narrative analysis strategy was reflected in the use of chronology to organize many of the research findings. Within this general chronological structure, however, there was more traditional coding and categorization, i.e., Polkinhorne's analysis of narrative approach. Although both approaches were used throughout my research, I primarily employed the analysis of narrative approach.

Initially, I gained interest in Polkinghorne's two approaches after seeking guidance from my committee chair. Additionally, I had consulted a dissertation by Brian 
Matthews (2004) and learned about the hybrid approach used in his research methodology. Although our approaches were similar, Brian's emphasis was on narrative analysis vs. analysis of narrative.

Overall, this hybrid approach (i.e., analysis of narrative and narrative analysis) was helpful to make sense of and display the data I had collected. The narrative analysis approach provided a way to chronology key events, and therefore add additional context to the underlying story of FA initiative. Additionally, this approach allowed me to use the two timelines to think about and make sense of participants' experiences. Polkinghorne's analysis of narratives approach was also useful to analyze data and develop descriptions of themes across participant stories. This approach provided a systematic way to organize interview responses and categorize data across various themes while still allowing flexibility to identify and develop emergent themes.

Another aspect of my research methodology related to my role as a researcher. As alluded to earlier in Chapter 3, in this study, I conducted backyard research and played the role of a researcher as a participant observer. In other words, I was an active member in the FA change process that was studied. The difference between this study and most participant observer studies, however, was that I approached my consultant role and researcher role sequentially. During the FA, I participated and viewed the change initiative as a consultant. I conducted analysis, made recommendations and implemented changes as part of my role as a hired consultant for the organization. Later on, I put on my researcher's hat and looked back on the FA from a different perspective. I relied on my notes, observations, documents and reflections as a researcher to try to make sense of the data I had gathered, reviewed, analyzed and presented and the notes I had taken in my consultant role. 
In some ways, this separation between my role as a consultant and researcher was helpful to objectively look at the data and the findings that emerged from this change story. From this perspective, the analysis of narrative approach was particularly useful for exploring the complex nature of culture and the phenomenon of change. On the other hand, at times I felt removed from how I personally experienced the FA change effort, both as a practitioner and as a researcher. My emphasis on using the analysis of narrative approach may have also led me to artificially categorize some interview responses and distance my own personal reflections in ways that I might not of done had I followed a more traditional story-telling approach. In this last section, I discuss some of these personal reflections and observations in more detail.

\section{Personal Reflections}

As alluded to earlier, because this was backyard research, I intentionally tried to remove myself from this change story. I did this to highlight the primary actresses and their experiences in this story, as well as to minimize my bias in my role of researcher as a participant observer. This was my aim up to now, but clearly, my experiences and my role in the FA change initiative is an important part in this story. Therefore, at this point, I want to tell—albeit briefly—a more personal story about the FA process.

In many ways, the role of a consultant is not glamorous. Often we are asked to help an organization make significant change; usually this must be done under stressful circumstances. This often means working long hours and late nights to analyze data and provide recommendations within tight deadlines that often result in little recognition. Additionally, consultants are frequently seen as the "bad guys" or "bearers of bad news" who are trying to change the organization. Frequently, I felt this description matched my own experiences in the FA. 
Often during the FA, I felt like our team were hired hands (which, of course, we literally were). One reason that this status had a negative valance was that we were seen as dispensable by leadership. This generally created a tenuous relationship between our team and the leaders who hired us. On the one hand, we were hired to provide objective advice. One the other hand, the advice at times was painful and difficult for the leaders to hear. Since we knew our contract could be terminated, this sometimes made it difficult to say what we really felt to avoid adversely impacting our relationships or future business opportunities.

The role of the consultant also meant that we were hired to do the organization's dirty work. This included making—and, in a sense, "owning"-some unpopular recommendations, such as recommendations to cut back resources and staff to achieve particular organizational goals. As I reflect on Heifetz's (1994) perspective of leadership and change, it seems in some ways that the leaders in the organization hired consultants to do their adaptive work (i.e., the work that involves making hard choices and choosing between conflicting criteria) for them. At least two repercussions seem to result from this action. One is that the organization can easily reject the recommendations that the consultants make. Another is that the consultants can become the scapegoats when things aren't going as expected. In both cases, the organization avoids the adaptive work that Heifetz suggests is crucial for growing and learning organizations.

In several ways, the consultant culture also affected the role I played during the FA. For example, my company supported the view that the client was always right. While this attitude was aimed at promoting client satisfaction and maintaining positive relationships, it sometimes resulted in constraining the advice and decisions that would otherwise be made. 
In summary, I felt that consultant culture influenced the role I played in the change process and had a significant impact on the way that I viewed the FA and interpreted this research study. Additionally, I also have come to appreciate the delicate balancing act that doing backyard research requires. The fact that I put on the researcher hat only after I had played an active participant role, in some ways, made it easier to negotiate the different roles that one must play when doing backyard research. On the other hand, my attempts to be as objective as I could be and keep my contributions to the process carefully bracketed and in the distance, certainly skewed the story that was told here.

\section{Summary}

This dissertation presented findings from a study about leaders' perceptions of organizational culture at a combined government and military organization. Chapter 1 provided the background to the dissertation topic, the statement of the problem, the purpose of the study, and a discussion of the importance of studying leadership, culture and change. In addition, the research questions were articulated. Finally, the significance and limitations of the dissertation were discussed.

Chapter 2 reviewed the relevant literature in the field of organizational change, culture, and leadership. This literature review laid the foundation for the study. Chapter 3 outlined, in detail, the methodological procedures that guided the research process for this study.

Chapter 4 presented the findings of the dissertation through a analysis of narrative framework that also, at times, incorporated elements of narrative analysis. Finally, Chapter 5 summarized the dissertation and provided succinct direct answers to the research questions. This chapter also discussed implications for theorizing about 
organizational culture, implications for practice, as well as recommendations for future inquiry. Methodological insights-especially insights related to Polkinghorne's analysis of narratives and narrative analysis distinction-also were discussed in this final chapter.

The overall results in this dissertation study - that were implicit in Chapter 4 and made explicit in this Chapter, include: (a) the construct of culture had been part of the leaders conscious and unconscious framework for most, but not all, members of the FA team; (b) those who used the construct attached somewhat different, although not completely inconsistent, meanings to the term; (c) those interviewed identified various mechanisms and strategies used in FA change initiative; (d) the change mechanisms used by FA leaders appear to be similar, although somewhat incomplete, to those used in the literature; and (e) most team members interviewed described being constrained in various ways by the existing culture despite the change strategies used. In most situations and especially during implementation, interviewees suggested "push back" and resistance to change had more to do with the culture of the military and civilian organization than with the adequacy of the mechanisms and change strategies themselves. 


\section{References}

Agocs, C. (June 1997). Institutionalized resistance to organizational change: denial, inaction and repression. Journal of Business Ethics 16, 917-931.

Akin, G. \& Palmer, I. (2000). Putting metaphors to work for change in organizations. Organizational Dynamics, 28 (3). 67-79.

Argyris, C. \& Schon, D. (1974). Theory in practice: increasing professional effectiveness. San Francisco: Jossey-Bass.

Argyris, C. (1990). The next challenge. In F. Hesselbein, M. Goldsmith, \& R. Beckhard (Eds.), The organization of the future (pp. 367-376). San Francisco: Jossey Bass

Argyris, C. (1993). Knowledge for action: A guide to overcoming barriers to organizational change. San Francisco: Jossey-Bass. Publishers.

Bowman, L. G. \& Deal, T. E. (1997). Reframing organizations: artistry, choice and leadership. San Francisco: Jossey-Bass.

Burke, W. W. (1993, Winter). The changing world of organization change. Consulting Psychology Journal, 45, 1, 9-17.

Burns, J. M. (1978). Leadership. New York: Harper Row.

Champy, J. A. (1997). Preparing for organizational change. In F. Hesselbein, M. Goldsmith, \& R. Beckhard (Eds.), The organization of the future. San Francisco: Jossey Bass Publishers, 9-16.

Conger, J.A., Spreitzer, G. M., \& Edward E. L. III. (Eds.). (1999). The leader's change handbook: An essential guide to setting direction and taking action. San Francisco: Jossey-Bass.

Cook, S. D. \& Yanow, D. (2001). Culture and organizational learning. In Shafritz, J. M. \& Ott, J. S. Fifth Eds., Classics of organization theory. Fort Worth. Harcourt College Publishers (p. 400-424).

Covey, S. R. (1989). The seven habits of highly effective people. New York: Simon \& Schuster. Cypress, H. L., Reengineering. (February 1994). OR/MS Today, 21.

Cummings; T. G. (1995, Winter). From programmed change to self design: Learning how to change organizations. Organization Development Journal, 13 (4), 20-31. 
Deal, T.E. \& Kennedy, A.A. (1982). Corporate cultures: The rites and rituals of corporate life. Reading, MA: Addison Wesley.

Dennison, D. R. (1996). What is the difference between organizational culture and organizational climate? A native's point of view on a decade of paradigm wars [Electronic version]. Academy of Management Review, 21 (3), 619-645.

Dess, G. G. \& Picken, J. C. (2000). Changing roles: leadership in the $21^{\text {st }}$ century. Organizational Dynamics, Vol 28 (3), 18-34.

Detert, J. R., Schroeder, R. G., \& Mauriel, J. J. (2000). A framework for linking culture and improvement initiatives in organizations. Academy of Management Review, 4, 850-863.

Donmoyer, R. (1990). Generalizability and the single-case study. In E. Eisner and A Peshkin (Eds.), Qualitative research in education: The debate continues (pp. 175-200). New York: Teachers College Press.

Jones, J., Staub, C, \& Powers, E. (2004). Four antidotes to change resistance. Booz Allen Hamiliton Strategy + Business. http://www.strategy-business.com/article /14114.

Fairholm, Gilbert, W. (1995). Leadership: a function of interactive trust. The journal of leadership studies, 2 (2), 9-19.

Ferch, S. R. (2004). Servant-leadership, forgiveness, and social justice. In Spears, L. C. and Lawerence, M. Ed., Practicing servant leadership: succeeding through trust, bravery, and forgiveness. San Francisco. Jossey-Bass. 225-240.

Freedman, A. M. (1997). The undiscussable sides of implementing transformational change. Consulting Psychology Journal, 49 (1), 57-76.

Fullan, M. (1993). Change forces: Probing the depths of educational reform. London: Falmer Press.

Fullan, M. (2001). Leading in a culture of change. San Francisco: Jossey-Bass.

Gagliardi, P. (1986). The creation and change of organizational cultures: $A$ conceptual framework. Organization Studies, 7, 117-34.

Galpin, T. (March 1996). Connecting culture to organizational change. Human Resources Magazine, 41 (3), 84-90.

Glesne, C. (1999). Becoming qualitative researchers: An introduction. New York: Longman. 
Goleman, D., Boyatzis, R., \& McKee, A. (2002). Primal leadership: The hidden driver of great performance. Boston: Harvard Business Press.

Goodstein, L. D. \& Burke, W. W. (1991, Spring). Creating successful organization change. Organizational Dynamics, p. 5-17.

Gore, A. (1993). Creating a government that works better \& costs less: Report of the national performance review. In Shafritz, J. M. \& Ott, J. S. Fifth Eds., Classics of organization theory. Fort Worth. Harcourt College Publishers, 460-468.

Greenleaf, A. (1970). Servant leadership. New York. Paulist Press.

Hammer, M. (1997). The soul of the new organization. In F. Hesselbein, M. Goldsmith, \& R. Beckhard (Eds.), The organization of the future. San Francisco: Jossey Bass Publishers, 25-32.

Hammer, M., and Champy, J. (1993). Reengineering the corporation: a manifesto for business revolution. New York: Harper Collins.

Hammer, M., and Champy, J. (1993). Reengineering the corporation: the enabling role of information technology. In Shafritz, J. M. \& Ott, J. S. Fifth Eds., Classics of organization theory. Fort Worth. Harcourt College Publishers (p. 490-498).

Hatch, M. J. (1997). Organization theory: Modern, symbolic and postmodern perspectives. Oxford, England: Oxford University Press.

Hatch, M. J. (2000). The cultural dynamics of organizational change. In N. M. Ashkanasy, C. P. M. Wilderom, \& M. F. Peterson (Eds.), Handbook of organizational culture and climate. Thousand Oaks, CA: Sage Publications, 245-261.

Heifetz, R. A. (1994). Leadership without easy answers. Harvard University Press: Cambridge, Massachusetts.

Herscovitch, L. \& Meyer, J. P. (2002). Commitment to organizational change: Extension of a three-component model. Journal of Applied Psychology, 87 (3), 474-487.

Hofstede, G. (1991). Cultures and organizations. McGraw-Hill Book Company.

Hofstede, G. (1994). Uncommon sense about organizations: Case studies, and field observations. Thousand Oaks, CA: Sage Publications. 
Holman, T. R. (1999). Reinventing Government. Consulting psychology journal 45 (1), 25-26.

Horner, M. (1997). Leadership theory: Past, present and future. Team Performance Management, 3 (4), 270-287.

Hughes, J. (2000). Avoidance of emotional pain during downsizing in a public agency. Consulting Psychology Journal, 52, (4), 256-268.

Katz, D. \& Kahn, R. L. (1966). Organizations and the system concept. In Shafritz, J. M. \& Ott, J. S. Fifth Eds., Classics of organization theory. Fort Worth. Harcourt College Publishers (p. 257-267).

Koethlisberger, F. J. (1941). The hawthorne experiments. Classics of organization theory. Fort Worth. Harcourt College Publishers, 158-166.

Kotter, J. P. (1991). What Leaders Really Do. In Gabarro, J. G. Ed., Managing people and organizations. Boston, Massachusetts: Harvard business school publications (p. 102-114).

Kotter, J. P. (March-April 1995). Leading change: why transformation efforts fail. Harvard Business Review, 73 (2), 59-67.

Kotter, J. P. (1996). Leading change. Boston, Massachusetts: Harvard Business School Press.

Kotter, J. P. \& Schlesinger, L. A. (1992) Choosing strategies for change. In Gabarro, J. G. Ed., Managing people and organizations. Boston, Massachusetts: Harvard business school publications (p. 395-409).

Lakomski, G. (2001). Organizational change, leadership, and learning: Culture as a cognitive process. International Journal of Educational Management, 15 (2), 68-77.

Leonard, H.S. (2003). Leadership development for the postindustrial modern information age. Consulting Psychology Journal, 55 (1), 3-14.

Levesque, D. A., Prochaska \& Prochaska, J. O. (1999). Stages of change and integrated service delivery. Consultaning Psychology Journal, 51 (4), 226241 .

Lewin, K. (1951). Field theory in social sciences. New York. Harper \& Row.

Linstead, S. (1997). Resistance and return: Power, command and change management. Studies In Cultures, Organizations, And Societies, 3, 67-89. 
Martin, J. (1992). Cultures in organizations: Three perspectives. New York: Oxford University Press.

Matthews, B. (2004). Leaders' influence on school reculturing: A case study of an international school (Doctoral dissertation, University of San Diego, 2004). Dissertation Abstracts International, 61, 1200.

Mattison, S. (1988). Why triangulate? Educational Researcher, 17 (2), 13-17.

Mayo, G. E. (1993). The human problems of an industrial civilization. Boston, MA: Harvard Business School, Division of Research.

McGregor, D. M. (1960). The human side of enterprise. NY: McGraw-Hill.

Merriam, S. B. (1998). Qualitative research and case study application in education. Jossey-Bass Inc, San Francisco.

Michela, J. L., \& Burke, W. W. (2000). Organizational culture and climate in transformations for quality and innovation. In N. M. Ashkanasy, C. P. M.

Miles, M., \& Huberman, M. (1984). Drawing valid meaning from qualitative data. Educational Researcher, 13, 20-30.

Murray, W. (1999). Does military culture matter? Orbis 43, 27-42.

Northouse, Peter. G. (2004). Leadership: theory and practice (3rd ed.). Thousand Oaks, California. Sage Publications, Inc.

Oreg, S. (2003). Resistance to change: developing an individual differences measure. Journal of Applied Psychology, 88 (4), 680-693.

Osborne, D., \& Gaelber, T. (1992). Reinventing government: how the entrepreneurial spirit is transforming the public sector. Reading, MA: Addison-Wesley.

Ouchi, W.G., (1981). The zs organization. In Shafritz, J. M. \& Ott, J. S. Fifth Eds., Classics of organization theory. Fort

Patton, M.Q. (2002). Qualitative evaluation and research methods. Newbury Park, CA: Sage Publications.

Peshkin, A. (1988). In search of subjectivity-one's own. Education Researcher, 17 (7), 17-21.

Peters, T. J. \& Waterman, R. H. (1982). In search of excellence: lessons from america's best-run companies. New York. Harper \& Row. 
Peters, T. J. \& Waterman, R. H. (1982). In search of excellence: simultaneous loosetight properties. In Shafritz, J. M. \& Ott, J. S. Fifth Eds., Classics of organization theory. Fort Worth. Harcourt College Publishers (p. 446-450).

Polkinghorne, D. E. (1995). Narrative configuration in qualitative analysis. Qualitative Studies in Education, 8 (1), 5-23.

Ridgway, K. A. (2001). Leadership practices, cultural values, and organizational performance. Performance Improvement Quarterly, 14(1), 77-95.

Rosen, R. H. (1997). Learning to lead. In F. Hesselbein, M. Goldsmith, \& R. Beckhard (Eds.), The organization of the future (pp. 303-312). San Francisco: Jossey Bass Publishers.

Rost, J. C . (1993). Leadership for the twenty-first century. Praeger Publishers, Westport CT.

Rousseau, D. M. (1990). Assessing organizational culture: the case for multiple methods. In B. Schneider (Ed.), Organizational climate and culture. San Francisco: Jossey-Bass. 153-192.

Rousseau, D. M. \& Tijoriwala, S. A. (1999). What's a good reason to change? Motivated reasoning and social accounts in promoting organizational change. 84 (4), 514-528.

Ruvolo, C. M. and Bullis, R. C. (2003). Essentials of culture change: lessons learned the hard way. Consulting Psychology Journal: Practice and Research, 55, (3) 155-168.

Sarason, S. (1996). Revisiting "the culture of the school and the problem of change." New York: Teachers College Press.

Schein, E. H. (1992). Organizational culture and leadership. Jossey-Bass, San Francisco. 2nd Edition.

Schein, E. H. (1993). Defining organizational culture. In Shafritz, J. M. \& Ott, J. S. Fifth Eds., Classics of organization theory. Fort Worth. Harcourt College Publishers, 369- 376.

Schein, E. H. (1996). Culture: The concept missing in organization studies [Electronic version]. Administrative Science Quarterly, 41 (2), 229-241.

Schein, E. H. (1999). How to set the stage for a change in organizational culture.

Schein, E. H. (2000). Sense and nonsense about culture and climate. In N. M. 
Schneider, B., \& Bartlett, J. (1968). Individual differences and organizational climate I: the research plan and questionnaire development. Personal Psychology, 21, 323-333.

Schneider, B., \& Bartlett, J. (1970). Individual difference and organizational climate II: Measurement of organizational climate by multitrait-multirater matrix. Personal Psychology, 23, 493-512.

Schneider, B. (1990). Organizational climate and culture. San Francisco: JosseyBass.

Senge, P. M. (1990). The fifth discipline. New York: Currency Books.

Senge, P. M. (1999). The dance of change. Doubleday. New York, New York.

Sims, R. R. (2000). Changing an organization's culture under new leadership [Electronic version]. Journal of Business Ethics 25 (1), 65-78.

Spradley, J. P. (1979). The ethnographic interview. Harcourt Brace Jovanovich College Publishers.

Sternberg, R. J. (2002). Effecting organizational change: A "mineralogical" theory of organizational modifiability. Consulting Psychology Journal: Practice and Research, 54 (3), 147-156.

Strebel, P. (May-June 1996). Why do employees resist change? Harvard Business Review. Cambridge, Massachusetts.

Tichy, N. and Devanna, M. A. (1986). The transformational leader. New York: Wiley \& Sons.

Trice, H. M., \& Beyer, J. M. (1991). Cultural leadership in organizations [Electronic version]. Organization Science, 2 (2), 149-169.

Trice, H. M. \& Beyer J. M. (1993). Changing organizational cultures. In Shafritz, J. M. \& Ott, J. S. Fifth Eds., Classics of organization theory. Fort Worth. Harcourt College Publishers, 414-424.

Van Mannen, J. (1988). Tales of the field: On writing ethnography. Chicago: University of Chicago Press.

Van Mannen, J. (1990). Researching lived experience: Human science for an action sensitive pedagogy. State University of New York Press. Albany, N.Y. 
Varney, G. H. (1996). Organization development and change. In Craig, R. L., Fourth Eds., The ASTD training and development handbook. McGraw-Hill, 601-621.

Winum, P., Ryterband, E., \& Stephenson, P. (1997). Helping organizations change: a model for guiding consultation. Consulting Psychology 49 (1); 6-16.

Worren, N. A. M., Ruddle, K., \& Moore, K. (1999). From organizational development to change management: the emergence of a new profession. The Journal of Applied Behavior Science, 35, 3, 273-286. 
Appendix A

Preliminary Study Interview Questions 
Preliminary Study Interview Questions

- Tell me about your role as a Program Lead/FA Team Lead during the FA Study?

- Describe your experience of the FA Study?

- What was the actual process of change like from your perspective?

- What do you do to minimize change resistance? Maximize change acceptance/openness? (Are these the same behaviors/actions?)

- In what ways did you see the organization support/accept or resist change during the FA? 
Appendix B

Interview Guide 


\section{Interview Guide}

Note: The following questions will be used heuristically to guide, rather than direct, the conversation.

- Personal Information/Background \& Demographics: (Obtain before interview if possible)

- Personal Information:
- Name:
o Title:
- Years in Organization:
- Years in Current Position:
- Prior Work Experience:
- Gender:

- Can you please draw for me a timeline from the time that you were born until now and mark key moments in your life?

- Can you please tell me about each of these points.

Organization Context/Background:

- How would you describe what life is like in this organization to someone that wasn't familiar with your organization?

- Can you tell me how this organization is similar or different than others that you have worked in?

- This organization is unique in that it is a combined military and government-staffed organization. How would you describe this kind of organization to someone who is has never been associated with a military and government-staffed organization?

- What are things a person needs to know in order to be successful in this organization? How would you stay out of trouble?

General Questions About the FA Initiative:

- What are some things people would say about the FA effort now? Would what they say now be different that what they would have said during the change process? Did what you told me represent all the different views of the FA effort then and now? If not, what might some of these different views be?

- What are things people would see here in the organization now (as a result of the FA) that they wouldn't have seen before?

- What are things you would hear people say about the organization as a result of the FA change effort that they wouldn't have said before?

Change Initiative Timeline:

- Can you please draw for me a timeline from the start of the Functionality Assessment change initiative to the end and mark significant events that occurred? 
- Please describe the significant events marked on the timeline and describe why you marked them [participants will be asked to point out times they specifically intervened in the FA change process and how].

Influential Individuals/Groups:

- Can you please point to times on the timeline [or additional points on the timeline] when you specifically intervened in the FA change effort and tell me what you did during these interventions?

- Are there any other individuals/groups that aren't represented on the timeline that are important in the change process? If so, can you tell me about them and their actions?

- Our company helped with change, did that impact you in anyway [or in any other ways]? Please describe.

Opposition from Individuals/Groups (Resistance Factors):

- I've noticed that you haven't said anything about people "fighting back" (resisting change) on your timeline? Did you experience any resistance? Can you talk about times when you experienced push back (or observed it with others)? [Or can you tell me about any additional times when you experienced push back]?

- What specifically stands out in your mind about an event where you experienced resistance in the FA? Can you please describe what this was and if you did anything or observed others doing something about this?

- Can you think of anytime specifically where you tried to influence individuals/groups that tried to oppose the FA change process? What did you do? What were you thinking when you took this action? Was this a routine [automatic] action for you or did you specifically think about and plan what you were going to do? What were the results-what happened?

Factors that Influenced the Change Effort (Culture):

- You've talked in terms of "culture"-where did you pick this up? Can you think of how you were introduced to this term? What does it mean to you? In what specific [or other] ways did the notion of organizational culture impact your thinking and actions during the FA change effort?

(OR)

- Some literature on organizational change mentions needing to attend to the organizational "culture" during change effort? Are you familiar with the term organizational culture?

o If yes: What does this term mean to you? Do you remember how you became familiar with the term? I was wondering if you thought in cultural terms at any point during the FA change effort. If so, can you describe your thinking and how your thinking influenced your actions? $[O r$, were the things that you thought about during the FA change effort, in retrospect, in any way consistent with the notion of organizational culture?] 
- If no: [Supply the definition of organizational culture]. Were the things that you thought about during the FA change effort, in retrospect, in any way consistent with the notion of organizational culture? If so, can you describe your thinking and how your thinking influenced your actions?

\section{Final Question}

- Is there anyone else in this organization that I can interview that would have a much different view of the FA change effort than what you've described? 


\section{Appendix C}

\section{Life Timeline}


Life Timeline

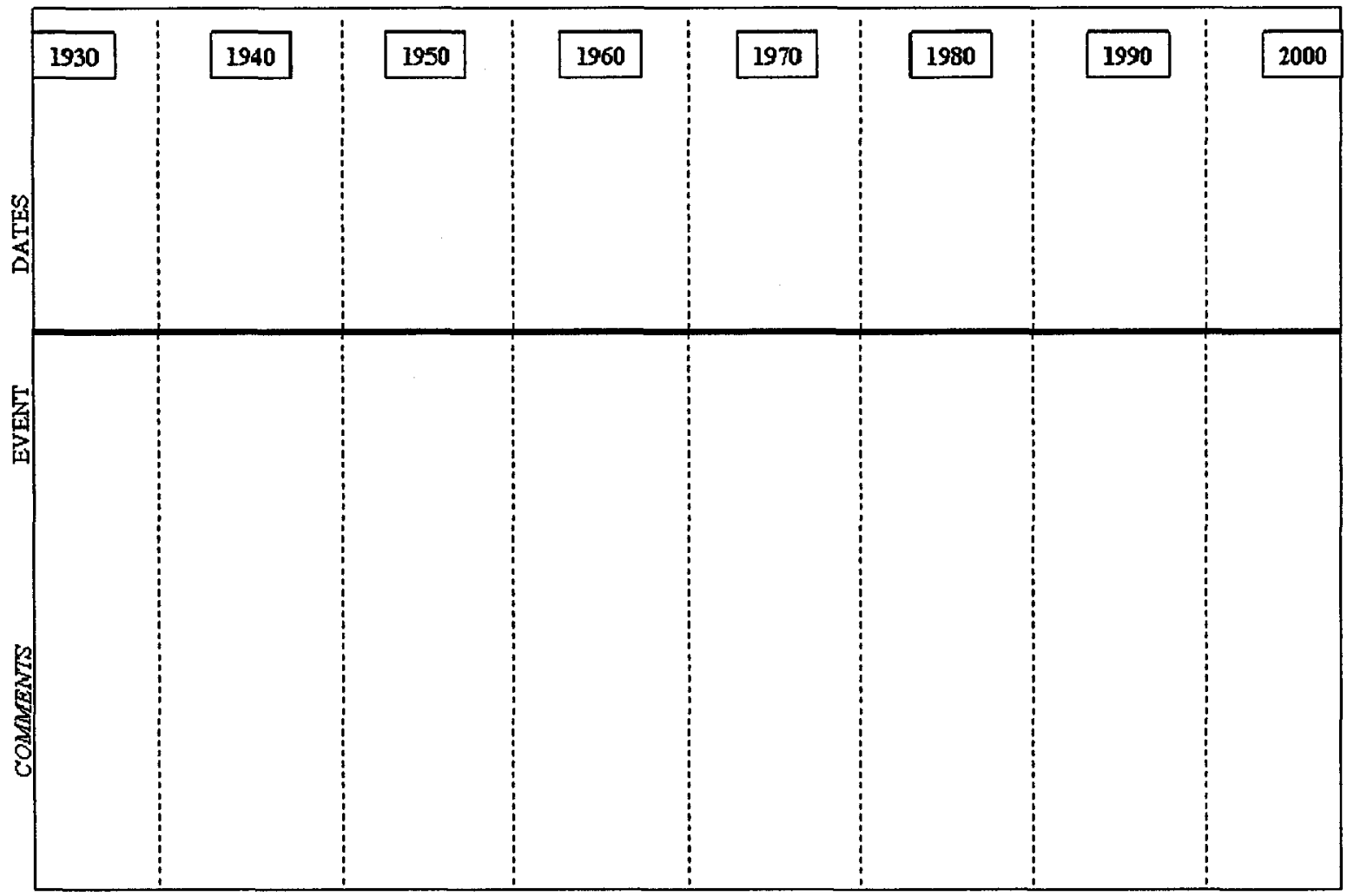




\section{Appendix D}

Functionality Assessment Timeline 
Functionality Assessment Timeline (Blank)

Functionality Assessment Timeline

\begin{tabular}{|l|l|l|l|l|}
\hline 1999 & 2000 & 2001 & & 2002 \\
\hline \\
\hline
\end{tabular}


Functionality Assessment Timeline (Reference)

FA Dates: September 25, 2000-March 25, 2000

FA Implement. Ext:: March 26. 2302 - June. 2602

FA Metries Ext: Narch 25, 2002 - June, 2002

Functionality Assessment Timeline

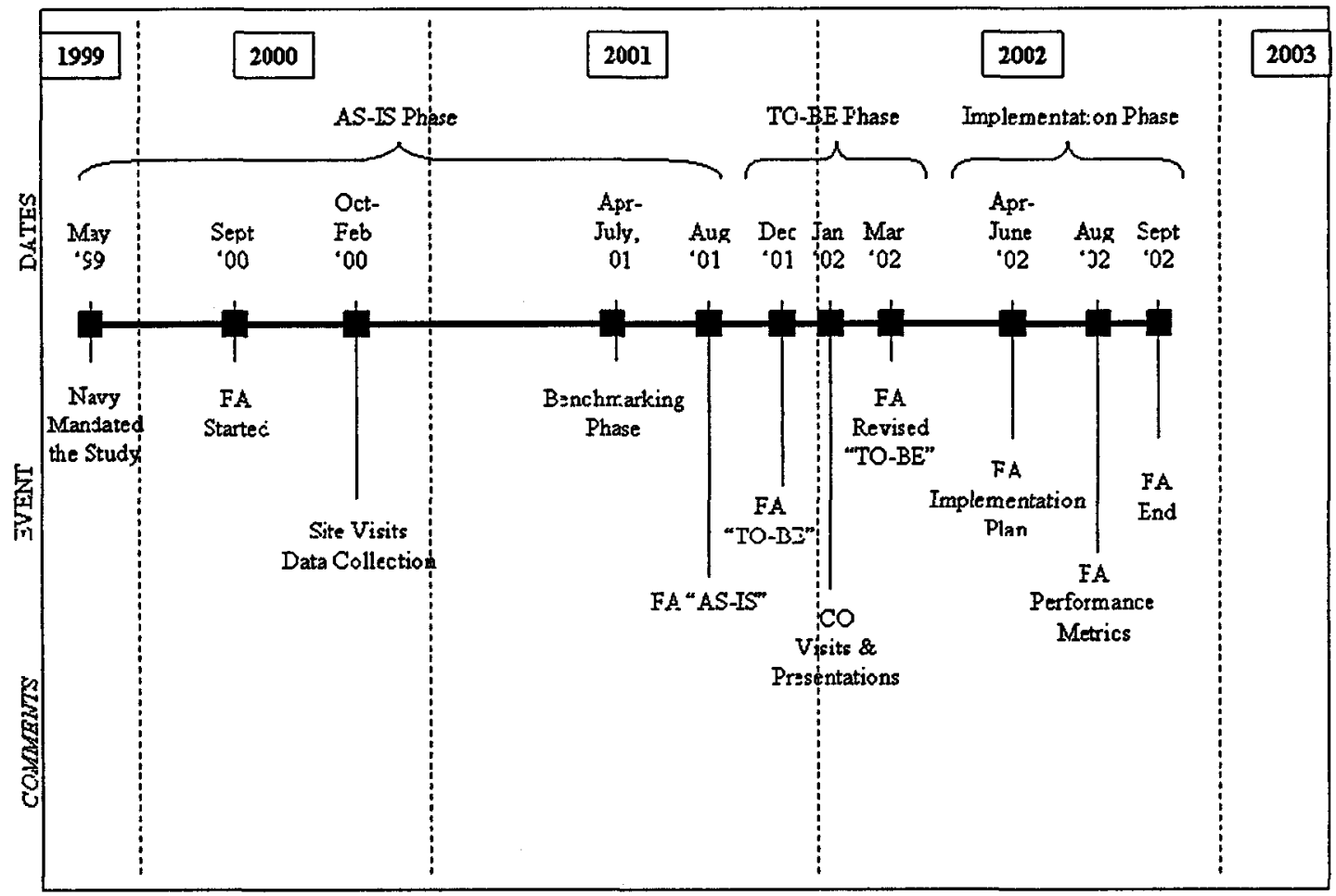


Appendix E

Preliminary (Pilot) Research Study Permission Letter 


\section{Preliminary (Pilot) Research Study Permission Letter}

Captain Avila

Assistant Chief of Staff for Community Support Services

Commander Navy Region Southwest

San Diego, CA

February 28, 2003

Captain Avila,

Background:

As a former consultant with your organization during the FA project, I would like to request your permission to conduct a pilot study with the Support Services organization. The purpose of this pilot study is to conduct empirical research on leadership and the organizational change process. The pilot research study would help fulfill partial requirements in the course: Advanced Qualitative Research in the Leadership Studies doctoral program at the University of San Diego.

I think your organization would make a very good environment for observing the study in which I am interested. During the Navy's FA Study, I was able to interact extensively with staff and gain first-hand experience with the Navy's Support Services operations. For this study I am interested in learning how leaders respond and relate to the change process during a large-scale, organizational change initiative (e.g., the Functionality Assessment).

Methodology:

This study will be conducted using a qualitative method, with myself as the primary researcher. Two members from the FA leadership team will be selected for an interview. Selection will be based on your staff member's availability and willingness to participate. The interviews will be conducted on-site and will take approximately one hour to complete. The interviewee will be informed about the nature of the interview and purpose of the study prior to the interview. Documents and observation notes collected during the FA Study may be used to help supplement interview data and general observations pertaining to the research. The study will be conducted during the month of March 2003 and will focus on San Diego metro installations: Naval Station, San Diego; Naval Amphibious Base, Coronado; and Point Loma. Data collection and findings from the research will be kept strictly confidential and will only be used in a class presentation and research report.

If you have any questions pertaining the nature of this study or intended use or purpose, please contact me.

Sincerely,

Derek Noether 
Appendix F

Research Study Permission Letter 
Research Study Permission Letter

\author{
Captain Avila \\ Assistant Chief of Staff for Community Support Services \\ Commander Navy Region Southwest \\ San Diego, CA
}

February 10, 2004

Captain Avila,

Approximately one year ago, you gave me permission to conduct a preliminary research study with the Community Support Services organization. This research study allowed me to collect some initial data about organizational culture and leadership. These data helped me refine my research interests and focus. I am now ready to begin my dissertation work and would very much like to conduct this research in your organization.

I have selected your organization as my preferred study site because of the understanding I have of it. This understanding is partially the result of the research study I conducted last year; my work as a consultant with the FA project in your organization also provided additional understanding and background. My experience as an FA consultant also helped me develop the sort of rapport with people in your organization that is required to effectively execute the study I am planning. Consequently, I am requesting your permission to conduct a dissertation study with the Support Services organization.

The study will examine how leaders used the notion of culture to manage resistance during the earlier change process. Interviewing would be the primary method of gathering data. Interviews with the six members of the leadership team that managed the change process would be conducted. These interviews would last no longer than one hour each and would be conducted in a way and at a time so they did not interfere with the work the individuals were currently doing in the organization. In addition, up to six additional interviews could be conducted if any of the original six interviewees identify additional employees who are likely to have a different view of the change process than members of the leadership team have. Once again, interviews will be arranged so as not to interfere with interviewees current work responsibilities. In all instances, participation in interviews will be voluntary. On occasion, there may be a need to contact an interviewee to clarify a point that is less than clear, but these follow-up contacts normally will be in the form of brief telephone calls or email messages.

Participation in the study will be completely voluntary. Potential interviewees will be invited to participate in the study, in other words, but will be told that they have the option of declining the invitation. My experience in the past suggests that most 
people welcome the opportunity to talk about-and, in the process of talking, reflect upon-their work.

I very much appreciated the opportunity to study your organization in the past. I hope you will be able to give me permission to continue this work in the next stage of my research. The insights that this research should produce hopefully will be useful to all of us who work in organizations and, on occasion, must lead and manage large-scale change efforts.

If you have any questions, please contact me either by telephone (619.725.6797) or email (noether derek@bah.com). You should also feel free to contact my dissertation advisor at the University of San Diego, Robert Donmoyer (619.260.7445 or donmoyer@sandiego.edu).

Sincerely,

Derek Noether 


\section{Appendix G}

Research Study Consent Form 


\section{Research Study Consent Form}

Community Support Services

Commander Navy Region Southwest

San Diego, CA

February 26, 2004

Dear Participant,

I am inviting you to be a part of my research study. The purpose of the study is to examine how leaders used the notion of culture to manage resistance during the Functionality Assessment (FA) change effort.

If you agree to participate in the study, I will contact you to schedule an interview. This interview will last no longer than one hour and will be conducted in a way and at a time so to not interfere with your work. Participation in this study is completely voluntary. You have the option of declining to participate in this study at any time.

I hope you will be able to participate in my research. The insights that this research should produce hopefully will be useful to all of us who work in organizations and, on occasion, must lead and manage large-scale change efforts. If you have any questions, please contact me either at the above address or by telephone (619.725.6797) or email (noether_derek@bah.com). You should also feel free to contact my dissertation advisor at the University of San Diego, Robert Donmoyer (619.260.7445 or donmoyer@sandiego.edu).

Sincerely,

Derek Noether 


\section{Consent to Participate in a Research Study}

A doctoral student in the Leadership Studies Program in the School of Education at the University of San Diego, is conducting a study of leadership's perceptions of organizational change in the Commander Navy Region Southwest's (CNRSW) Community Support Services (CSS) in San Diego, California. The title of the study is, "How Leaders use the Construct of Culture to Influence Change Resistance: A Public Organization Perspective". Below are the conditions under which participants in the study will be evaluated:

1. Participants will be asked to share their perceptions of what they experienced during the Functionality Assessment (FA) Study.

2. Efforts will be undertaken to keep the identities of participants confidential. For example pseudonyms will be used both for the organization being studied and organization members who are interviewed as part of the study.

However, those familiar with the Navy's CSS organization and the FA study may still be able to identify participants. Hence, confidentiality cannot be guaranteed even though every effort will be made to provide it.

3. Interviews will be recorded and the recordings will be transcribed; tapes, transcriptions, and research artifacts will be kept in a locked cabinet and/or on a password protected computer. Data will be destroyed five years after the dissertation has been completed and approved.

4. Interviews will be arranged in a place and time that is convenient to the participants so that they do not distract from participants' current work responsibilities.

5. Participation in the study is completely voluntary. Participants can withdraw from the study at any time. Data collected prior to withdrawal will not be used unless a participant agrees to let it be used.

6. If participants have questions or concerns at any point, they are encouraged to contact Derek Noether (619.696.3460 or noether_derek@.com) or his advisor, Dr. Robert Donmoyer (619.260.7445 or donmoyer@sandiego.edu).

7. The information collected will be used in Derek Noether's dissertation and any addition publications emerging from the dissertation.

8. There is no agreement, written or verbal, beyond that which is expressed on this consent form.

I, the undersigned, understand the above conditions and give my consent to my voluntary participation in the research that has been described.

Signature of the Interviewee: Date:

Printed Name: Address:

Contact Information: Phone: Fax: E-Mail: 
Appendix $\mathrm{H}$

Research Study Consent Letter 
DEPARTMENT OF THE NAVY

COMMANDER NAVY REGION SOUTHWEST

937 NO. HARBOR DR.

SAN DIEGO. CA $92132-0058$
W REPLY REFER TO:

February 13, 2004

To Whom it May Concern:

I, Captain Nancy L. Avila, U. S. Navy, Assistant Chief of Staff for Community Support Services, authorize and give permission for Derek Noether to conduct a research study with members of the Community Support Services.

I understand that the purpose of this study is to conduct empirical rescarch on leadership and the organizational change process. I am aware that the research study will result in a dissertation in partial fulfillment of the Leadership Studies doctoral program at the University of San Dicgo.

I am aware that participation in the study will be completely voluntary and that the researcher will protect the confidentiality of participants. Also, a copy of said dissertation must be provided to the Assistant Chief of Staff for Community Support Services when finalized.

Sincerely,

N. L. AVILA

Captain, U. S. Navy

Assistant Chief of Staff

for Community Support Services 
Appendix I

Definitions \& Terminology 
AS-IS - The "AS-IS" refers to the baseline or current state of the organization.

Business Process Reengineering (BPR) - Involves examining and changing the organizations fundamental business processes to ensure they are aligned with the organization's mission and primary objectives.

Change Agent - Selected organizational member with the purpose of assisting and guiding a planned change effort.

Change Initiative/Effort - Generally refers to a specific project that proactively seeks to fundamentally change an organization.

Commander Navy Region Southwest (CNRSW) - CNRSW is a very large collection of military installations (11 bases) located throughout California and Nevada. The CSS organization is one of the many supporting organizations within the CNRSW.

Southern California Support Services (SCSS) - The CSS organization provides a variety of community services to military members and their families in the Southwest region of the United States. SCSS consists of five community support organizations that include: Bachelor Housing, Food Services, Military Family Housing, Morale, Welfare and Recreation, and Social Services. These support organizations represent a total annual operating budget of approximately $\$ 260$ million. Over 2,200 positions are included in the assessment, representing military billets and civilians supported by appropriated and non-appropriated funds.

Functionality Assessment (FA) - A large-scale, planned organizational change initiative that was completed over two and one-half years, from 1999 to 2002. This change initiative involved five divisions in the CSS organization and included significant reform in operations, staff, organizational structure and facilities. The FA process is similar to other large planned change efforts commonly referred to as Business Process Reengineering (Hammer, 1993).

Large-scale, planned change - a planned change effort that involves several people and has significant impact on any combination of organizational aspects including staff, information systems, processes, infrastructure or other resources.

TO-BE - The "TO-BE" refers to the designs and plans (i.e., blueprint) for the future state of the organization. 